\title{
CALAGEM EM SISTEMA DE SEMEADURA DIRETA E EFEITOS SOBRE A ACIDEZ DO SOLO, DISPONIBILIDADE DE NUTRIENTES E PRODUÇĀO DE SOJA
}

\author{
SILVINO GUIMARÃES MOREIRA \\ Engenheiro Agrônomo
}

Orientador: Prof. Dr. JORGE DE CASTRO KIEHL

Dissertação apresentada à Escola Superior de Agricultura "Luiz de Queiroz", Universidade de São Paulo, para obtenção do título de Mestre em Agronomia, Área de Concentração: Solos e Nutrição de Plantas.

PIRACICABA

Estado de São Paulo - Brasil

Novembro -1999 
Dados Internacionais de Catalogação na Publicação (CIP) DIVISÃo DE BIBLIOTECA E DOCUMENTAÇÃO - Campus "Luiz de Queiroz"/USP

Moreira, Silvino Guimarães

Calagem em sistema de semeadura direta e efeitos sobre a acidez do solo, disponibilidade de nutrientes e produção de soja / Silvino Guimarães Moreira. - - Piracicaba, 1999.

$87 \mathrm{p}$.

Dissertação (mestrado) - Escola Superior de Agricultura Luiz de Queiroz, 1999.

Bibliografia

1. Acidez do solo 2. Calagem 3. Nutriente 4. Plantio direto 5. Semeadura direta 6. Sistema de cultivo 7. Soja I. Título

CDD 633.34 


\begin{abstract}
À Rosangela Cristina Marucci, pelo incentivo, paciência, carinho e compreensão.
\end{abstract}

\title{
DEDICO
}




\section{AGRADECIMENTOS}

A Deus, por estar sempre presente na minha vida, em todos os momentos;

Aos Prof. Dr. Jorge de Castro Kiehl e Luís Ignácio Prochnow, pela orientação, paciência, apoio, atenção e amizade durante todo o tempo;

Aos Prof. Dr. Hilton Thadeu e José Eduardo Corrente, pela ajuda na execução e interpretação das análises estatísticas;

Ao Pesquisador Volnei Pauletti, da Fundação ABC, pela amizade e ajuda em todas as etapas da realização dos trabalhos de campo;

À Fundação $\mathrm{ABC}$ e todos os seus funcionários e estagiários, pela ajuda na execução do trabalho, em especial ao Técnico Agrícola Luís Carlos Costa, pela presteza e dedicação na execução dos trabalhos de campo;

Aos Prof. Dr. Luís Reynaldo Ferracciú Alleoni e Gil Miguel de Sousa Câmara, pelas sugestões apresentadas;

Ao Químico Luís Silva Júnior, do Departamento de Solos e Nutrição de Plantas da ESALQ/USP, pela grande colaboração na execução das análises laboratoriais;

Aos funcionários do Departamento de Solos e Nutrição de Plantas da ESALQ/USP, Anderson Scarazati, José L. Vicente, Udson R. Moraes, Luís Eduardo Bombo, José I. Silva, Elisangela Santos, Marcos A. Camargo, Eleusa Brancalion, João A. Granja, Lara e Leandro Goia, que muito contribuíram na execução das análises laboratoriais, e aos demais funcionários que de alguma forma colaboraram; 
Aos funcionários do laboratório de física do solo da ESALQ/USP, Luciano D. Ferraz e Wladimir J. Rosignolo pela ajuda na execução das análises granulométricas;

Ao Pesquisador João Carlos Moraes de Sá, pelas sugestões no plano de pesquisa;

Aos meus pais, Antônio Moreira e Espedita Luiz Moreira, ao meu irmão Silvânio e às minhas irmãs Edna, Cláudia e Dayane, pelo carinho e compreensão;

Aos amigos que, de alguma forma, ajudaram com comentários, críticas e sugestões, em especial à Márcia Simonete, Luís Pedro Plese, Aderbal Rocha, Cristiano Andrade, Marcos Piedade e Aildison Duarte;

Ao grande amigo Eduardo Milton Albuquerque e à toda sua família, pela ajuda e incentivo durante toda a vida;

Aos companheiros de república Jorge Guimarães, Felipe e Everaldo, pela amizade;

À Coordenação do Curso em Solos e Nutrição de Plantas e aos seus professores do curso, pela colaboração e apoio;

À Coordenação de Aperfeiçoamento de Pessoal de Nível Superior (CAPES), pela concessão da bolsa de estudos. 


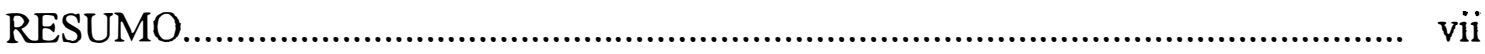

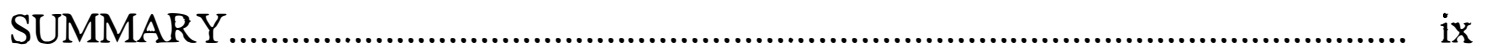

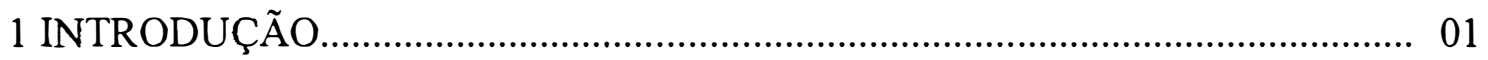

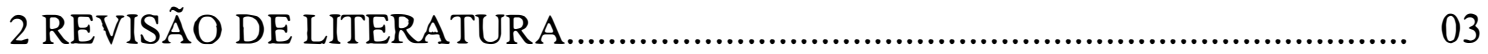

2.1 O Sistema de Semeadura Direta..................................................................... 03

2.2 Características Químicas dos Solos sob Semeadura Direta.................................. 05

2.3 Calagem em Sistema de Semeadura Direta......................................................... 09

2.3.1 Correção das Camadas Subsuperficiais......................................................... 14

2.3.2 Influência dos Sistemas de Cultivo e da Calagem Superficial nos Teores Foliares de Macronutrientes...................................................................... 16

2.4 Micronutrientes para a Soja em Sistema de Semeadura Direta............................ 17

2.4.1 Disponibilidade de micronutrientes e a produtividade de soja......................... 18

3 MATERIAL E MÉTODOS.............................................................................. 22

4 RESULTADOS E DISCUSSÃO................................................................. 30

4.1 Características Químicas dos Solos............................................................... 30

4.1.1 Efeito das Épocas de Amostragens e dos Tempos de Cultivo sob Sistema de Semeadura Direta......................................................................................... 30

4.1.2 Efeito da Calagem nos Atributos Químicos dos Solos...................................... 33

4.1.2.1 Acidez Ativa............................................................................................ 34

4.1.2.2 Acidez Trocável...................................................................................... 36

4.1.2.3 Cálcio e Magnésio Trocáveis................................................................... 37

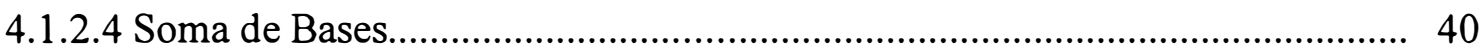

4.1.2.5 Saturação por Bases........................................................................................... 41

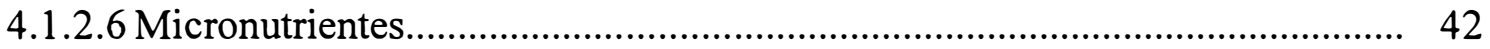

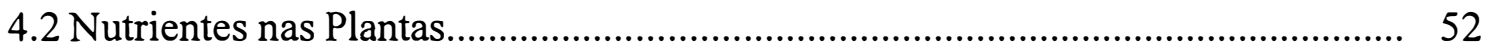

4.2.1 Efeito das Épocas de Amostragens................................................................ 52

4.2.2 Efeito da Calagem nos Teores de Nutrientes .................................................. 54 
4.2.2.1 Nitrogênio ................................................................................................ 54

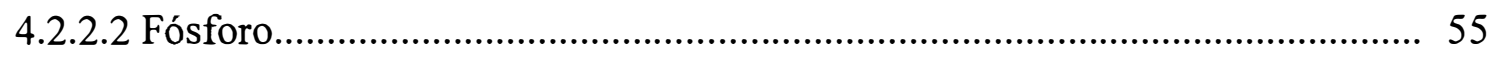

4.2.2.3 Potássio ............................................................................................... 57

4.2.2.4 Cálcio ...................................................................................................... 58

4.2.2.5 Magnésio ............................................................................................... 59

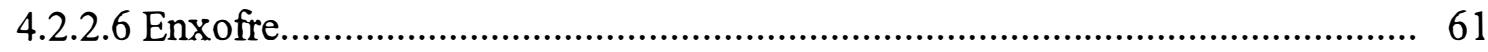

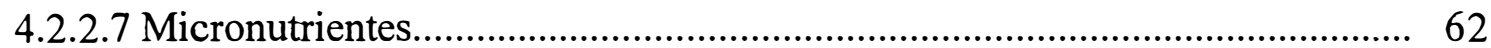

4.3 Efeito da Calagem e dos Tempos de Cultivo sob Sistema de Semeadura Direta na Produção de Soja........................................................................................... 70

5 CONCLUSÃO

REFERÊNCIAS BIBLIOGRÁFICAS................................................................ 74 


\title{
CALAGEM EM SISTEMA DE SEMEADURA DIRETA E EFEITOS SOBRE A ACIDEZ DO SOLO, DISPONIBILIDADE DE NUTRIENTES E PRODUÇÃO DE SOJA
}

\author{
Autor: SILVINO GUIMARÃES MOREIRA \\ Orientador: Prof. Dr. JORGE DE CASTRO KIEHL
}

\section{RESUMO}

Realizou-se o presente trabalho com o objetivo de avaliar o efeito da calagem na correção da acidez do solo, na disponibilidade de nutrientes e na produção de soja em um Latossolo Vermelho Escuro, submetido a diferentes tempos de cultivo sob sistema de semeadura direta (TCSSD) (3, 6 e 9 anos), do município de Tibagi, PR. Os tratamentos constituíram-se de quatro doses de calcário $(0 \%, 33,3 \%, 66,7 \%$ e $100 \%$ da quantidade calculada para elevar a V\% a 70), aplicadas em superficie, e um tratamento adicional com a última dose, incorporada de 0 a $20 \mathrm{~cm}$ de profundidade. $\mathrm{O}$ efeito dos tratamentos foi avaliado em duas épocas (estágio vegetativo V4 e época do florescimento), ocasião em que se coletaram amostras de solo e folhas. O solo foi amostrado nas profundidades de $0-5,5-10,10-20$ e $20-30 \mathrm{~cm}$.

Houve distribuição mais uniforme em profundidade de $\mathrm{Ca}, \mathrm{Mg}$, soma de bases e V\% no local com maior TCSSD. Neste solo, os teores de $\mathrm{Al}$ foram baixos e não variaram com a profundidade, e os valores de $\mathrm{pH}$ foram pouco alterados. Em todos os TCSSD, os teores de B não variaram em profundidade. Em geral, os teores de Mn foram maiores nas camadas superficiais, e os de $\mathrm{Cu}$, menores. A maior variação do $\mathrm{Fe}$ em profundidade ocorreu no solo com 6 anos de cultivo, sendo que, quase sempre a camada superficial apresentou o menor teor.

No solo com menor TCSSD, a maior dose de corretivo aplicada na superficie resultou maiores teores de $\mathrm{Ca}$ e $\mathrm{Mg}$ e valores de soma de bases na camada de 0-5 cm, e o $\mathrm{pH}$ e a $\mathrm{V} \%$ não variaram. A incorporação da dose integral elevou o $\mathrm{pH}$, o teor de $\mathrm{Ca}$ e a soma de bases na camada de 10-20 cm; elevou o teor de $\mathrm{Mg}$ e a V\% das camadas de 10- 
20 e 20-30 cm, e diminuiu o teor de $\mathrm{Al}$ da camada de 20-30 cm. No solo com 6 anos de cultivo, $\mathrm{pH}, \mathrm{Ca}, \mathrm{Mg}$ e soma de bases da camada superficial, comumente, aumentaram com a aplicação das maiores doses de corretivo na superfície. A incorporação do calcário, em geral, diminuiu o teor de $\mathrm{Al}$ e aumentou os de $\mathrm{Ca}$ e $\mathrm{Mg}$, a soma de bases e a V\% nas camadas inferiores do solo, sendo que nestas camadas, estes atributos não foram alterados pela aplicação superficial do corretivo. No solo com maior TCSSD, o efeito da calagem ocorreu apenas na camada superficial. O corretivo aplicado na superfície, comumente, resultou maiores teores de $\mathrm{Ca}$ e $\mathrm{Mg}$ e maiores valores de $\mathrm{pH}$, soma de bases e V\% do que a incorporação, mas esta não alterou os valores originais desses atributos.

A incorporação do calcário diminuiu o teor de B no solo com maior TCSSD. As maiores doses aplicadas na superfície resultaram os menores teores de $\mathrm{Cu}$ no solo com menor TCSSD. No solo com 6 anos de cultivo, 2/3 da dose na superfície diminuíram o teor de $\mathrm{Fe}$ na camada superficial em grau maior que a dose integral incorporada, e na camada de $5-10 \mathrm{~cm}$ ocorreu efeito inverso. A camada superficial dos solos com maiores TCSSD apresentou menor teor de Mn devido à incorporação, e até 20 $\mathrm{cm}$ de profundidade, quaisquer uma das doses, aplicadas na superfície, reduziram os teores de $\mathrm{Zn}$ do solo com menor TCSSD. Os teores de micronutrientes no solo apresentaram-se dentro ou acima da faixa de teores considerados adequados, com exceção do B, que apresentou teores médios a baixos nos locais com 3 e 9 anos de cultivo.

Os teores de $\mathrm{N}, \mathrm{P}, \mathrm{K} \mathrm{S}, \mathrm{B}, \mathrm{Cu} \mathrm{Fe}$ e $\mathrm{Zn}$ nas folhas não variaram com a calagem. Na primeira amostragem, os teores de Mn dos locais com maior TCSSD diminuíram com a incorporação, e no solo com menor TCSSD, com a maior dose na superfície. Apenas os teores de $\mathrm{P}$ (primeira amostragem) e de $\mathrm{S}$ e dos micronutrientes $\mathrm{Cu}$ e $\mathrm{B}$ (solos com 3 e 9 anos de cultivo) apresentaram-se abaixo dos níveis considerados adequados para a soja, e em nenhuma das amostragens houve deficiência visual de nutrientes nas folhas de soja.

A produção de grãos somente foi influenciada pelos TCSSD. O local com 6 anos de cultivação apresentou a maior produção de grãos em relação aos demais. 


\title{
LIMING UNDER NO-TILLAGE AND EFFECTS ON SOIL ACIDITY, SOIL NUTRIENT AVAILABILITY AND YIELD OF SOYBEANS
}

\author{
Author: SILVINO GUIMARÃES MOREIRA \\ Adviser: Prof. Dr. JORGE DE CASTRO KIEHL
}

\section{SUMMARY}

A field experiment was conducted in the State of Paraná, Brazil, to evaluate the effect of liming on soil acidity, soil nutrient availability and yield of soybeans on a Dark-Red Latosol (Oxysol), which had been cultivated for 3, 6 and 9 years under notillage (NT). Lime was broadcasted to the soil surface in four rates- $0 \%, 33,3 \%, 66,7 \%$ and $100 \%$ of the amount calculated to increase the soil base saturation (V\%) to $70 \%$; an additional treatment consisted of broadcasting the highest rate of lime and mixing it to the $0-20 \mathrm{~cm}$ layer of the soil. The effect of lime and time of cultivation under NT was evaluated by collecting soil and leaf samples at the V4 vegetative stage and at blossoming. Soil was sampled at the depths of 0-5, 5-10, 10-20 and 20-30 cm.

Calcium, magnesium, sum of bases and V\% showed the most uniform distribution in the profile when soil was cultivated under NT for 9 years; in addition, exchangeable $\mathrm{Al}$ was low and $\mathrm{pH}$ was constant in all the studied soil layers. In all NT cultivation periods soil available B was not changed with depth. In general, soil Mn content was highest in the surface layers, while $\mathrm{Cu}$ content was lowest. The highest change in Fe content with soil depth was observed when soil was cultivated for 6 years under NT; under this situation the $0-5 \mathrm{~cm}$ soil layer showed the lowest amount of $\mathrm{Fe}$ in most cases.

In the soil cultivated for 3 years, the highest figures for $\mathrm{Ca}, \mathrm{Mg}$ and sum of bases in the $0-5 \mathrm{~cm}$ layer were observed when lime was broadcasted on soil surface at the full rate, while $\mathrm{pH}$ and $\mathrm{V} \%$ were not changed with liming. The highest lime rate mixed in the soil increased $\mathrm{pH}$, sum of bases and $\mathrm{Ca}$ content of the $10-20 \mathrm{~cm}$ layer, as well as the $\mathrm{Mg}$ and $\mathrm{V} \%$ of both layers of $10-20$ and $20-30 \mathrm{~cm}$. This treatment also reduced the $\mathrm{Al}$ content of the $20-30 \mathrm{~cm}$ layer. In the soil with 6-year cultivation period $\mathrm{pH}, \mathrm{Ca}, \mathrm{Mg}$ and sum of bases of the upper layer generally increased with the highest 
rates of lime broadcasted to the soil surface. When mixed to the soil, lime reduced the exchangeable $\mathrm{Al}$ and increased the sum of bases, $\mathrm{V} \%$ and content of $\mathrm{Ca}$ and $\mathrm{Mg}$ of the deepest soil layers; these soil attributes were not modified by lime applied to the surface. In the soil cultivated for 9 years, lime influenced only the surface layer; when applied on the surface, the increase in $\mathrm{pH}$, sum of bases, $\mathrm{V} \%, \mathrm{Ca}$ and $\mathrm{Mg}$ by lime was generally higher than when mixed to the soil; in this later form of application, lime did not influence these soil characteristics.

Mixed application of lime reduced B content in the soil cultivated for 9 years under NT. Applying the highest rates on the surface resulted the lowest contents of B in the 3-year cultivated soil. When soil was cultivated for 6 years, 2/3 of the full rate applied on the surface reduced $\mathrm{Fe}$ content in the $0-5 \mathrm{~cm}$ layer more than the maximum rate mixed in the soil, whereas in the $5-10 \mathrm{~cm}$ layer the most intense reduction occurred for the mixed application. Mixed application resulted the lowest $\mathrm{Mn}$ content in the surface layer of the soils under 6 and 9 years of cultivation. Up to the depth of $20 \mathrm{~cm}$ all lime rates broadcasted in the surface reduced the amount of $\mathrm{Zn}$ of the soil cultivated for 3 years under NT. The contents of all the studied micronutrients were in or above the normal range for soils except $B$, which contents were sometimes bellow the normal range in soils under 3 and 9 years of cultivation.

Liming did not influence the contents of $\mathrm{N}, \mathrm{P}, \mathrm{K}, \mathrm{S}, \mathrm{B}, \mathrm{Cu}, \mathrm{Fe}$ and $\mathrm{Zn}$ in the soybean leaves. In the first leaf sampling, the Mn content in plants grown on soil cultivated for 6 and 9 years under NT were decreased by lime mixed in the soil, whereas in the soil cultivated for 3 years the content was reduced by lime applied on the surface at the highest rate. Only the content of $\mathrm{P}$ in the first leaf sampling and of $\mathrm{S}, \mathrm{Cu}$ and $\mathrm{B}$ in plants grown on soils cultivated for 3 and 9 years showed to be bellow the range considered normal for soybeans. Nutrient deficiency symptoms in the soybean plants were not observed in any of the sampling occasions. Soybean grain yield was influenced only by time of cultivation under NT, being highest yield was obtained in the soil cultivated for 6 years under NT. 


\section{INTRODUÇÃO}

As primeiras semeaduras no sistema de semeadura direta (SSD), feitas com sucesso, ocorreram por volta dos anos cinqüenta nos Estados Unidos da América do Norte. O desenvolvimento de produtos químicos, principalmente aqueles utilizados no controle de plantas daninhas, juntamente com as primeiras semeadoras construídas especialmente para a utilização em SSD, possibilitaram a expansão dessa prática entre os produtores.

Existem relatos na literatura de que as primeiras semeaduras realizadas em SSD, no Brasil, ocorreram no estado de Minas Gerais. Contudo, sua grande evolução ocorreu notoriamente no Estado do Paraná, a partir da década de setenta, como fruto, de um trabalho conjunto de agricultores, pesquisadores e extensionistas, desenvolvido com o objetivo principal de se controlar a erosão.

Devido às inúmeras vantagens do SSD, houve grande aceitação por parte dos agricultores, e isto possibilitou sua expansão para as demais regiões brasileiras. Após a adoção do SSD, vários questionamentos surgiram, sobretudo com relação ao manejo da fertilidade do solo neste novo sistema. Com a sua utilização, muitos agricultores conseguiram melhorar vários atributos do solo e aumentar a produtividade de diversas culturas, não se dispondo mais a arar o solo para incorporação do corretivo da acidez. Assim, tornou-se necessário o estudo de alternativas para a correção da acidez que não exigissem a movimentação do solo.

Uma das principais dúvidas era se, com a aplicação do calcário em superficie, seria possivel manter a produtividade das culturas em SSD, implantadas em áreas onde a correção da acidez havia sido adequadamente realizada antes da adoção do sistema, assim como naquelas onde este procedimento não foi inicialmente adotado. 
O ponto principal de discussão quanto à eficiência da aplicação do calcário superficialmente sempre foi em relação à diminuição da superfície de contato do corretivo com os colóides do solo.

Trabalhos iniciais com a finalidade de responder tais questionamentos vem demonstrando viabilidade técnica e econômica do SSD, comparado ao sistema de semeadura convencional (SSC). Tem-se verificado ser possível a correção das camadas arável e subsuperficial através da calagem superficial, com a vantagem dos menores custos desta operação. No entanto, têm-se verificado freqüentes reduções de produtividade devidas às deficiências de micronutrientes, principalmente Mn para a soja e $\mathrm{Zn}$ para o milho. Essas deficiências têm sido atribuídas ao excessivo aumento de $\mathrm{pH}$ na camada superficial do solo. Contudo, parece que essa explicação nem sempre procede porque tem-se constatado a presença de altos teores de micronutrientes nas camadas superficiais dos solos sob SSD, mesmo em condições de elevado $\mathrm{pH}$ e altos teores de matéria orgânica.

Atualmente não têm sido obtidos aumentos na produção de grãos em solos submetidos por longo tempo ao SSD, em função da calagem. Assim, existem especulações que a medida que aumenta o tempo de cultivo em sistema de semeadura direta (TCSSD) as doses de corretivo podem ser diminuídas, mas este fato precisa ser estudado. Também existem dúvidas quanto a dose de calcário a ser empregada, de acordo com o tempo de implantação do SSD.

Realizou-se o presente trabalho com o objetivo de avaliar o efeito do calcário em diferentes doses, aplicado na superfície ou incorporado à camada de 0-20 $\mathrm{cm}$ de profundidade, na correção da acidez do solo, na disponibilidade de nutrientes, e na produção de soja em um Latossolo Vermelho Escuro, submetido a diferentes TCSSD. Também objetivou-se estudar a influência dos TCSSD na acidez e disponibilidade de nutrientes no solo e às plantas. 


\section{REVISÃO DE LITERATURA}

\subsection{O Sistema de Semeadura Direta}

O sistema de semeadura direta (SSD) pode ser definido como um sistema no qual a semeadura é feita diretamente sobre os resíduos de uma cultura anterior, morta com a utilização de produtos químicos ou por meios mecânicos, sem o preparo mecânico do leito de semeadura (Muzilli, 1985a).

As primeiras citações sobre este sistema de cultivo são provenientes dos EUA, onde o mesmo teve grande expansão, principalmente após a última Grande Guerra; é que a partir dessa época acelerou-se a produção de agroquímicos (Derpsch, 1984; Castro, 1985; Dick et al.,1991) e desenvolveram-se as primeiras semeadoras adaptadas ao SSD (Castro, 1985).

No Brasil, o marco oficial de sua introdução ocorreu no início da década de 70 nos municípios de Londrina e Ponta Grossa, no Paraná, com o desenvolvimento das primeiras pesquisas pelo Ministério da Agricultura (Muzilli, 1985a). Contudo, existe relato na literatura de que os primeiros cultivos teriam se iniciado em Minas Gerais (Muzilli, 1981'1', citado por Sá, 1995a). A maior evolução na utilização do SSD ocorreu no final da década de 70 (Muzilli, 1985a) e nos anos 80 (Derpsch, 1984). Após o grande crescimento do SSD, ocorrido na década de 90 na região sob cerrado, existem estimativas de que a área cultivada em SSD já ultrapassa 10 milhões de hectares (Sá, 1998).

\footnotetext{
${ }^{1}$ MUZILLI, O. Princípios e perspectivas de expansão. In: Plantio Direto no Paraná. Londrina-PR: Fundação Instituto Agronômico do Paraná/IAPAR, 1981. p.11-17. (Circular técnica, 23).
} 
O SSD apresenta diversas vantagens em relação ao sistema de semeadura convencional (SSC), como melhor aproveitamento dos nutrientes, devido à diminuição das perdas por erosão; aumento do teor da matéria orgânica, que implica em melhorias nas propriedades físicas, químicas e biológicas do solo; aumento nos rendimentos das culturas e, como conseqüência, maior retorno econômico decorrente de menores custos de produção (Muzilli, 1985a; 1985b; 1985c; Sá, 1995a).

$\mathrm{O}$ aumento nos teores de matéria orgânica, $\mathrm{P}, \mathrm{K}, \mathrm{Ca}$ e $\mathrm{Mg}$ na superfície do solo, juntamente com maior teor de umidade e temperaturas mais amenas, devido à não incidência direta dos raios solares, tem promovido aumento substancial da atividade da biomassa e da população microbiana nos solos (Hungria et al., 1997; Voss \& Sidiras, 1985). Este fato é de grande importância, uma vez que esses microorganismos podem imobilizar nutrientes em quantidades apreciáveis, liberando-os de forma lenta e gradual e evitando-se perdas (Hungria et al., 1997). Cattelan \& Vidor (1990), quantificaram um total de 147, 114, 96 e $14 \mathrm{~kg} \mathrm{ha}^{-1} \mathrm{de} \mathrm{N}, \mathrm{P}, \mathrm{K}$ e Ca, imobilizados na camada de 0-15 cm, respectivamente.

No SSD, também tem sido observada maior taxa de colonização de raízes pelos fungos micorrízicos para várias culturas, aumentando o aproveitamento principalmente do P (Mulligan et al.,1985; Vivekanandan \& Fixen, 1991) e, no caso específico da soja, aumentando o tamanho, o peso e o número de nódulos por planta, o que pode resultar em maior taxa de fixação de nitrogênio (Voss \& Sidiras, 1985).

Sem o revolvimento do solo pelas operações de preparo, existe também uma tendência em diminuir os custos da adubação fosfatada (Muzilli, 1985a, 1985b). Nesta situação, o P aplicado está menos sujeito às reações de fixação com os colóides do solo devido ao menor contato com as partículas (Castro, 1995), além do aumento das formas de P orgânico em função do aumento da matéria orgânica (Sá, 1995b).

Em relação ao controle da erosão e perdas de nutrientes, em condições de chuva simulada, Vieira et al. (1978) observaram perdas de 3 e 5 vezes maiores de P e matéria orgânica, respectivamente, e também maiores perdas de $\mathrm{Ca}$ e $\mathrm{Mg}$ em solos arados do que em locais sem preparo. Em condições naturais, Castro et al. (1986) não observaram perdas de solo, e quantificaram menores perdas de água e de nutrientes em 
SSD do que em diversos outros métodos de preparo. Resultados semelhantes foram observados por Dedecek et al. (1986) em solos sob cerrado.

Quanto ao rendimento de grãos, melhores resultados têm sido encontrados por diversos autores para o SSD do que para o SSC, como foi observado por Estes (1972), Phillips et al. (1980), Sidiras et al. (1983), Centurion (1984) e Edwards et al. (1988). Maiores rendimentos de grãos podem ocorrer em SSC em situações específicas, como foi observado por Phillips et al. (1980), Griffith et al. (1988) e Dick et al. (1991) em solos orgânicos mal drenados. Nesta situação, a presença dos restos culturais na superfície aumenta a disponibilidade de água, baixa a temperatura do solo e prejudica a germinação das sementes, além de favorecer a perda de nitrato por desnitrificação devido ao aumento das condições redutoras do solo (Phillips et al., 1980).

Sistemas de cultivos contínuos, envolvendo monoculturas, também podem apresentar menores produtividades nos primeiros anos de adoção do SSD, se a dose de nitrogênio não for incrementada, no caso da cultura do milho (Muzilli, 1985c). No entanto, mesmo nestas condições, a produtividade tende a aumentar com o tempo de adoção do SSD (Dick et al., 1991; Kitur et al., 1994).

\subsection{Caraterísticas Químicas dos Solos sob Semeadura Direta}

Resultados de pesquisas de longa duração em diversas localidades têm demonstrado aumento na camada superficial do solo dos teores de matéria orgânica (Muzilli, 1983; Lal et al., 1990; Edwards et al., 1992; Maria \& Castro, 1993; Kitur et al. 1994); de fósforo (Hargrove et al., 1982; Sidiras \& Pavan, 1985; Lal et al., 1990; Maria \& Castro, 1993; Kitur et al., 1994); de potássio (Lal, 1976; Lal et al., 1990; Maria \& Castro, 1993); e de cálcio e magnésio (Muzilli, 1983; Santos \& Reis, 1989; Lal et al., 1990). Também foram observados maiores valores de $\mathrm{pH}$ (Lal, 1976; Santos \& Reis, 1989; Santos \& Siqueira, 1996) de CTC efetiva (Sidiras \& Pavan, 1985) e do teor de micronutrientes (Castro et al., 1992; Edwards et al., 1992), assim como diminuição do Al trocável (Sidiras \& Pavan, 1985; Santos et al., 1995; Pottker \& Ben, 1998). 
Teores de matéria orgânica e P mais elevados no SSD em relação ao SSC se devem à decomposição mais lenta dos resíduos vegetais na superfície em decorrência das menores temperaturas e aeração do solo, face ao não revolvimento no SSD, uma vez que a quantidade de material vegetal introduzida é a mesma em ambos os sistemas (Centurion, 1988; Castro, 1995). A elevação dos teores de matéria orgânica na superfície é mais rápida através da utilização de sequiências de cultivo com predominância de gramíneas que produzem altas quantidades de resíduos (Havlin et al., 1990; Lal et al., 1990; Santos \& Siqueira, 1996).

Os altos níveis de $\mathrm{Ca}$ e $\mathrm{Mg}$ em SSD foram atribuídos por Edwards et al. (1992) à elevação da CTC do solo devido ao aumento do teor de matéria orgânica. Menores valores de $\mathrm{pH}$ no SSC podem ser explicados pela maior mineralização da matéria orgânica neste sistema, seguidas de lavagens dos nutrientes da camada arável pela água da chuva (Sidiras \& Pavan, 1985).

Menores valores de $\mathrm{pH}$ na camada superficial foram observados em solos norte-americanos, em condições de monocultivo e com predomínio de gramíneas, nos locais onde eram empregadas altas doses de fertilizantes nitrogenados (Blevins et al., 1986; Follett \& Peterson, 1988; Edwards et al., 1992). Entretanto, Muzilli (1983) não observou diminuição do $\mathrm{pH}$ de solos do Paraná cultivados há longo tempo em SSD, mesmo em sucessões contínuas de milho e trigo. Resultados semelhantes foram observados por Santos \& Tomm (1996). Além do mais, em muitos casos a mudança do pH é muito pequena (Lal et al., 1990; Franzluebbers \& Hons, 1996).

Lal et al. (1990) observaram redução de apenas 0,2 unidade de $\mathrm{pH}$ até $10 \mathrm{~cm}$ de profundidade de um solo argiloso mal drenado, com alta fertilidade inicial, após 12 anos no SSD. Resultados similares foram encontrados por Franzluebbers \& Hons (1996) na camada de $0-5 \mathrm{~cm}$ de solos sob cultivos com predomínio de gramíneas. Apesar disso, não encontraram diferenças entre os sistemas de cultivo quanto ao $\mathrm{pH}$ em nenhuma camada entre 5 e $90 \mathrm{~cm}$ de profundidade.

A diminuição do $\mathrm{pH}$ na superfície do solo pode aumentar a disponibilidade de certos micronutrientes nesta camada (Grove \& Blevins, 1988; Follett \& Peterson, 1988; Edwards et al., 1992). Grove \& Blevins (1988) constataram aumento no teor de 
Mn no solo devido à aplicação de altas doses de $\mathrm{N}$ na cultura do milho. Resultados semelhantes foram observados por Edwards et al. (1992) em monocultivos de milho ou rotações com predomínio de milho. Follett \& Peterson (1988) também observaram aumento dos teores de $\mathrm{Fe}$ até a profundidade de $5 \mathrm{~cm}$ e de $\mathrm{Mn}$ na camada de 0-10 $\mathrm{cm}$, devido à fertilização nitrogenada.

Em outras situações têm-se observado aumentos dos teores de micronutrientes em solos sob SSD (Castro et al., 1992; Edwards et al., 1992; Walters et al., 1992; Franzluebbers \& Hons, 1996). Castro et al. (1992) observaram que os teores de $\mathrm{Cu}$ e $\mathrm{Mn}$ em todas as camadas avaliadas até $50 \mathrm{~cm}$ de profundidade em um Latossolo Vermelho Amarelo, argiloso, após três anos de cultivo em SSD, eram maiores que os encontrados no solo sob cultivo em SSC. Maiores teores de Mn e Zn também foram encontrados por Hargrove et al. (1982) e Edwards et al. (1992) em solos sob SSD, em relação ao SSC.

Em estudo conduzido em solo que estava sob SSD e SSC há oito anos, foram encontrados maiores teores de $\mathrm{Fe}$ e $\mathrm{Cu}$ na camada superficial e uma tendência de maiores teores de $\mathrm{Mn}$ e $\mathrm{Zn}$ totais no SSD do que no SSC. Foi observado aumento nas frações trocáveis e orgânicas de $\mathrm{Fe}$ e diminuição das frações amorfas e residual, como também aumento da fração orgânica de Mn e decréscimo da amorfa no SSD, em comparação ao solo submetido ao SSC (Shuman \& Hargrove, 1985).

Follett \& Peterson (1988) estudaram as características químicas de um solo após 16 anos de cultivo em SSD e SSC, comparando-os com um campo nativo de gramíneas. Relataram que o SSD apresentou fertilidade próxima à do campo nativo, e que os teores de $\mathrm{Cu}, \mathrm{Fe}, \mathrm{Mn}$ e $\mathrm{Zn}$ na camada superficial eram superiores aos do solo sob SSC.

Os maiores teores de $\mathrm{Mn}$ e $\mathrm{Zn}$ são também devido à alta quantidade de resíduos culturais na superfície do solo (Hargrove et al., 1982), que aumentam o conteúdo de matéria orgânica no SSD (Edwards et al., 1992). Foi encontrada alta correlação entre Zn e Mn extraídos por DTPA e a matéria orgânica de solos sob SSD (Castro et al., 1992). 
A acumulação da matéria orgânica e manutenção de alta disponibilidade de água próxima à superfície no SSD podem causar decréscimo do potencial redox do solo $\mathrm{e}$, assim, possibilitar incremento na disponibilidade de $\mathrm{Fe}$ e $\mathrm{Mn}$ às culturas (Follett \& Peterson, 1988). As condições de redução do solo também podem ser induzidas pela adubação nitrogenada, devido ao maior consumo de $\mathrm{O}_{2}$ pelos microorganismos que são estimulados a decompor resíduos ricos em carbono na presença de $\mathrm{N}$ e, assim, aumentando a disponibilidade de $\mathrm{Cu}, \mathrm{Fe}$ e Mn (Franzluebbers \& Hons, 1996).

Walters et al. (1992) observaram maiores teores de $\mathrm{Mn}, \mathrm{Fe}$ e $\mathrm{Cu}$ no solo nos períodos iniciais de decomposição da ervilhaca, sendo que estes teores decresceram no final da decomposição. Sugeriram que este fato ocorreu em função da maior liberação dos produtos da decomposição nos períodos iniciais, juntamente com o maior consumo de $\mathrm{O}_{2}$, aumentando as condições de redução do solo e, por conseqüência, a disponibilidade de $\mathrm{Cu}, \mathrm{Fe}$ e $\mathrm{Mn}$. Contudo, após a completa decomposição, ocorre uma reoxidação destes elementos e a disponibilidade é diminuída. Outra possibilidade seria a reprecipitação de $\mathrm{Mn}, \mathrm{Fe}$ e $\mathrm{Cu}$ na forma de carbonatos.

O potencial redox de solos aerados, quando são submetidos a excesso de umidade, torna-se mais eletronegativo, e a disponibilidade de $\mathrm{Mn} \mathrm{e} \mathrm{Fe}$ aumenta inicialmente em decorrência da redução desses elementos e dissolução dos seus óxidos (Borkert, 1991). Num segundo momento, a disponibilidade desses elementos pode diminuir como conseqüência do aumento do $\mathrm{pH}$ do meio, devido ao maior consumo de prótons do que de elétrons nas reações de redução (Mello et al., 1992).

Nos locais com alta disponibilidade de água e condições aeróbias, a decomposição de resíduos pode aumentar a disponibilidade de $\mathrm{Cu}, \mathrm{Fe}$ e $\mathrm{Mn}$ no período inicial de decomposição, sendo posteriormente baixada rapidamente devido à reoxidação destes nutrientes (Walters et al., 1992). 


\subsection{Calagem em Sistema de Semeadura Direta}

No SSC é conhecido o efeito da acidez impondo uma série de limitações para o cultivo dos solos, como altos teores de alumínio tóxico às plantas e baixos teores de cátions trocáveis, com a possibilidade de aumentar a adsorção de fósforo na superficie das partículas de argila e dos óxidos de $\mathrm{Fe}$ e $\mathrm{Al}$ e/ou favorecer a formação de fosfatos insolúveis de $\mathrm{Fe}$ e $\mathrm{Al}$ (Raij, 1991). E como conseqüência, tem-se menor desenvolvimento das raízes e baixo crescimento das plantas (Sousa et al., 1987).

Essas questões podem ser solucionadas mediante a adoção de técnicas de melhoramento vegetal e manejo do solo (Sousa et al., 1987; Lopes, 1994). Em algumas situações, a recomendação mais adequada é a combinação de práticas de manejo do solo com o cultivo de plantas tolerantes à acidez (Sousa et al., 1987). Dentre as práticas de manejo, a principal é a calagem (Lopes, 1994). Diversas técnicas para caracterizar a acidez do solo e avaliar a necessidade de calagem foram desenvolvidas ao longo dos anos (Raij, 1991), mas, como o SSD provoca alterações químicas, físicas e biológicas no solo, há necessidade de desenvolver novas práticas de manejo adaptadas ao sistema (Pottker, 1995; Sá, 1995a).

Os primeiros trabalhos com o objetivo de estudar a viabilidade da calagem sem a incorporação do corretivo foram realizados fora do Brasil, produzindo resultados satisfatórios (Estes, 1972; Mochler et al., 1973; Lal, 1976; Hargrove et al., 1982; Grove \& Blevins, 1988).

Em estudo realizado para avaliar a produção de matéria seca de milho, durante oito anos em solos sob SSD e SSC, com e sem aplicação de calcário, foi observada maior produção de milho no SSD. O solo sob esse sistema também apresentou maiores teores de $\mathrm{Ca}$ e $\mathrm{Mg}$, maiores valores de $\mathrm{pH}$ e menores teores de $\mathrm{H}^{+}$e $\mathrm{Al}^{3+}$ até a profundidade de $20 \mathrm{~cm}$ (Mochler et al., 1973). Resultados semelhantes foram posteriormente obtidos por Lal (1976) em solos da Nigéria, por Hargrove et al. (1982) e Follett \& Peterson (1988) em solos norte-americanos e por Arshad \& Gill (1996) e Arshad et al. (1997) em solos do Canadá. 
No Brasil, após a adoção do SSD, muitos agricultores conseguiram melhorar vários atributos do solo e aumentar a produtividade. Desse modo, não desejavam mais arar o solo para incorporação do corretivo da acidez. Assim, tornou-se necessário o estudo de métodos alternativos para a correção da acidez que não a incorporação (Pottker, 1995). Uma das principais dúvidas era se, com a aplicação do calcário em superfície, seria possível manter a produtividade das culturas em SSD, implantadas em áreas onde a correção da acidez havia sido adequadamente realizada antes da adoção do sistema, assim como naquelas onde este procedimento não foi inicialmente adotado (Sá, 1995c; Pottker, 1995; Cassol et al., 1995). O ponto principal de discussão quanto à eficiência da aplicação do calcário superficialmente sempre foi em relação à diminuição da superfície de contato do corretivo com os colóides do solo (Sá, 1998).

Trabalhos com a finalidade de responder tais questionamentos vem sendo conduzidos. Sá (1995c), comparando formas de aplicação de calcário (incorporado ou em superfície) em um Latossolo Vermelho Escuro argiloso, de elevada acidez, situado em Tibagi, PR, há 9 anos sob o SSD, não encontrou diferenças significativas na produtividade de soja, trigo e milho devido às diferentes formas de aplicação do corretivo. Embora, inicialmente, as cultivares susceptíveis à acidez mostrassem respostas à incorporação, com o tempo, foi notória a melhoria do subsolo pela ação do calcário aplicado em superfície. E o melhor retorno econômico foi obtido pela aplicação do corretivo na superfície.

Em outros dois experimentos realizados por Sá (1995c), em Podzólico e Cambissolo arenosos, também não foram encontradas diferenças nas produtividades das culturas ao longo de três anos de estudos entre a aplicação do calcário na superfície e a incorporação. Nesses solos arenosos, o calcário aplicado em superfície mostrou-se mais eficiente na correção da acidez em profundidade do que no solo argiloso, citado anteriormente.

Em um Podzólico Vermelho Escuro de textura franco argilosa, sob SSD e SSC há quatro anos, foram aplicadas $3,7 \mathrm{t} \mathrm{ha}^{-1}$ de calcário em superficie. As avaliações realizadas após treze meses indicaram maiores valores de $\mathrm{pH}$, de CTC efetiva e de $\mathrm{Ca}$ trocável, e menores teores de Al, apenas na camada de 0 a $2,5 \mathrm{~cm}$ (Cassol et al., 1995). 
Santos et al. (1995), realizando experimento em um Latossolo Vermelho Escuro argiloso, verificaram que após três anos de cultivo, não houve diferença de $\mathrm{pH}$ entre a aplicação de calcário superficialmente no SSD e a incorporação a $20 \mathrm{~cm}$ no SSC. Foram encontrados maiores teores de $\mathrm{Ca}+\mathrm{Mg}$ e menores de $\mathrm{Al}$ trocável nas camadas de 0-5 e 5-10 cm no SSD, do que no SSC. No primeiro ano de cultivo, a produção de aveia branca foi maior no SSD do que no SSC, contudo, nos anos posteriores não foram observadas diferenças quanto à produção da aveia branca e soja entre esses sistemas de cultivo.

Devido à necessidade de se definir um método de recomendação de calagem para o SSD, decorrente da cobrança por parte dos produtores e extensionistas, foi proposta uma primeira aproximação por Sá (1995c): aplicar à superfície de 1/3 a 1/2 da necessidade de calcário calculada pelo método da saturação por bases para solos argilosos, e $1 / 2$ da dose para solos de textura média a arenosa. Recomenda-se não utilizar doses acima de 2,5 $\mathrm{t} \mathrm{ha}^{-1}$ para solos argilosos e 1,5 a 2,0 $\mathrm{t}$ ha ${ }^{-1}$ para textura arenosa ou média. Também, através de observações práticas, o autor não recomenda fazer a calagem quando a saturação por bases for igual ou superior a $45-50 \%$.

Face à necessidade de estudos que definam melhor a calagem no SSD, devido principalmente aos constantes problemas de deficiência de Mn para a cultura da soja (Pauletti, 1998) e de Zn para a cultura do milho (Motta \& Prevedello, 1995), que vem ocorrendo em campo, outros trabalhos têm sido conduzidos. Também existem dúvidas quanto a dose de calcário a ser empregada, de acordo com o tempo de implantação do SSD.

Experimentos comparando a aplicação de calcário em superfície e incorporado a $20 \mathrm{~cm}$ de profundidade em Latossolo Vermelho Escuro foram realizados em campos nativos do Paraná (vegetação caracterizada por extensos campos limpos, onde predominam gramíneas baixas e perenes). As aplicações variaram de 25 a $100 \%$ da necessidade de calcário (elevação da saturação por bases a $70 \%$ ) e os resultados mostraram que os métodos de aplicação tiveram efeitos semelhantes no rendimento de grãos de soja (Sá, 1997). Outro estudo similar, realizado em campos naturais do Rio Grande do Sul, mostrou que a aplicação do corretivo na superfície é uma boa alternativa 
à calagem tradicional, para o cultivo de culturas anuais ou forrageiras (Ben Jr. et al., 1997).

Em um Latossolo Vermelho Escuro de textura argilosa e com elevada acidez, Oliveira \& Pavan (1996) observaram aumento de produtividade de soja em função da calagem, independentemente do sistema de cultivo. Contudo, não foram observadas diferenças na produtividade entre a aplicação superficial e a incorporada.

Pottker \& Ben (1998) avaliaram o efeito de doses de calcário e modos de aplicação (superficial ou incorporado) sobre produção de soja, trigo, aveia e cevada em Latossolo Vermelho Escuro textura média e Latossolo Roxo argiloso no Rio Grande do Sul. Foram observadas diferenças na produção de soja e cevada apenas quando foram comparados os tratamentos com aplicação de calcário e a testemunha. Em ambos os solos, após 11 meses da aplicação de calcário em superfície, observou-se incremento do $\mathrm{pH}$ e nos teores de $\mathrm{Ca}$ e $\mathrm{Mg}$ e diminuição do $\mathrm{Al}$ trocável até $10 \mathrm{~cm}$ de profundidade.

As produções de soja, trigo e milho foram avaliadas em um Latossolo Vermelho Escuro textura média do município de Ponta Grossa (PR) há 15 anos sob SSD, em função da aplicação superficial de calcário para elevar a saturação por bases a 50,70 e $90 \%$. A calagem não influenciou a produção de grãos das culturas, embora tenha provocado aumento do $\mathrm{pH}$ e dos teores de $\mathrm{Ca}$ e $\mathrm{Mg}$, além da diminuição do $\mathrm{Al}$ trocável (Caires et al., 1999). Resultados semelhantes foram encontrados por Caires et al. (1998) em solo com pH em CaCl $20,01 \mathrm{~mol} \mathrm{~L}^{-1}$ igual a 4,5 e saturação por bases de $32 \%$.

O fato de as culturas não estarem respondendo à calagem em SSD pode ser devido à existência de teores adequados de $\mathrm{Ca}, \mathrm{Mg}$ e $\mathrm{K}$, resultando em uma relação adequada com o Al trocável (Caires et al., 1998; Caires et al., 1999). Esse fato evidencia a existência de uma relação crítica entre aqueles elementos e o $\mathrm{Al}$ no solo.

Por outro lado, Caires et al. (1999) acreditam que o menor efeito da calagem em SSD pode também estar relacionado ao menor efeito tóxico do $\mathrm{Al}$ sobre as plantas neste sistema, decorrente da formação de compostos orgânicos solúveis capazes de complexar o Al. Assim, têm sido estudados os efeitos dos produtos da decomposição de 
resíduos de culturas e dos ácidos orgânicos na diminuição da acidez do solo (Hue et al., 1986; Kretzschmar et al.,1991; Miyazawa et al., 1992; Miyazawa et al., 1993).

Miyazawa et al. (1992) avaliaram a amenização da toxicidade de $\mathrm{Al}$ às raízes de trigo, através do fornecimento de ácidos orgânicos exogenamente em solução nutritiva. Concluíram que a formação de complexos de $\mathrm{Al}$ com ácidos orgânicos tornou o Al menos tóxico às raízes de trigo, sendo o ácido cítrico o mais eficiente dos ácidos naturais estudados. Diminuição da toxicidade de $\mathrm{Al}$ pelo ácido cítrico também já havia sido observada por Hue et al. (1986) em raízes de plantas de algodão, e por Muchovej et al. (1988) em plantas de centeio.

Estudos conduzidos por Hue et al. (1986) demonstraram que solos sob floresta possuem maior quantidade de ácidos orgânicos que solos cultivados convencionalmente. Assim, mesmo na presença de alta concentração de $\mathrm{Al}$, os solos sob floresta proporcionaram maior crescimento de raízes de algodão, devido à maior quantidade de $\mathrm{Al}$ na forma de complexos com ácidos orgânicos e à menor quantidade de Al na forma de $\mathrm{Al}^{3+}$, em relação aos solos cultivados. Hue et al. (1992) também observaram diminuição de todas as formas tóxicas de $\mathrm{Al}$ após a aplicação de lodo de esgoto ou esterco de galinha, devido à maior concentração de ácidos orgânicos nos solos tratados com estes resíduos.

Foi estudado o efeito da palhada de milheto sobre as características químicas de um solo arenoso africano em condições de campo, durante seis cultivos (Kretzschmar et al., 1991). Observaram aumento do $\mathrm{pH}$ e dos teores de $\mathrm{Ca}$ e $\mathrm{Mg}$, e diminuição do teor de $\mathrm{Al}$ onde a palha era deixada no solo. Experimentos de incubação em laboratório mostraram que os efeitos da palhada sobre as características químicas do solo foram semelhantes aos observados no campo. Em estudo posterior com plantas de milheto foi observado maior crescimento e produção de matéria seca de raízes dessa cultura cultivadas nas amostras de solo tratadas com palhada do que nas não tratadas. Resultados semelhantes, sobre as características químicas dos solos, foram obtidos por Miyazawa et al. (1993) em vasos, adicionando o equivalente a $10 \mathrm{t} \mathrm{ha}^{-1}$ de matéria seca de 22 tipos de resíduos vegetais na superfície do solo. 
Salet et al. (1994) estudaram a atividade do Al de um Latossolo Vermelho Escuro argiloso, sob SSD e SSC há oito anos. Demonstraram que o solo em SSD apresentou a maior parte do $\mathrm{Al}$ na forma orgânica e menor percentual das formas tóxicas de alumínio $\left(\mathrm{Al}^{3+}\right.$ e $\left.\mathrm{AlOH}^{2+}\right)$ em relação ao $\mathrm{SSC}$. No $\mathrm{SSD}$, o $\mathrm{Al}^{3+}$ apresentou menor atividade na solução do solo, comparado ao SSC.

A diminuição do $\mathrm{Al}$ tóxico, através de substâncias orgânicas, também é explicada pela precipitação do $\mathrm{Al}$ causada pelo aumento de $\mathrm{pH}$, e pela complexação do Al por ligantes orgânicos solúveis (Kretzschmar et al., 1991; Miyazawa et al., 1993). Reações de troca de ligantes entre ânions orgânicos e o Fe e Al terminais dos hidróxidos de $\mathrm{Al}$ e óxidos de $\mathrm{Fe}$ podem liberar $\mathrm{OH}^{-}$o qual precipita o $\mathrm{Al}$ (Hue et al., 1992). Estudos realizados por Miyazawa et al. (1993) demonstraram que a diminuição da acidez devido à complexação organo-metálica é maior para os resíduos de gramíneas, e que o efeito da precipitação do $\mathrm{Al}$ predominou para as leguminosas devido ao aumento do $\mathrm{pH}$ do solo.

\subsubsection{Correção das Camadas Subsuperfíciais}

Vários trabalhos têm demonstrado diminuição da acidez e aumento dos teores de nutrientes nas camadas subsuperficiais dos solos em SSD (Centurion, 1988; Oliveira \& Pavan, 1996; Miyazawa et al., 1996; Caires et al., 1999). Oliveira \& Pavan (1996) observaram em condições de campo diminuição do $\mathrm{Al}$ trocável e aumento do $\mathrm{pH}$ até $40 \mathrm{~cm}$ de profundidade, 32 meses da aplicação do calcário na superfície, na dose calculada para elevar a saturação por bases a 60\%. Da mesma forma, Caires et al. (1999) relataram aumento do $\mathrm{pH}$ e dos teores de $\mathrm{Ca}$ e $\mathrm{Mg}$, além da diminuição do $\mathrm{Al}$ trocável, até a camada de $40 \mathrm{~cm}$ de profundidade, após 18 meses da aplicação do corretivo.

A correção das camadas inferiores do solo pode ser explicada pela movimentação vertical física (Sá, 1995c; Oliveira \& Pavan, 1996) e química (Sá, 1995c; Miyazawa et al., 1996; Pavan, 1998) dos nutrientes no perfil dos solos, principalmente de $\mathrm{Ca}$, em função da calagem, apesar da baixa solubilidade em água do calcário.

A movimentação física do calcário pode ocorrer através de canais formados por raízes mortas e organismos do solo (Oliveira \& Pavan, 1996), principalmente 
minhocas (Dick et al., 1991) e algumas espécies de besouros (Gassen, 1998) que ocorrem em grande número neste sistema. Esses poros e o fendilhamento natural do solo, favorecem o deslocamento de partículas finas, junto com o movimento descendente da água, e outro fator é a formação de "sítios de matéria orgânica" enriquecidas de Ca e Mg nas camadas subsuperficiais, através da mistura de partículas de calcário com resíduos culturais, pela fauna do solo (Sá, 1995c).

A movimentação química do calcário por complexos orgânicos foi estudada por Miyazawa et al. (1996) através da aplicação de resíduos de aveia, nabo, centeio, milheto, tremoço, ervilhaca, mucuna e crotalária na superfície do solo, associada ou não ao calcário. Todos os resíduos vegetais com calcário aumentaram o $\mathrm{pH}$ e os teores de $\mathrm{Ca}$, e diminuíram o $\mathrm{Al}$ trocável até $60 \mathrm{~cm}$ de profundidade, sendo o efeito mais pronunciado produzido pela aveia.

A hipótese para explicar esta movimentação é que na decomposição dos resíduos vegetais, ocorre a liberação de ânions orgânicos (ligantes orgânicos), formando complexos com $\mathrm{H}^{+}, \mathrm{Ca}^{2+} \mathrm{e} \mathrm{Mg}^{2+}$ na superfície do solo. Deste modo, ocorre a elevação do $\mathrm{pH}$ na superfície e formação de pares iônicos com $\mathrm{Ca}$ e $\mathrm{Mg}$, sem carga e com grande facilidade para lixiviar para a subsuperfície. Após a lixiviação, ocorre reação dos pares iônicos com $\mathrm{H}^{+}$e $\mathrm{Al}^{3+}$ nas camadas inferiores do solo, liberando $\mathrm{Ca}$ e $\mathrm{Mg}$ e, desta forma, aumentando o $\mathrm{pH}$ e os teores de $\mathrm{Ca}$ e $\mathrm{Mg}$ e diminuindo o $\mathrm{Al}$ trocável (Miyazawa et al., 1996; Pavan, 1998). Na mineralização da matéria orgânica, também poderiam ser liberados ânions $\mathrm{SO}_{4}{ }^{\circ}$ e $\mathrm{NO}_{3}{ }^{\circ}$, que atuariam como íons acompanhantes, deslocando o $\mathrm{Ca}$ em profundidade (Sá, 1998).

A redução da acidez na subsuperfície também pode ser provocada, pelo menos em parte, por reações dependentes da nitrificação, mediante lixiviação de nitratos de $\mathrm{Ca}$ e $\mathrm{Mg}$ para camadas mais profundas, com maior absorção de nitrato no subsolo (Caires et al., 1999). Raij et al. (1988) observaram que a movimentação de sais de nitrato para subsolos ácidos elevou o $\mathrm{pH}$ e diminuiu o teor de $\mathrm{Al}$ trocável, devido à absorção de nitrogênio na forma de nitrato pelas raízes de plantas de sorgo. Quando o nitrogênio é absorvido na forma de nitrato, as raízes secretam ânions hidroxila ou bicarbonato para preservar a eletroneutralidade dentro da planta. 


\subsubsection{Influência dos Sistemas de Cultivo e da Calagem Superficial nos Teores Foliares de Macronutrientes}

Quanto à influência da calagem nos teores dos nutrientes nas folhas em SSD, poucos trabalhos têm sido encontrados na literatura. A maioria dos estudos realizados são referentes à comparação entre métodos de cultivo e/ou sobre a calagem no SSC. Em um trabalho sobre o efeito de sistemas de cultivo nos teores foliares de nutrientes, Lal et al. (1990) não encontraram variações nos teores de macronutrientes devido aos métodos de cultivo. Centurion (1988) comparou os teores de nutrientes em plantas de milho cultivadas sob vários sistemas, concluindo que a concentração de nutrientes estava dentro da faixa adequada exigida pela cultura, independente do sistema utilizado. No entanto, observaram maiores teores de $\mathrm{P}$ em folhas de milho no SSD do que no SSC. Muzilli (1983) também verificou maior teor de $\mathrm{P}$ em plantas de milho cultivadas sob SSD.

O maior acúmulo foliar de $\mathrm{P}$ em SSD em relação ao SSC pode ser atribuído ao fato de o SSD apresentar maior teor de umidade na camada superficial, favorecendo a taxa de difusão do $\mathrm{P}$ até as raízes (Phillips et al., 1980; Muzilli, 1985c).

Blevins et al. (1986) observaram que a absorção de Ca por plantas de milho não foi afetada pelos sistemas de cultivo. Contudo, no SSD houve menor absorção de $\mathrm{Mg}$, atribuída à alta absorção de K. Estes (1972) também notou menor concentração de $\mathrm{Ca}, \mathrm{Mg}$ e $\mathrm{Al}$ nas folhas de milho no SSD, comparado ao SSC, que também foi relacionada à maior concentração foliar de K. Centurion (1988), trabalhando com a cultura do milho encontrou maior concentração foliar de K no SSD do que no SSC.

A aplicação de calcário em solos submetidos por longo tempo ao SSD não tem modificado os níveis foliares de Ca e Mg (Oliveira \& Pavan, 1996; Caires et al., 1998), os teores foliares de S (Caires et al., 1998; Caires et al., 1999) e os teores de N em plantas de soja (Caires et al., 1998). Contudo, em um outro estudo conduzido em solo mantido durante quinze anos sob SSD foi obtido aumento da concentração de $\mathrm{Ca} e$ Mg, em função da calagem (Caires et al., 1999). 
No SSC tem ocorrido aumento nos teores de $\mathrm{Ca}$ e $\mathrm{Mg}$ nas folhas de milho e soja em função da calagem (Ernani et al., 1998; Quaggio et al., 1998). Estes aumentos têm sido obtidos com o emprego de calcário dolomítico e, assim, às vezes não são observadas elevações nos teores foliares de Ca (Oliveira et al.,1997), ou esses valores são pequenos quando comparados aos do Mg (Ernani et al., 1998). No solo, o Ca é preferencialmente adsorvido nas cargas negativas criadas pelo aumento do $\mathrm{pH}$, em relação ao $\mathrm{Mg}$. Deste modo, mesmo havendo aumento dos teores de $\mathrm{Ca}$ trocável no solo, praticamente não se alteram os teores de Ca na solução, enquanto os de $\mathrm{Mg}$ aumentam, induzindo às elevações verificadas na concentração de $\mathrm{Mg}$ nas folhas (Oliveira et al.,1997).

\subsection{Micronutrientes para a Soja em Sistema de Semeadura Direta}

Os micronutrientes $\mathrm{B}, \mathrm{Cu}, \mathrm{Fe}, \mathrm{Mn}$ e $\mathrm{Zn}$ são absorvidos pelas plantas predominantemente nas formas de $\mathrm{H}_{3} \mathrm{BO}_{3}, \mathrm{Cu}^{2+}, \mathrm{Fe}^{2+} \mathrm{Mn}^{2+}$ e $\mathrm{Zn}^{2+}$, respectivamente (Malavolta, 1980). De maneira geral, a concentração das formas assimiláveis pelas plantas de todos estes nutrientes é diminuída pela elevação do $\mathrm{pH}$ e influenciada pelas condições de umidade e aeração (Tisdale et al., 1985). O Cu pode ser fortemente complexado pela matéria orgânica (Basta \& Tabatabai, 1992), diminuindo sua disponibilidade, e as formas de $\mathrm{Mn}$ e o $\mathrm{Fe}$ são amplamente alteradas na solução em função das condições de oxi-redução do solo (Tisdale et al., 1985).

Ainda não se determinaram os níveis críticos no solo para os micronutrientes no SSD. Entretanto, existem classificações, como a de Raij et al. (1996), que podem ser usadas como referência, embora seja desenvolvida para o SSC. Estes autores consideram teores baixos para $\mathrm{Cu}, \mathrm{Fe}, \mathrm{Mn}$ e $\mathrm{Zn}$, extraídos com DTPA, de 0-0,2, 0-4,0, 0-1,2 e 0-0,5 $\mathrm{mg} \mathrm{dm}{ }^{-3}$, respectivamente. Para o $\mathrm{B}$ extraído em água quente, o teor considerado baixo é de $0-0,2 \mathrm{mg} \mathrm{dm}^{-3}$.

Levantamento realizado por Lopes (1983) em áreas do Brasil Central (Goiás e Triângulo Mineiro), no qual foram considerados os níveis críticos de 5,0, 1,0 e 0,8 mg 
$\mathrm{kg}^{-1}$ para $\mathrm{Mn}, \mathrm{Zn}$ e $\mathrm{Cu}$ (Mehlich I), mostrou que $95 \%$, 58\% e $37 \%$ dos solos se apresentavam deficientes em $\mathrm{Zn}, \mathrm{Cu}$ e $\mathrm{Mn}$, respectivamente.

Quanto aos teores de micronutrientes nas folhas considerados adequados, existe uma ampla faixa para cada nutriente, sugerindo que estes níveis ainda não estão bem definidos, mesmo em SSC. Para a soja, são considerados adequados os teores de 21-55, 10-30, 51-350, 21-100 e 21-50 $\mathrm{mg} \mathrm{kg}^{-1}$ de $\mathrm{B}, \mathrm{Cu}, \mathrm{Fe}, \mathrm{Mn}$ e $\mathrm{Zn}$, respectivamente (Malavolta et al., 1997). No caso do $\mathrm{Mn}, 20 \mathrm{mg} \mathrm{kg}^{-1}$ é considerado o nível crítico (Tanaka \& Mascarenhas, 1992).

Até recentemente não havia grande preocupação com deficiência de micronutrientes em soja no Brasil pelo fato de a maior parte da área cultivada, na tradicional região sul e leste do país, ser formada de solos ricos nestes nutrientes (Borkert, 1991). Com a expansão da utilização de solos de regiões pobres nesses elementos, os problemas relacionados à deficiência apareceram e atualmente tendem a agravar com o crescimento do SSD.

Este fato foi mais relevante para o $\mathrm{Mn}$, que é atualmente o elemento causador de maiores perdas de produtividade no campo. E como a soja é uma cultura prejudicada tanto pelo excesso como pela deficiência de Mn (Quaggio, 1991), a atenção era apenas para a sua toxicidade, e a maior parte das pesquisas nas últimas décadas tiveram como objetivo estudar os efeitos de seu excesso (Borkert, 1991).

\subsubsection{Disponibilidade de Micronutrientes e a Produtividade da Soja}

São conhecidos os efeitos da calagem sobre a concentração foliar de micronutrientes em SSC (Robertson et al., 1973; Mascarenhas et al., 1988; Oliveira et al., 1997). Redução das concentrações foliares de B (Quaggio et al., 1998); de Fe (Muchovej et al., 1993); de Mn (Novaes et al., 1989; Muchovej et al., 1993; Bell, 1996; Quaggio et al., 1998) e de $\mathrm{Zn}$ (Mascarenhas et al., 1988; Muchovej et al., 1993; Quaggio et al., 1998) em soja têm sido relatadas devido ao aumento do pH no SSC, com sintomas de deficiências nas plantas, podendo reduzir a produção (Novaes et al., 1989; 
Mascarenhas et al., 1991; Tanaka et al., 1993). Contudo, a maior preocupação ainda tem sido com relação ao Mn, tanto em SSD como SSC.

Robertson et al. (1973) observaram restrição de crescimento e sintomas de deficiência de $\mathrm{Mn}$ em folhas de soja, causados pela elevação do $\mathrm{pH}$ do solo a 7,0. Resultados semelhantes foram obtidos por Parker et al. (1981) em oito cultivares de soja. Observaram diminuição do teor de $\mathrm{Mn}$ na folha, no peso de sementes e na produtividade, e os níveis críticos de $\mathrm{Mn}$ foliar e de suficiência foram de 18 e 29 $\mathrm{mg} \mathrm{kg}^{-1}$, respectivamente.

No Brasil, foram relatados sintomas de deficiência de $\mathrm{Mn}$ em solos derivados de arenitos no Sul do Paraná por Borkert (1991), devido à pobreza desses solos nesse elemento, e em solos sob cerrados com elevado pH (Novaes et al., 1989). Em todos os locais o teor foliar de Mn era menor que o nível considerado crítico (20 mg $\mathrm{dm}^{-3}$ ) por Tanaka \& Mascarenhas (1992).

Tanaka et al. (1993) relataram redução do teor de Mn foliar, presença de sintomas de deficiências de $\mathrm{Mn}$ em soja e diminuição de produtividade de 3600 para $1500 \mathrm{~kg} \mathrm{ha}^{-1}$, quando a saturação por bases aumentou de 50 para $83 \%$, após 6 anos de estudos com aplicação de elevadas doses de calcário. A má incorporação do calcário, juntamente com a utilização de doses elevadas, têm sido os principais fatores responsáveis pela deficiência de Mn na cultura da soja no SSC (Tanaka \& Mascarenhas, 1992).

A concentração de $\mathrm{Zn}$ nas folhas de milho foram menores no SSD que no SSC, após a calagem, sendo que a concentração foliar de Mn não foi afetada pelo sistema de cultivo (Estes, 1972). Os teores foliares de $\mathrm{Mn} \mathrm{e} \mathrm{Cu}$ apresentaram-se menores no SSD que no SSC, sendo que os de Fe e $\mathrm{Zn}$ não foram afetados pelo sistema de cultivo (Centurion, 1988). Shuman \& McCracken (1999a) observaram diminuição dos teores foliares de Mn em plantas de soja em função da calagem no SSD e os teores de $\mathrm{Zn}$ foram reduzidos apenas nos locais submetidos ao SSC.

Grove \& Blevins (1988) observaram aumento no teor de Mn foliar em milho devido a altas doses de $\mathrm{N}$ aplicadas em solo sob SSD. Este fato foi atribuído ao 
abaixamento do $\mathrm{pH}$ nas camadas superficiais do solo, causando aumento dos níveis de Mn no solo (Blevins et al., 1986; Edwards et al., 1992).

A deficiência de $\mathrm{Mn}$ geralmente ocorre quando o $\mathrm{pH}$ em água atinge valores acima de 6,0 e a saturação por bases ultrapassa 60\% (Borkert, 1991; Quaggio, 1991; Sanzonowicz, 1995). Nessa situação, ocorre oxidação do $\mathrm{Mn}^{2+}$ a óxidos insolúveis (Sanzonowicz, 1995; Davis-Carter \& Shuman, 1993). A elevação do pH também aumenta a ação de microorganismos que oxidam o $\mathrm{Mn}^{2+}$ em complexos mais estáveis com a matéria orgânica (Sanzonowicz, 1995).

No SSD, as deficiências de $\mathrm{Mn}$ relatadas para a cultura da soja em muitos casos têm sido também atribuídas à utilização do calcário de forma indiscriminada. É freqüente o aparecimento das chamadas "manchas" de solo, locais com $\mathrm{pH}$ elevado e onde se nota a presença de plantas com sintomas típicos de deficiência de Mn devido à deposição de montes de corretivo na lavoura (Motta \& Prevedello, 1995). Contudo, em estudos conduzidos por Sá (1995c), durante o período de 5 anos, não foram observadas deficiências de $\mathrm{Mn}$ e $\mathrm{Zn}$ em nenhuma das culturas envolvidas nas rotações, causadas pela calagem superficial.

O SSD apresenta sempre maiores teores de micronutrientes na camada superficial que o SSC (Edwards et al., 1992; Castro et al., 1992) e, mesmo assim, altos valores de pH e teores de matéria orgânica nessa camada (Lal et al., 1990; Kitur et al., 1994). Assim, a explicação para as deficiências de micronutrientes ocorridas em campo parece não se resumir apenas a um aumento de pH. Aliado a isto, Estes (1972) encontrou menores teores foliares de nutrientes e maior produção de milho no SSD do que no SSC. Os autores sugerem que a mudança do sistema de cultivo possa levar à mudança do nível crítico dos nutrientes.

Apesar de a influência dos sistemas de cultivo ser mais notória na superfície do solo do que nas camadas inferiores, os teores de nutrientes nessas camadas devem ser considerados. Sintomas de carência inicial de $\mathrm{Mn}$ em mudas de álamo desapareceram com o crescimento das plantas à medida que suas raízes atingiram as camadas mais profundas do solo, ricas no nutriente (Motta \& Prevedello, 1995). Correlações positivas foram observadas entre o rendimento de soja e a presença do $\mathrm{Mn}$ em profundidade 
(Robertson et al., 1973). Sintomas de deficiências visuais iniciais de Mn em soja podem desaparecer com o crescimento das raízes para as camadas mais profundas, onde o $\mathrm{pH}$ é mais baixo e a disponibilidade de Mn é maior (Borkert, 1991; Pauletti, 1998).

Devido à matéria orgânica ser a principal fonte de $\mathrm{B}$ em solos ácidos (Tisdale et al., 1985); o Cu ser fortemente complexado pela matéria orgânica (Basta \& Tabatabai, 1992); a disponibilidade de $\mathrm{P}$ de solos sob SSD ser maior que nos solos sob SSC, podendo diminuir a absorção do $\mathrm{Zn}$ pelas plantas; e a disponibilidade de $\mathrm{Fe}$ e $\mathrm{Mn}$ depender principalmente das condições de $\mathrm{pH}$ e oxiredução do solo, que não são as mesmas nos dois sistemas (SSD e SSC), mais atenção deve ser dada a todos os micronutrientes em solos sob SSD. 


\section{MATERIAL E MÉTODOS}

O trabalho foi desenvolvido em condições de campo em Latossolo Vermelho Escuro argiloso, submetido a diferentes TCSSD. Os locais com os diferentes TCSSD (3, 6 e 9 anos) pertencem ao Campo Demonstrativo da Fundação ABC, à Fazenda Fortaleza e à Fazenda Lagoa, respectivamente, situadas no município de Tibagi, PR.

O município de Tibagi situa-se na região dos Campos Gerais, Centro-Sul do Paraná, compreendida entre o primeiro e o segundo planalto do Estado. O clima é subtropical úmido ( $\mathrm{cfb}$ ) mesotérmico, com verões frescos, geadas severas e freqüentes no inverno. A temperatura média do mês mais quente é de $22^{\circ} \mathrm{C}$, e do mais frio, $18^{\circ} \mathrm{C}$, sem estação seca. A altitude média varia de 840 a $980 \mathrm{~m}$, e o relevo é suavemente ondulado e ondulado, apresentando declives acentuados em partes do município ('Maack, 1968, citado por Sá, 1993).

O histórico do Latossolo Vermelho Escuro submetido a diferentes TCSSD está disposto na Tabela 1. Antes da adoção do SSD, a acidez do solo em todos os TCSSD foi corrigida elevando-se a saturação por bases a 70\%. O corretivo da acidez foi incorporado com arado de aivecas na camada de $0-20 \mathrm{~cm}$. Calagens posteriores foram efetuadas sempre que necessário, aplicando-se o corretivo superficialmente. Deste modo, o local com maior TCSSD recebeu duas aplicações de $2 \mathrm{t}$ ha ${ }^{-1}$ (dolomítico, $\mathrm{PRNT}=84 \%, \mathrm{PN}=97,8 \%, \mathrm{RE}=87,9 \%, \mathrm{CaO}=27 \%$ e $\mathrm{MgO}=20 \%$ ), e o solo com 6 anos em $\mathrm{SSD}$, uma aplicação de $2 \mathrm{t} \mathrm{ha}^{-1}$; o local com menor TCSSD não recebeu nenhuma aplicação de corretivo após a calagem inicial. Em 1998, ano de instalação dos experimentos, todos os locais estavam sem receber aplicação de calcário há três anos.

\footnotetext{
${ }^{2}$ MAACK, R. Classificação do Clima do Estado do Paraná. In: Geografia Física do Estado do Paraná. 2. ed., Rio de Janeiro: 1981. p. 175-189.
} 
Tabela 1. Histórico do Latossolo Vernelho Escuro submetido a diferentes tempos de cultivo sob sistema de semeadura direta.

\begin{tabular}{|c|c|c|c|c|c|c|}
\hline \multirow[t]{2}{*}{ Ano } & \multicolumn{2}{|c|}{ Campo Experimental } & \multicolumn{2}{|c|}{ Fazenda Fortaleza } & \multicolumn{2}{|c|}{ Fazenda Lagoa } \\
\hline & Inverno & Verão & Inverno & Verão & Inverno & Verão \\
\hline 1989 & Aveia Preta & Milho & - & & --------------- & - \\
\hline 1990 & Aveia Preta & Milho & --.------ & & & \\
\hline 1991 & Aveia Preta & Soja & & & & \\
\hline 1992 & Aveia Preta & Milho/Soja & -..--- & 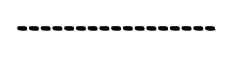 & & \\
\hline 1993 & Aveia Preta & Milho/Soja & Aveia Preta & Milho & & \\
\hline 1994 & Aveia Preta & Milho/Soja & Aveia Preta & Soja & & \\
\hline 1995 & Aveia Preta & Milho/Soja & Trigo & Soja & & \\
\hline 1996 & Aveia Preta & Milho/Soja & Aveia Preta & Milho/Feijão & Aveia Preta & Milho \\
\hline 1997 & Aveia Preta & Milho/Soja & Trigo & Soja & Triticale & Soja \\
\hline
\end{tabular}

Os tratamentos constituíram-se de três $\operatorname{TCSSD}(3,6$ e 9 anos) e de quatro doses de calcário $(0 \%, 33,3 \%, 66,7 \%$ e $100 \%$ da quantidade calculada para elevar a saturação por bases a 70\%), aplicadas em superfície, e um tratamento adicional, em que se aplicaram $100 \%$ da dose necessária para elevar a saturação por bases a $70 \%$, porém, incorporando-se o corretivo na profundidade de 0-20 cm. Para a determinação das doses de calcário (Tabela 2) foi efetuada a coleta de 20 amostras simples de terra na profundidade de 0-20 cm em cada TCSSD, e que depois se reuniram em uma composta. Os resultados das análises químicas de terra encontram-se na Tabela 3.

Tabela 2. Doses de calcário ${ }^{(1)}$ necessárias para atingir a $100 \%, 66,7 \%$ e $33,3 \%$ da saturação por bases, em cada solo, submetido a diferentes tempos de cultivo sob sistema de semeadura direta (TCSSD).

\begin{tabular}{cccc}
\hline TCSSD & $\mathbf{1 0 0}$ & $\mathbf{6 6 , 7}$ & $\mathbf{3 3 , 3}$ \\
\hline ano & & $\mathrm{kg} \mathrm{ha}$ & \\
$\mathbf{3}$ & 3031 & 2033 & 1016 \\
6 & 3381 & 2254 & 1127 \\
9 & 2484 & 1656 & 828 \\
\hline
\end{tabular}

(7) calcário dolomítico, PRNT $=84 \%, \mathrm{PN}=97,8 \%, \mathrm{RE}=87,9 \%, \mathrm{CaO}=27 \%$ e $\mathrm{MgO}=20 \%$. 
Tabela 3. Propriedades químicas do Latossolo Vermelho Escuro na camada de $0-20 \mathrm{~cm}$ antes da calagem inicial, para diferentes tempos de cultivo em sistema de semeadura direta (TCSSD).

\begin{tabular}{|c|c|c|c|c|c|c|c|c|c|c|c|c|}
\hline TCSSD & $\mathbf{p} \mathbf{H}_{\mathrm{CaCl}}$ & $\mathbf{P}_{\text {resina }}$ & MO & $\mathbf{H}+\mathbf{A l}$ & Al & $\mathbf{K}$ & Ca & Mg & SB & CTC & V & $\mathbf{m}$ \\
\hline ano & & \multicolumn{2}{|c|}{$\mathrm{mg} \mathrm{dm}^{-3}$} & 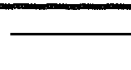 & & $-\mathrm{mm}$ & $\mathrm{ol}_{\mathrm{c}} \mathrm{dr}$ & $n^{-3}$ & & & \multicolumn{2}{|c|}{$-\%$} \\
\hline 3 & 5,0 & 33 & 55 & 58 & 1 & 3,7 & 28 & 26 & 57,7 & 115,7 & 50 & 1,7 \\
\hline 6 & 4,8 & 41 & 47 & 72 & 2 & 6,7 & 47 & 18 & 71,7 & 143,7 & 50 & 2,7 \\
\hline 9 & 5,1 & 44 & 47 & 52 & 0 & 2,6 & 34 & 21 & 57,6 & 109,6 & 53 & 0,0 \\
\hline
\end{tabular}

Antes da implantação do experimento, também foi realizada uma caracterização fisica e química detalhada dos solos em diferentes profundidades (Tabelas 4 e 5). Foram coletadas 20 amostras simples em cada TCSSD, através de trado calador, e a amostra composta foi submetida às determinações de argila, silte e areia, através do método do densímetro; de $\mathrm{pH}$, matéria orgânica, $\mathrm{P}, \mathrm{K}, \mathrm{Ca}, \mathrm{Mg}$ e $\mathrm{Al}$, conforme metodologias propostas por Raij et al. (1987); de $\mathrm{Cu}, \mathrm{Fe}, \mathrm{Mn}$ e $\mathrm{Zn}$, segundo Abreu \& Abreu (1996a) e de B, segundo Abreu \& Abreu (1996b).

Tabela 4. Caracterização das frações granulométricas do Latossolo Vermelho Escuro submetido a diferentes tempos de cultivo sob sistema de semeadura direta (TCSSD), para diferentes profundidades, antes da implantação do experimento.

\begin{tabular}{|c|c|c|c|c|c|c|c|c|c|}
\hline \multirow[t]{2}{*}{ Prof. } & \multicolumn{3}{|c|}{3 anos } & \multicolumn{3}{|c|}{6 anos } & \multicolumn{3}{|c|}{9 anos } \\
\hline & Argila & Silte & Areia & Argila & Silte & Areia & Argila & Silte & Areia \\
\hline $\mathrm{cm}$ & & & & & $\mathrm{g} \mathrm{kg}$ & & & & \\
\hline $0-5$ & 680 & 230 & 90 & 720 & 170 & 110 & 640 & 120 & 240 \\
\hline $5-10$ & 720 & 230 & 90 & 690 & 190 & 120 & 680 & 100 & 220 \\
\hline $10-20$ & 760 & 160 & 120 & 660 & 210 & 130 & 640 & 120 & 240 \\
\hline $20-30$ & 720 & 160 & 80 & 700 & 210 & 90 & 680 & 100 & 220 \\
\hline
\end{tabular}


Tabela 5. Atributos químicos e físicos do Latossolo Vermelho Escuro submetido a diferentes tempos de cultivo em sistema de semeadura direta (TCSSD), para diferentes profundidades, antes da implantação do experimento.

\begin{tabular}{|c|c|c|c|c|c|c|c|c|c|c|c|c|}
\hline Prof. & $\mathbf{p} \mathrm{H}_{\mathrm{CaCl}^{2}}$ & MO & $\mathbf{P}$ & $\mathbf{K}$ & Al & $\mathbf{C a}$ & Mg & B & $\mathbf{C u}$ & $\mathbf{F e}$ & Mn & $\mathbf{Z n}$ \\
\hline $\mathrm{cm}$ & & $\mathrm{mgd}$ & $\mathrm{m}^{-3}$ & -1 & $\mathrm{nmol}$ & $\mathrm{cdm}^{-}$ & - & & $=$ & $\mathrm{ng} \mathrm{dm}^{-1}$ & & 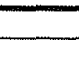 \\
\hline $0-5$ & 6,1 & 71 & 78 & 4,7 & 0 & $52^{3}$ & $\begin{array}{c}\text { annos } \\
40\end{array}$ & 0,07 & 1,8 & 19,6 & 3,2 & 2,2 \\
\hline $5-10$ & 6,0 & 52 & 41 & 3,3 & 0 & 40 & 33 & 0,09 & 2,0 & 18,2 & 2,0 & 1,6 \\
\hline $10-15$ & 5,4 & 55 & 41 & 2,9 & 1 & 22 & 19 & 0,09 & 2,4 & 24,2 & 1,8 & 1,2 \\
\hline $15-20$ & 5,2 & 48 & 27 & 2,6 & 0 & 19 & 16 & 0,06 & 2,6 & 26,6 & 1,6 & 0,8 \\
\hline $20-30$ & 4,8 & 49 & 12 & 2,4 & 4 & 12 & 11 & 0,11 & 2,4 & 24,4 & 0,8 & 0,2 \\
\hline $30-40$ & 4,5 & 44 & 6 & 1,6 & 8 & 5 & 5 & 0,06 & 2,0 & 21,0 & 0,6 & 0,2 \\
\hline & \multicolumn{12}{|c|}{6 anos } \\
\hline $0-5$ & 5,2 & 56 & 48 & 7,1 & 0 & 51 & 30 & 0,31 & 1,6 & 38,0 & 5,8 & 0,8 \\
\hline $5-10$ & 4,6 & 52 & 34 & 4,9 & 5 & 28 & 17 & 0,31 & 1,8 & 41,8 & 3,2 & 0,6 \\
\hline $10-15$ & 4,5 & 49 & 26 & 3,6 & 10 & 19 & 11 & 0,31 & 1,6 & 43,2 & 2,6 & 0,4 \\
\hline $15-20$ & 4,4 & 38 & 16 & 2,7 & 13 & 22 & 12 & 0,28 & 1,6 & 40,8 & 1,6 & 0,2 \\
\hline $20-30$ & 4,2 & 39 & 7 & 1,5 & 22 & 8 & 5 & 0,26 & 1,2 & 29,8 & 0,6 & 0,2 \\
\hline $30-40$ & 4,2 & 36 & 3 & 1,5 & 24 & 5 & 4 & 0,26 & 1,2 & 22,4 & 0,6 & 0,2 \\
\hline \multicolumn{13}{|c|}{9 anos } \\
\hline $0-5$ & 5,4 & 51 & 30 & 4,6 & 0 & 40 & 28 & 0,20 & 3,0 & 28,0 & 4,0 & 2,4 \\
\hline $5-10$ & 5,0 & 46 & 26 & 2,7 & 1 & 29 & 22 & 0,19 & 3,6 & 29,0 & 2,2 & 4,8 \\
\hline $10-15$ & 4,8 & 40 & 21 & 2,1 & 3 & 21 & 11 & 0,22 & 4,0 & 28,8 & 1,8 & 5,0 \\
\hline $15-20$ & 4,9 & 43 & 11 & 1,9 & 1 & 27 & 15 & 0,21 & 4,0 & 28,8 & 1,6 & 0,6 \\
\hline $20-30$ & 5,1 & 41 & 9 & 1,3 & 0 & 23 & 14 & 0,23 & 3,8 & 25,5 & 1,4 & 0,8 \\
\hline $30-40$ & 4,8 & 33 & 5 & 1,2 & 2 & 21 & 14 & 0,19 & 3,0 & 18,8 & 0,8 & 0,2 \\
\hline
\end{tabular}

O experimento foi iniciado no mês de maio de 1998, com a distribuição do corretivo manualmente, na superficie do solo. Nas parcelas em que o calcário foi incorporado, essa operação foi efetuada com arado de discos. O tamanho das parcelas dos locais sob 3 e 6 anos de cultivo foi de $6,4 \mathrm{~m} \times 7 \mathrm{~m}$ de comprimento $\left(45 \mathrm{~m}^{2}\right)$, e do local sob 9 anos de SSD, igual a $8,30 \mathrm{~m}$ x 12,50 m, totalizando $104 \mathrm{~m}^{2}$. As áreas úteis de 
cada parcela corresponderam às cinco linhas centrais com quatro metros de comprimento.

Logo após a calagem realizou-se a semeadura de aveia branca nos locais com 6 e 9 anos de cultivo, e de aveia preta no local com menor TCSSD, com o objetivo de se fazer cobertura morta para o solo. A semeadura foi realizada mecanicamente através de semeadora de parcelas, regulada para distribuir 60 e $70 \mathrm{~kg} \mathrm{ha}^{-1}$ de sementes de aveia preta e branca, respectivamente, no espaçamento de $15 \mathrm{~cm}$ entrelinhas. Não foi utilizada nenhuma fonte de adubo, apenas aproveitou-se 0 efeito residual dos fertilizantes aplicados nas culturas anteriores.

Durante o ciclo da aveia, o único trato cultural adotado foi o combate da ferrugem nos locais com 6 e 9 anos de cultivo. O local com maior TCSSD recebeu duas aplicações de fungicidas, a primeira do produto tebuconazole, na dosagem de $187,5 \mathrm{~g} \mathrm{ha}^{-1}$ de ingrediente ativo (i.a.), e a segunda da mistura de propiconazole e cyproconazole, nas dosagens de 125 e $20 \mathrm{~g} \mathrm{ha}^{-1} \mathrm{de}$ i.a, respectivamente. No solo com 6 anos de TCSSD foi realizada apenas uma aplicação de tebuconazole, na dosagem de $187,5 \mathrm{~g} \mathrm{ha}^{-1}$ de i.a.

Em todos os TCSSD, a aveia foi rolada no estágio de grãos leitosos, cerca de trinta dias antes da semeadura da soja, quando também realizou-se a dessecação das plantas remanescentes nas áreas, usando-se o ingrediente ativo sulfosate na dosagem de $1,44 \mathrm{~L} \mathrm{ha}^{-1}$ i.a.

Efetuou-se a semeadura da soja (Glycine max cv. EMBRAPA 59) a partir do dia 26 de outubro de 1998, utilizando-se o espaçamento de $45 \mathrm{~cm}$ entre linhas com 16 plantas por metro linear. A adubação de plantio foi realizada baseando-se nas quantidades adotadas pelos produtores da região, ou seja, $40 \mathrm{~kg} \mathrm{ha}^{-1} \mathrm{de} \mathrm{K}_{2} \mathrm{O}$ e $40 \mathrm{~kg} \mathrm{ha}^{-1} \mathrm{de} \mathrm{P}_{2} \mathrm{O}_{5}$, utilizando-se $200 \mathrm{~kg} \mathrm{ha}^{-1}$ da fórmula 0-20-20. As sementes de soja foram inoculadas com estirpes selecionadas de Bradyrhizobium em meio líquido com $64 \mathrm{~g}$ de molibdato de sódio e tratadas com $150 \mathrm{~g}$ i.a. de thiram para cada $50 \mathrm{~kg}$ de sementes.

Durante o cultivo da soja, efetuou-se o controle de lagartas (Anticarsia gemmatalis) utilizando-se lufenurom (7,5 $\mathrm{g} \mathrm{ha}^{-1}$ de i.a.), e de percevejos, aplicando-se 
deltamethrin $\left(3,75 \mathrm{~g} \mathrm{ha}^{-1}\right.$ de i.a). Para controle de plantas daninhas de folhas largas e estreitas, realizaram-se aplicações de imazethapyr ( $50 \mathrm{~g}^{-1} \mathrm{a}^{-1}$ de i.a) e clethodim $(0,096 \mathrm{~g}$ $\mathrm{ha}^{-1}$ de i.a), respectivamente.

Foram registradas as precipitações pluviais desde a época da instalação do experimento até a colheita da soja (Figura 1), comparando-as com a precipitação média dos últimos 24 anos. Vale ressaltar que, após a semeadura da soja, houve uma estiagem de 37 dias (26 de outubro de 1998 a 02 de dezembro de 1998). Durante o período de semeadura da soja até a colheita choveu $767 \mathrm{~mm}$.

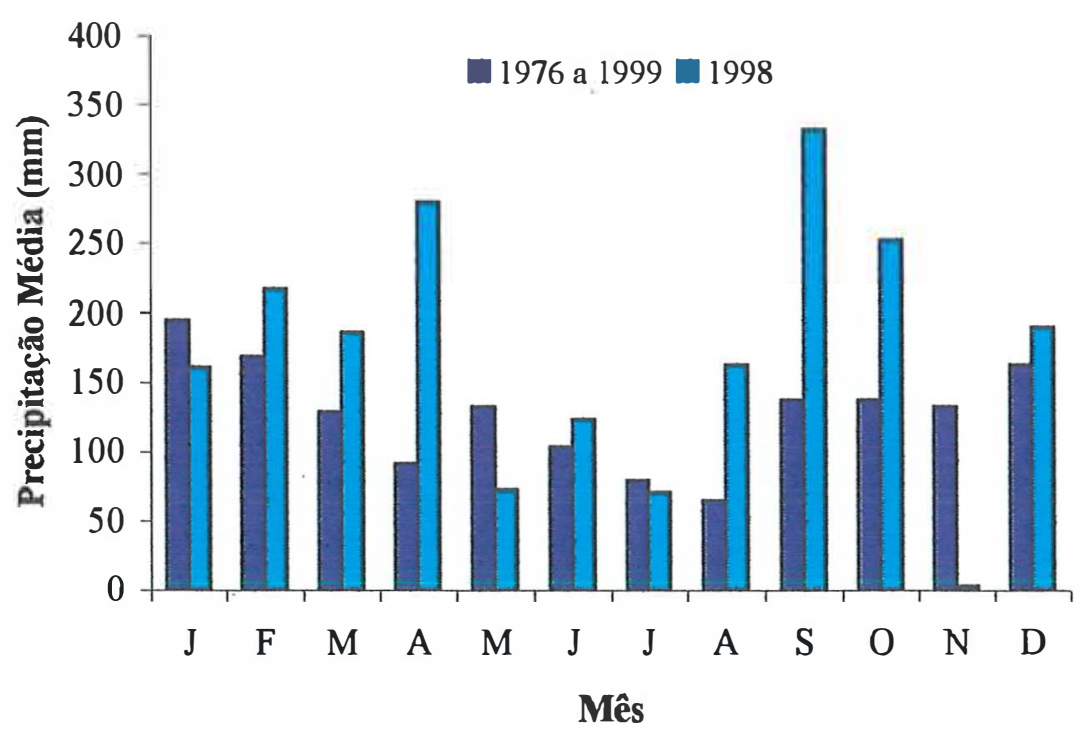

Figura 1. Precipitações pluviais médias mensais de 1976 a 1999, e do ano de instalação do experimento (1998).

O efeito das doses de calcário na disponibilidade de nutrientes às plantas foi avaliado pelo teor de nutrientes no solo e nas folhas, durante o cultivo da soja, em duas épocas de amostragens. As coletas de terra e folha foram realizadas no estágio V4 (três trifólios abertos) e na época do florescimento, respectivamente nos dias 17 de dezembro de 1998 e 26 de janeiro de 1999, quando já havia chovido 1174 e 1305 mm, após efetuada a calagem. 
Realizaram-se outras amostragens de terra e folha, além da época recomendada por Malavolta et al. (1997) (época de florescimento da soja), visto que deficiências de Mn têm ocorrido na cultura da soja (Pauletti, 1998), e de Zn no milho (Motta \& Prevedello, 1995) nos períodos iniciais de desenvolvimento, e desaparecido com o tempo.

As amostras de terra foram coletadas nas profundidades de 0-5, 5-10, 10-20 e 20-30 cm, através de trado calador, em número de 10 amostras simples por parcela. As amostras foram secas em estufa a $40^{\circ} \mathrm{C}$, destorroadas, moídas e passadas em peneira de $2 \mathrm{~mm}$. As amostras de folhas foram coletadas em número de 20 trifólios por parcela, retirando-se a terceira folha a partir do ápice das plantas. Essas amostras foram lavadas em água desionizada, colocadas para secar em estufa a $60^{\circ} \mathrm{C}$ até atingir massa constante, e moídas.

Nas amostras de terra determinaram-se $\mathrm{pH}, \mathrm{Al}, \mathrm{K}, \mathrm{P}, \mathrm{S}, \mathrm{Ca}$ e $\mathrm{Mg}$ segundo metodologia de Raij et al. (1987). Também foram determinados os micronutrientes Mn, $\mathrm{Cu}, \mathrm{Zn}$ e Fe com DTPA-TEA (Abreu \& Abreu, 1996a) e B com $\mathrm{BaCl}_{2} \cdot \mathrm{H}_{2} \mathrm{O}$ 0,125\% em microondas (Abreu \& Abreu, 1996b). A determinação de $\mathrm{Mn}, \mathrm{Cu}, \mathrm{Zn}$ e Fe foi efetuada no espectrofotômetro de absorção atômica, e a do B, no colorímetro. Foram calculados os valores de soma e saturação por bases. Nas amostras de folha foram determinados os teores de $\mathrm{N}, \mathrm{P}, \mathrm{K}, \mathrm{S}, \mathrm{Ca}, \mathrm{Mg}, \mathrm{Mn}, \mathrm{Zn}, \mathrm{B}, \mathrm{Cu}$ e Fe, conforme métodos descritos por Malavolta et al. (1997).

A colheita da soja foi realizada manualmente a partir de 30 de março de 1999, e a trilhagem mecanicamente, utilizando-se debulhadora de grãos estacionária, peneirando-se logo em seguida, pesando-se os grãos e lendo-se a umidade em medidor universal. Para os cálculos da produtividade, considerou-se um teor de umidade nos grãos de $13 \%$.

A análise de variância seguiu o delineamento em blocos ao acaso, com tratamentos em arranjo fatorial $3 \times 5$ ( 3 TCSSD $\times 5$ doses), com parcelas subsubdivididas (subparcelas $=2$ épocas de amostragens e sub-subparcelas $=4$ profundidades), em quatro blocos, para as variáveis do solo. Para as variáveis da planta, os tratamentos obedeceram um fatorial $3 \times 5$, com parcelas subdivididas no tempo 
(subparcelas $=2$ épocas de amostragens) em quatro blocos. No caso da variável produção, os tratamentos configuraram um fatorial $3 \times 5$.

Para avaliar o efeito dos tratamentos nos atributos do solo, inicialmente, estudaram-se os efeitos das épocas de amostragens e dos tempos de cultivo sob sistema de semeadura direta (TCSSD), através das interações entre épocas de amostragens e TCSSD para os valores de $\mathrm{pH}$, soma de bases, saturação por bases e dos teores de $\mathrm{Ca}$, $\mathrm{Mg}, \mathrm{Al}, \mathrm{B}, \mathrm{Cu}, \mathrm{Fe}, \mathrm{Mn}$ e $\mathrm{Zn}$. Posteriormente, estudaram-se os efeitos das doses de calcário através da interação tripla entre doses, TCSSD e profundidades, para os atributos que a interação foi significativa.

Para testar o efeito dos tratamentos nos teores de nutrientes nas folhas, estudaram-se as interações entre épocas de amostragens e TCSSD, e entre épocas de amostragens e doses de calcário para todos os nutrientes nas folhas das plantas de soja $(\mathrm{N}, \mathrm{P}, \mathrm{K}, \mathrm{S}, \mathrm{Ca}, \mathrm{Mg}, \mathrm{B}, \mathrm{Cu}, \mathrm{Fe}, \mathrm{Mn}$ e $\mathrm{Zn}$ ). Estudou-se também a interação tríplice entre TCSSD, épocas de amostragens e doses de calcário, para os nutrientes em que a mesma foi significativa.

Realizaram-se testes de médias, pelo teste de Tukey a 5\%, para todos os atributos em estudo. O teste de médias foi realizado devido à necessidade de comparação da aplicação do calcário de forma incorporada com a aplicação superficial.

Procederam-se estudos de correlações lineares simples entre os teores de macronutrientes ( $\mathrm{P}, \mathrm{K}, \mathrm{S}, \mathrm{Ca}$ e $\mathrm{Mg}$ ) e micronutrientes (B, $\mathrm{Cu}, \mathrm{Fe}, \mathrm{Mn}$ e $\mathrm{Zn}$ ) no solo e folha. Também foram realizadas correlações lineares entre os teores de micronutrientes no solo e $\mathrm{pH}$, entre os teores de micronutrientes no solo e matéria orgânica, e entre a concentração de micronutrientes nas folhas e o pH. As correlações foram realizadas por profundidades $(0-5,5-10,10-20$ e $20-30 \mathrm{~cm})$, separando-se o tratamento com incorporação do corretivo dos tratamentos sem revolvimento do solo, dentro de cada época de amostragem. Realizaram-se também correlações lineares entre os teores de nutrientes nas folhas de soja de cada época de amostragem e a produção de grãos. 


\section{RESULTADOS E DISCUSSÃO}

\subsection{Características Químicas dos Solos}

\subsubsection{Efeito das Épocas de Amostragens e dos Tempos de Cultivo sob Sistema de Semeadura Direta}

A interação entre épocas de amostragens e tempos de cultivo sob sistema de semeadura direta (TCSSD) foi significativa para todos os atributos do solo em estudo ( $\mathrm{pH}, \mathrm{Al}, \mathrm{Ca}, \mathrm{Mg}$, soma de bases, saturação por bases, $\mathrm{B}, \mathrm{Cu}, \mathrm{Fe}, \mathrm{Mn}$ e $\mathrm{Zn}$ ).

Na primeira amostragem, os TCSSD não diferiram quanto aos teores de $\mathrm{Ca} e$ $\mathrm{Mg}$ e aos valores de soma de bases (Tabela 6). Contudo, o solo com 6 anos de cultivo apresentou os menores valores de $\mathrm{pH}$ e de saturação por bases, e os maiores teores de $\mathrm{Al}$ trocável. Na segunda amostragem, este solo também apresentou os menores valores de $\mathrm{pH}$, saturação por bases e teores de $\mathrm{Mg}$, e os maiores teores de Al trocável, demonstrando maior acidez neste TCSSD do que nos demais.

Todos os TCSSD apresentaram altos teores de $\mathrm{Ca}$ e $\mathrm{Mg}$, altos valores de soma de bases e baixos teores de Al trocável, de acordo com a classificação sugerida por Lopes \& Guimarães (1989), exceto o solo com 6 anos de cultivo, que apresentou teores médios de $\mathrm{Al}$ na primeira amostragem (Tabela 6). A saturação por bases foi média, de acordo com classificação de Raij et al. (1996), exceto o solo com 6 anos sob SSD, que apresentou valores baixos na primeira amostragem. 
Tabela 6. Atributos químicos do Latossolo Vermelho Escuro em função do tempo de cultivo sob sistema de semeadura direta (TCSSD), para diferentes épocas de amostragens.

\begin{tabular}{|c|c|c|c|c|c|c|}
\hline TCSSD & $\mathrm{pH}_{\mathrm{CaCl} 2}$ & $\mathbf{C a}$ & Mg. & Al & SB & $\mathbf{V}$ \\
\hline \multirow[t]{2}{*}{ anos } & & & $-m$ & $n^{-3}$ & & $\%$ \\
\hline & \multicolumn{6}{|c|}{ Amostragem $1^{(1)}$} \\
\hline 3 & $5,1 \mathrm{a}^{(2)}$ & $41 \mathrm{a}$ & $27 \mathrm{a}$ & $1,4 \mathrm{~b}$ & $71 \mathrm{a}$ & $61 \mathrm{a}$ \\
\hline 6 & $4,6 \mathrm{c}$ & $45 \mathrm{a}$ & $26 \mathrm{a}$ & $5,7 \mathrm{a}$ & $77 \mathrm{a}$ & $43 c$ \\
\hline 9 & $4,9 \mathrm{~b}$ & $44 \mathrm{a}$ & $27 \mathrm{a}$ & $1,0 \mathrm{~b}$ & $74 \mathrm{a}$ & $53 \mathrm{~b}$ \\
\hline & \multicolumn{6}{|c|}{ Amostragem 2} \\
\hline 3 & $5,2 \mathrm{a}$ & $52 \mathrm{~b}$ & $43 \mathrm{a}$ & $0,7 \mathrm{~b}$ & 99 a & $61 \mathrm{~b}$ \\
\hline 6 & $4,8 \mathrm{~b}$ & $49 \mathrm{~b}$ & $31 \mathrm{c}$ & $2,2 \mathrm{a}$ & $86 \mathrm{~b}$ & $55 \mathrm{c}$ \\
\hline 9 & $5,1 \mathrm{a}$ & $57 \mathrm{a}$ & $35 \mathrm{~b}$ & $0,1 \mathrm{c}$ & $93 \mathrm{ab}$ & $67 \mathrm{a}$ \\
\hline
\end{tabular}

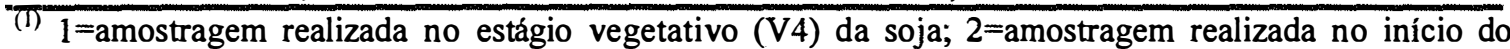
florescimento da soja. ${ }^{(2)}$ Letras comparam TCSSD dentro de cada amostragem, pelo teste de Tukey ao nível de $5 \%$. Os dados referentes ao $\mathrm{Al}$ foram transformados em $(\mathrm{Al}+1)^{1 / 2}$, para a análise de variância e teste de médias, segundo Nogueira (1997).

Em todos os TCSSD, os valores de $\mathrm{pH}$, os teores de $\mathrm{Ca}$ e $\mathrm{Mg}$ e a soma de bases foram maiores na segunda amostragem do que na primeira, sendo que para a saturação por bases este fato foi observado somente nos solos com 6 e 9 anos de TCSSD (Tabela 7). Os teores de $\mathrm{Al}$ trocável diminuíram da primeira para a segunda amostragem, demonstrando maior efeito da calagem na correção da acidez na última amostragem. Esta amostragem foi realizada aproximadamente 40 dias após a primeira. As elevadas precipitações pluviais registradas após a aplicação do calcário (1173,5 e 1304,5 mm, antes da primeira e segunda amostragens, respectivamente) podem ter facilitado a reação do calcário no solo. Entretanto, antes da primeira amostragem houve um veranico de 37 dias.

Nas duas épocas de amostragens, o solo com 6 anos de cultivo apresentou os maiores teores de $\mathrm{B}$ e Fe e os menores de $\mathrm{Cu}$ (Tabela 8). Este solo também mostrou o maior teor de $\mathrm{Mn}$ na primeira amostragem, e os menores de $\mathrm{Zn}$, em ambas as amostragens. De acordo com os níveis apresentados por Raij et al. (1996), os teores de B dos solos com 3 e 9 anos sob SSD, na primeira amostragem, são considerados baixos, e o do de 6 anos, médio; na segunda amostragem os teores foram médios em todos os 
TCSSD. Os teores de $\mathrm{Cu}$ e $\mathrm{Fe}$ foram altos para todos os TCSSD, os teores de $\mathrm{Mn}$ médios, e os de $\mathrm{Zn}$ dentro das faixas de teores médios a altos.

Tabela 7. Atributos químicos do Latossolo Vermelho Escuro em função da época de amostragem, para diferentes tempos de cultivo sob sistema de semeadura direta (TCSSD).

\begin{tabular}{|c|c|c|c|c|c|c|}
\hline Amostragem $^{(\mathrm{I})}$ & $\mathrm{pH}_{\mathrm{Ca}} \mathrm{Cl} 2$ & Ca & Mg & Al & SB & $\mathbf{V}$ \\
\hline & & \multicolumn{4}{|c|}{$-\mathrm{mmol}_{\sigma} \mathrm{dm}^{-3}$} & $\%$ \\
\hline & \multicolumn{6}{|c|}{3 anos } \\
\hline 1 & $5,1 b^{(2)}$ & $41 \mathrm{~b}$ & $27 \mathrm{~b}$ & $1,4 \mathrm{a}$ & $71 \mathrm{~b}$ & $61 \mathrm{a}$ \\
\hline 2 & $5,2 \mathrm{a}$ & $52 \mathrm{a}$ & $43 \mathrm{a}$ & $0,7 \mathrm{~b}$ & 99 a & $61 \mathrm{a}$ \\
\hline & \multicolumn{6}{|c|}{6 anos } \\
\hline 1 & $4,6 \mathrm{~b}$ & $45 \mathrm{~b}$ & $26 \mathrm{~b}$ & $5,7 \mathrm{a}$ & $77 \mathrm{~b}$ & $43 \mathrm{~b}$ \\
\hline 2 & $4,8 \mathrm{a}$ & $49 a$ & $31 \mathrm{a}$ & $2,2 \mathrm{~b}$ & $86 \mathrm{a}$ & $55 \mathrm{a}$ \\
\hline & \multicolumn{6}{|c|}{9 anos } \\
\hline 1 & $4,9 \mathrm{~b}$ & $44 \mathrm{~b}$ & $27 \mathrm{~b}$ & $1,0 \mathrm{a}$ & $74 \mathrm{~b}$ & $53 \mathrm{~b}$ \\
\hline 2 & $5,1 \mathrm{a}$ & $57 \mathrm{a}$ & $35 \mathrm{a}$ & $0,1 \mathrm{~b}$ & $93 \mathrm{a}$ & $67 \mathrm{a}$ \\
\hline
\end{tabular}

Tabela 8. Teores de micronutrientes do Latossolo Vermelho Escuro em função do tempo de cultivo sob sistema de semeadura direta (TCSSD), para diferentes épocas de amostragens.

\begin{tabular}{|c|c|c|c|c|c|}
\hline TCSSD & B & $\mathbf{C u}$ & $\mathbf{F e}$ & Mn & $\mathbf{Z n}$ \\
\hline \multirow[t]{2}{*}{ anos } & & & $\mathrm{gdm}^{-3}$ & & \\
\hline & \multicolumn{5}{|c|}{ Amostragem $1^{(1)}$} \\
\hline 3 & $0,15 b^{(2)}$ & $2,7 \mathrm{~b}$ & $27,7 \mathrm{c}$ & $3,1 \mathrm{~b}$ & $2,9 \mathrm{a}$ \\
\hline 6 & $0,29 \mathrm{a}$ & $1,9 \mathrm{c}$ & $59,0 \mathrm{a}$ & $4,4 \mathrm{a}$ & $0,9 \mathrm{c}$ \\
\hline \multirow[t]{2}{*}{9} & $0,15 \mathrm{~b}$ & $4,2 \mathrm{a}$ & $39,2 \mathrm{~b}$ & $2,2 \mathrm{c}$ & $1,8 \mathrm{~b}$ \\
\hline & \multicolumn{5}{|c|}{ Amostragem 2} \\
\hline 3 & $0,23 \mathrm{~b}$ & $2,5 \mathrm{~b}$ & $24,7 \mathrm{c}$ & $3,0 \mathrm{a}$ & $2,7 \mathrm{a}$ \\
\hline 6 & $0,31 \mathrm{a}$ & $1,4 \mathrm{c}$ & $37,2 \mathrm{a}$ & $2,9 \mathrm{a}$ & $0,8 \mathrm{c}$ \\
\hline 9 & $0,23 \mathrm{~b}$ & $3,4 \mathrm{a}$ & $31,1 \mathrm{~b}$ & $2,9 \mathrm{a}$ & $1,6 \mathrm{~b}$ \\
\hline
\end{tabular}


Nos solos com 3 e 9 anos de SSD foram observados maiores teores de B na segunda amostragem do que na primeira (Tabela 9). Os teores de $\mathrm{Cu}$ e Fe diminuíram da primeira para a segunda amostragem em todos os TCSSD, exceto o $\mathrm{Cu}$ no menor TCSSD; no caso do Mn, este fato foi observado apenas no local com 6 anos sob SSD, sendo que no solo com maior TCSSD, o maior teor de Mn ocorreu na segunda amostragem. Para o $\mathrm{Zn}$, não houve efeito das épocas de amostragens. Contudo, era esperado menor teor de todos os micronutrientes na segunda amostragem devido ao maior valor de $\mathrm{pH}$ ocorrido nessa ocasião, que poderia tornar estes elementos menos disponíveis (Malavolta, 1980).

Tabela 9. Teores de micronurientes do Latossolo Vermelho Escuro em função da época de amostragem, para diferentes tempos de cultivo sob sistema de semeadura direta (TCSSD).

\begin{tabular}{|c|c|c|c|c|c|}
\hline Amostragem $^{(1)}$ & B & $\mathrm{Cu}$ & $\mathrm{Fe}$ & Mn & $\mathbf{Z n}$ \\
\hline & & & $\mathrm{mg} \mathrm{dm}$ & & \\
\hline $\begin{array}{l}1 \\
2\end{array}$ & $\begin{array}{l}0,15 b^{(2)} \\
0,23 a\end{array}$ & $\begin{array}{l}2,7 \mathrm{a} \\
2,5 \mathrm{a}\end{array}$ & $\begin{array}{l}3 \text { anos } \\
27,7 \mathrm{a} \\
24,7 \mathrm{a}\end{array}$ & $\begin{array}{l}3,1 \mathrm{a} \\
3,0 \mathrm{a}\end{array}$ & $\begin{array}{l}2,9 a \\
2,7 a\end{array}$ \\
\hline $\begin{array}{l}1 \\
2\end{array}$ & $\begin{array}{l}0,29 a \\
0,31 \mathrm{a}\end{array}$ & $\begin{array}{c}1,9 \mathrm{a} \\
1,4 \mathrm{~b}\end{array}$ & $\begin{array}{l}6 \text { anos } \\
59,0 \mathrm{a} \\
37,2 \mathrm{~b}\end{array}$ & $\begin{array}{l}4,4 \mathrm{a} \\
2,9 \mathrm{~b}\end{array}$ & $\begin{array}{l}0,9 \mathrm{a} \\
0,8 \mathrm{a}\end{array}$ \\
\hline $\begin{array}{l}1 \\
2\end{array}$ & $\begin{array}{l}0,15 \mathrm{~b} \\
0,23 \mathrm{a}\end{array}$ & $\begin{array}{l}4,2 \mathrm{a} \\
3,4 \mathrm{~b}\end{array}$ & $\begin{array}{l}9 \text { anos } \\
39,2 \mathrm{a} \\
31,1 \mathrm{~b}\end{array}$ & $\begin{array}{l}2,2 \mathrm{~b} \\
2,9 \mathrm{a}\end{array}$ & $\begin{array}{l}1,8 \mathrm{a} \\
1,6 \mathrm{a}\end{array}$ \\
\hline
\end{tabular}

\subsubsection{Efeito da Calagem nos Atributos Químicos dos Solos}

A interação tripla entre doses de calcário, TCSSD e profundidades foi significativa para os valores de pH, soma de bases, saturação por bases e para os teores 
de $\mathrm{Ca}, \mathrm{Mg}, \mathrm{Al}, \mathrm{Fe}, \mathrm{Mn}$ e $\mathrm{Zn}$. Para os casos em que a interação tripla não foi significativa $(\mathrm{B} \mathrm{e} \mathrm{Cu})$, estudaram-se as interações duplas significativas.

\subsubsection{Acidez Ativa}

No solo com 3 anos sob SSD não houve efeito das doses de calcário nos valores de $\mathrm{pH}$, exceto na camada de 10-20 cm, cujo $\mathrm{pH}$ elevou-se somente com a aplicação das maiores quantidades do corretivo (Tabela 10). Santos et al. (1995) também não encontraram diferenças quanto ao $\mathrm{pH}$ do solo, entre a aplicação de calcário superficialmente e a incorporação de $2 \mathrm{t} \mathrm{ha}^{-1}$ de calcário ( $\mathrm{PRNT}=100 \%$ ), após três anos de cultivos sob SSD em um Latossolo Vermelho Escuro argiloso.

Tabela 10. Valores de pH do Latosssolo Vermelho Escuro em função de doses de calcário, para diferentes tempos de cultivo sob sistema de semeadura direta (TCSSD) e profundidades.

\begin{tabular}{|c|c|c|c|c|c|}
\hline \multirow[t]{2}{*}{ Prof. } & \multicolumn{5}{|c|}{ Doses de calcário $^{(1)}$} \\
\hline & $100 \mathrm{I}$ & $100 \mathrm{~S}$ & $66,7 \mathrm{~S}$ & $33,3 \mathrm{~S}$ & $\mathbf{0}$ \\
\hline $\mathrm{cm}$ & & & 3 anos & & \\
\hline $0-5$ & $5,45 \mathrm{aA}^{(2)}$ & $5,61 \mathrm{aA}$ & $5,50 \mathrm{aA}$ & $5,48 \mathrm{aA}$ & $5,46 \mathrm{aA}$ \\
\hline $5-10$ & $5,25 \mathrm{abA}$ & $5,36 \mathrm{aA}$ & $5,46 \mathrm{aA}$ & $5,33 \mathrm{abA}$ & $5,31 \mathrm{aA}$ \\
\hline $10-20$ & $5,50 \mathrm{aA}$ & $5,31 \mathrm{aAB}$ & 5,18 aABC & $4,94 \mathrm{bcBC}$ & $4,83 \mathrm{bC}$ \\
\hline $20-30$ & $4,90 \mathrm{bA}$ & $4,69 \mathrm{bA}$ & $4,74 \mathrm{bA}$ & $4,56 \mathrm{cA}$ & $4,55 \mathrm{bA}$ \\
\hline $\begin{array}{c}0-5 \\
5-10 \\
10-20 \\
20-30\end{array}$ & $\begin{array}{l}4,76 \mathrm{aB} \\
4,85 \mathrm{aA} \\
4,85 \mathrm{aA} \\
4,63 \mathrm{aA}\end{array}$ & $\begin{array}{l}5,51 \mathrm{aA} \\
4,66 \mathrm{bA} \\
4,51 \mathrm{bcA} \\
4,21 \mathrm{cB}\end{array}$ & $\begin{array}{l}6 \text { anos } \\
5,13 \mathrm{aAB} \\
4,60 \mathrm{bA} \\
4,50 \mathrm{bA} \\
4,20 \mathrm{bB}\end{array}$ & $\begin{array}{l}5,16 \mathrm{aAB} \\
4,70 \mathrm{bA} \\
4,66 \mathrm{bcA} \\
4,25 \mathrm{cAB}\end{array}$ & $\begin{array}{l}5,08 \mathrm{aB} \\
4,66 \mathrm{bA} \\
4,49 \mathrm{bcA} \\
4,24 \mathrm{cAB}\end{array}$ \\
\hline $\begin{array}{c}0-5 \\
5-10 \\
10-20 \\
20-30\end{array}$ & $\begin{array}{l}5,03 \mathrm{aB} \\
4,98 \mathrm{aA} \\
5,15 \mathrm{aA} \\
4,90 \mathrm{aA}\end{array}$ & $\begin{array}{l}5,40 \mathrm{aAB} \\
5,06 \mathrm{aA} \\
5,14 \mathrm{aA} \\
5,04 \mathrm{aA}\end{array}$ & $\begin{array}{l}9 \text { anos } \\
5,46 \mathrm{aA} \\
4,89 \mathrm{bA} \\
5,09 \mathrm{abA} \\
4,96 \mathrm{bA}\end{array}$ & $\begin{array}{l}5,33 \mathrm{aAB} \\
4,93 \mathrm{abA} \\
4,93 \mathrm{abA} \\
4,86 \mathrm{bA}\end{array}$ & $\begin{array}{l}5,04 \mathrm{aB} \\
4,71 \mathrm{aA} \\
4,85 \mathrm{aA} \\
4,84 \mathrm{aA}\end{array}$ \\
\hline C.V. & $4,8 \%$ & & - & 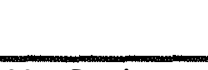 & \\
\hline
\end{tabular}


Para a camada superficial do solo do local com 6 anos de cultivo, a aplicação de $100 \%$ da dose recomendada à superfície propiciou um valor de $\mathrm{pH}(5,51)$ superior ao obtido com a aplicação da mesma dose de forma incorporada $(4,76)$. Por sua vez, na camada de 20-30 cm ocorreu o inverso. No solo com 9 anos sob SSD, a aplicação superficial de $2 / 3$ da dose resultou maior $\mathrm{pH}(5,46)$ que a incorporação da dose total $(5,03)$. Resultados semelhantes foram obtidos por Sá (1995c), Pottker \& Ben (1998) e Oliveira \& Pavan (1996), ao compararem a aplicação do calcário à superfície com a aplicação de modo incorporado.

Quando o calcário foi incorporado na dose correspondente a $100 \%$ da necessidade de calagem, os valores de $\mathrm{pH}$ não variaram com a profundidade nos solos há 6 e 9 anos de SSD. O solo com maior TCSSD também apresentou, de modo geral, menores variações de $\mathrm{pH}$ entre as camadas, para todas as doses de calcário. Contudo, este efeito não pode ser atribuído às doses de calcário porque não houve diferenças nos valores de $\mathrm{pH}$ nas camadas inferiores do solo devido a estes tratamentos.

O aumento do TCSSD pode ter melhorado a fertilidade das camadas inferiores devido a uma possível movimentação física (Sá, 1995c; Oliveira \& Pavan, 1996) associada à química (Sá, 1995c; Miyazawa et al., 1996; Pavan, 1998) dos nutrientes no perfil do solo. Crozier et al. (1999), avaliando 59 locais sob SSD nos Estados Unidos da América do Norte, observaram que as áreas com mais de 6 anos de cultivo apresentaram maior homogeneidade dos nutrientes no perfil, não mostrando diferenças significativas entre as camadas de 0-10 e 10-20 cm quanto aos valores de $\mathrm{pH}$.

No presente estudo, pode ser que o tempo entre a aplicação do calcário à superfície do solo e a retirada das amostras de terra (por volta de 7 meses) não tenha sido suficiente para que o calcário reagisse e corrigisse as camadas inferiores. De fato, Oliveira \& Pavan (1996) obtiveram aumento de $\mathrm{pH}$ até $40 \mathrm{~cm}$ de profundidade somente após 32 meses da calagem superficial. Resultados similares foram obtidos por Caires et al. (1998) e Caires et al. (1999) em solos de textura média. 


\subsubsection{Acidez Trocável}

No solo com menor TCSSD houve efeito das doses de calcário no teor de $\mathrm{Al}$ trocável apenas na camada de 20-30 cm, cujo teor foi reduzido de 4,3 para 0,9 $\mathrm{mmol}_{\mathrm{c}}$ $\mathrm{dm}^{-3}$ pela incorporação do corretivo (Tabela 11). Santos et al. (1995) também não observaram efeito da calagem superficial no teor de Al trocável de um Latossolo Vermelho Escuro submetido por 3 anos ao SSD.

Tabela 11. Teores de Al trocável em Latosssolo Vermelho Escuro em função de doses de calcário, para diferentes tempos de cultivo sob sistema de semeadura direta (TCSSD) e profundidades.

\begin{tabular}{|c|c|c|c|c|c|}
\hline \multirow[t]{2}{*}{ Prof. } & \multicolumn{5}{|c|}{ Doses de calcário $^{(1)}$} \\
\hline & $100 \mathrm{I}$ & $100 \mathrm{~S}$ & $66,7 \mathrm{~S}$ & $33,3 \mathrm{~S}$ & $\mathbf{0}$ \\
\hline $\mathrm{cm}$ & & & $\mathrm{nmol}_{\mathrm{c}} \mathrm{dm}^{-}$ & & \\
\hline $\begin{array}{c}0-5 \\
5-10 \\
10-20 \\
20-30\end{array}$ & $\begin{array}{l}0,3 \mathrm{aA}^{(2)} \\
0,4 \mathrm{aA} \\
0,0 \mathrm{aA} \\
0,9 \mathrm{aB}\end{array}$ & $\begin{array}{c}0,0 \mathrm{bA} \\
0,1 \mathrm{bA} \\
0,5 \mathrm{bA} \\
2,9 \mathrm{aAB}\end{array}$ & $\begin{array}{c}3 \text { anos } \\
0,0 \mathrm{bA} \\
0,1 \mathrm{bA} \\
0,4 \mathrm{bA} \\
3,5 \mathrm{aA}\end{array}$ & $\begin{array}{c}0,1 \mathrm{bA} \\
0,1 \mathrm{bA} \\
1,6 \mathrm{abA} \\
3,4 \mathrm{aA}\end{array}$ & $\begin{array}{c}0,3 \mathrm{bA} \\
0,3 \mathrm{bA} \\
1,5 \mathrm{bA} \\
4,3 \mathrm{aA}\end{array}$ \\
\hline $\begin{array}{c}0-5 \\
5-10 \\
10-20 \\
20-30\end{array}$ & $\begin{array}{c}0,8 \mathrm{bA} \\
0,8 \mathrm{bA} \\
1,0 \mathrm{bB} \\
4,0 \mathrm{aB}\end{array}$ & $\begin{array}{c}0,4 \mathrm{cA} \\
1,6 \mathrm{cA} \\
5,9 \mathrm{bA} \\
11,0 \mathrm{aA}\end{array}$ & $\begin{array}{c}6 \text { anos } \\
0,6 \mathrm{cA} \\
1,9 \mathrm{cA} \\
6,8 \mathrm{bA} \\
12,0 \mathrm{aA}\end{array}$ & $\begin{array}{c}1,1 \mathrm{cA} \\
1,8 \mathrm{bcA} \\
3,5 \mathrm{bAB} \\
9,0 \mathrm{aA}\end{array}$ & $\begin{array}{c}0,3 \mathrm{cA} \\
1,8 \mathrm{cA} \\
5,4 \mathrm{bA} \\
10,0 \mathrm{aA}\end{array}$ \\
\hline $\begin{array}{c}0-5 \\
5-10 \\
10-20 \\
20-30\end{array}$ & $\begin{array}{c}0,5 \mathrm{aA} \\
0,8 \mathrm{aA} \\
0,4 \mathrm{aA} \\
0,6 \mathrm{aA}\end{array}$ & $\begin{array}{l}0,3 \mathrm{aA} \\
0,8 \mathrm{aA} \\
0,4 \mathrm{aA} \\
0,5 \mathrm{aA}\end{array}$ & $\begin{array}{c}9 \text { anos } \\
0,5 \mathrm{aA} \\
0,8 \mathrm{aA} \\
0,9 \mathrm{aA} \\
0,5 \mathrm{aA}\end{array}$ & $\begin{array}{l}0,3 \mathrm{aA} \\
0,5 \mathrm{aA} \\
0,6 \mathrm{aA} \\
0,4 \mathrm{aA}\end{array}$ & $\begin{array}{c}0,4 \mathrm{aA} \\
0,9 \mathrm{aA} \\
0,5 \mathrm{aA} \\
0,8 \mathrm{aA}\end{array}$ \\
\hline C.V. & $25,5 \%$ & & & & \\
\hline
\end{tabular}

(1) Percentagem da dose necessária para elevar a saturação por bases a 70\%; I = incorporado a $20 \mathrm{~cm} ; \mathrm{S}=$ aplicado superficialmente. (2) Análise de variância e teste de médias realizados com os dados transformados em $(\mathrm{Al}+1)^{1 / 2}$, segundo Nogueira (1997). Letras minúsculas comparam profundidades dentro de cada dose de calcário e TCSSD e as maiúsculas comparam as doses dentro de cada TCSSD e profundidade, pelo teste de Tukey ao nível de $5 \%$.

Nas camadas inferiores do local com 6 anos sob SSD, o teor de Al trocável diminuiu com a incorporação do calcário, e no solo com maior TCSSD os teores não 
variaram com as doses de corretivo. Por outro lado, tem sido observado maior efeito da aplicação superficial do corretivo na diminuição do $\mathrm{Al}$ nas camadas superficiais do que de solos onde esse material foi incorporado (Moschler et al., 1973; Sá, 1995c; Caires et al., 1998), tendendo esta correção da acidez a se estender às camadas subsuperficiais ao longo do tempo de cultivo (Oliveira \& Pavan, 1996; Caires et al., 1998; Caires et al., 1999).

$\mathrm{Na}$ camada inferior dos solos com menores TCSSD geralmente foram encontrados os maiores teores de $\mathrm{Al}$ trocável do que nas demais, enquanto no local com 9 anos sob SSD não houve variação em profundidade.

Todos os teores de $\mathrm{Al}$ do solo com maior TCSSD estão abaixo de $3 \mathrm{mmol}_{\mathrm{c}}$

$\mathrm{dm}^{-3}$, considerados baixos de acordo com os critérios de Lopes \& Guimarães (1989), e para os solos com 6 e 3 anos de cultivo este fato ocorreu até 10 e $20 \mathrm{~cm}$ de profundidade, respectivamente.

\subsubsection{Cálcio e Magnésio Trocáveis}

No solo com menor TCSSD, a maior dose de corretivo aplicada na superfície resultou teores de $\mathrm{Ca}$ e $\mathrm{Mg}$ na camada de 0-5 cm maiores do que quando aplicado de forma incorporada (Tabelas 12 e 13). Na camada superficial dos solos com os maiores TCSSD, quaisquer das doses aplicadas na superfície elevaram os teores de $\mathrm{Ca}$ e $\mathrm{Mg}$ mais do que a dose integral de forma incorporada. Aumentos dos teores de $\mathrm{Ca}$ e $\mathrm{Mg}$ nas camadas superficiais de solos sob SSD em função da calagem superficial têm sido freqüentemente observados (Sá, 1995c, Oliveira \& Pavan, 1996, Caires et al., 1998).

Em todos os TCSSD, o calcário aplicado de forma incorporada não modificou os teores originais de $\mathrm{Ca}$ e $\mathrm{Mg}$ das camadas superficiais, mas aumentou os teores na camada de 10-20 cm do solo com menor TCSSD e das duas inferiores do local com 6 anos de cultivo.

Os teores de $\mathrm{Ca}$ e $\mathrm{Mg}$ não variaram em profundidade quando o corretivo foi incorporado, exceto no solo com menor TCSSD. Com as demais doses, os maiores teores de $\mathrm{Ca}$ e $\mathrm{Mg}$ geralmente ocorreram na camada superficial. No solo com 9 anos sob 
$\mathrm{SSD}$, os teores de $\mathrm{Ca}$ e $\mathrm{Mg}$ das camadas abaixo de $0-5 \mathrm{~cm}$, não variaram em profundidade, fato que não ocorreu nos outros TCSSD (Tabela 12 e 13). Contudo, como os teores de $\mathrm{Ca}$ e $\mathrm{Mg}$ das camadas inferiores do solo não foram influenciados pelas doses de corretivo, este efeito não pode ser atribuído à ação destes tratamentos, e sim a um possível efeito do tempo de cultivo na distribuição destes elementos em profundidade. Crozier et al. (1999), avaliando 59 locais sob SSD nos Estados Unidos da América do Norte, observaram que as áreas com mais de 6 anos de cultivo apresentaram distribuição mais uniforme dos teores de $\mathrm{Ca}$ no perfil, não mostrando diferenças significativas entre as camadas de 0-10 e 10-20 cm quanto aos teores de Ca.

Tabela 12. Teores de Ca do Latosssolo Vermelho Escuro em função de doses de calcário, para diferentes tempos de cultivo sob sistema de semeadura direta (TCSSD) e profundidades.

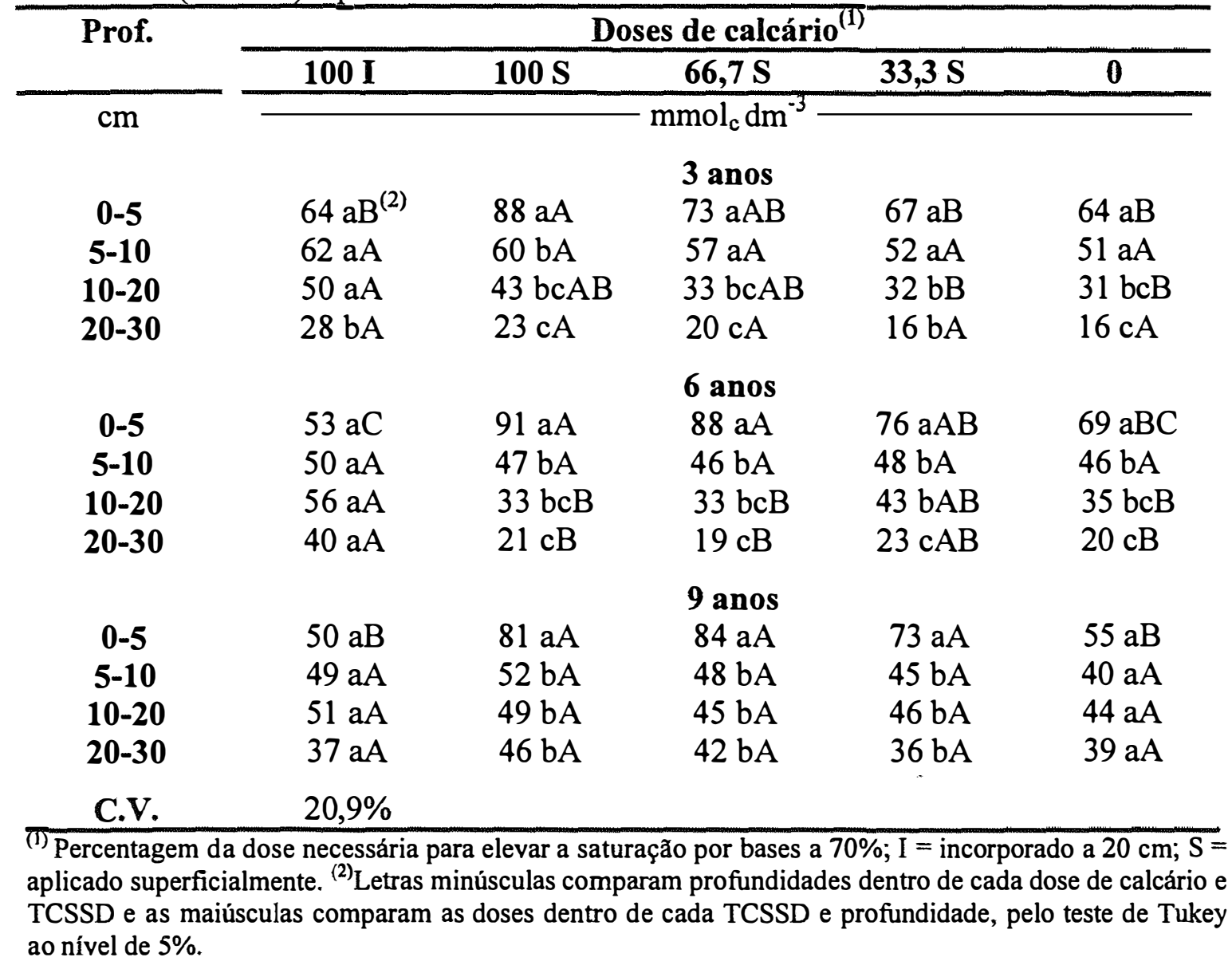


A distribuição dos nutrientes no perfil pode ocorrer devido à movimentação física (Caires et al., 1999) associada à química (Sá, 1995c; Miyazawa et al., 1996) dos nutrientes da superfície para as camadas inferiores. Oliveira \& Pavan (1996) e Caires et al. (1999) observaram aumento no teor de $\mathrm{Ca}$ e $\mathrm{Mg}$ até $40 \mathrm{~cm}$ de profundidade, respectivamente após 32 e 18 meses da aplicação do calcário na superfície de dois Latossolos Vermelho Escuros, um argiloso e outro com textura média, este submetido há 15 anos sob SSD.

Tabela 13. Teores de $\mathrm{Mg}$ do Latosssolo Vermelho Escuro em função de doses de calcário, para diferentes tempos de cultivo sob sistema de semeadura direta (TCSSD) e profundidades.

\begin{tabular}{|c|c|c|c|c|c|}
\hline \multirow[t]{2}{*}{ Prof. } & \multicolumn{5}{|c|}{ Doses de calcário ${ }^{(1)}$} \\
\hline & $100 \mathrm{I}$ & $100 \mathrm{~S}$ & $66,7 \mathrm{~S}$ & $33,3 \mathrm{~S}$ & $\mathbf{0}$ \\
\hline $\mathrm{cm}$ & & & $\mathrm{nmol}_{\mathrm{c}} \mathrm{dm}^{-3}$ & & \\
\hline $\begin{array}{c}0-5 \\
5-10 \\
10-20 \\
20-30\end{array}$ & $\begin{array}{l}39 \mathrm{aC}^{(2)} \\
40 \mathrm{aA} \\
42 \mathrm{aA} \\
24 \mathrm{bA}\end{array}$ & $\begin{array}{l}66 \mathrm{aA} \\
48 \mathrm{bA} \\
33 \mathrm{cAB} \\
17 \mathrm{dA}\end{array}$ & $\begin{array}{l}3 \text { anos } \\
56 \mathrm{aAB} \\
41 \mathrm{bA} \\
27 \mathrm{cB} \\
13 \mathrm{dA}\end{array}$ & $\begin{array}{l}49 \mathrm{aBC} \\
40 \mathrm{abA} \\
27 \mathrm{bB} \\
12 \mathrm{cA}\end{array}$ & $\begin{array}{l}49 \mathrm{aBC} \\
40 \mathrm{aA} \\
26 \mathrm{bB} \\
11 \mathrm{cA}\end{array}$ \\
\hline $\begin{array}{c}0-5 \\
5-10 \\
10-20 \\
20-30\end{array}$ & $\begin{array}{l}32 \mathrm{aD} \\
33 \mathrm{aA} \\
37 \mathrm{aA} \\
27 \mathrm{aA}\end{array}$ & $\begin{array}{l}64 \mathrm{aA} \\
28 \mathrm{bA} \\
18 \mathrm{bcB} \\
11 \mathrm{cB}\end{array}$ & $\begin{array}{l}6 \text { anos } \\
54 \mathrm{aAB} \\
27 \mathrm{bA} \\
18 \mathrm{bcB} \\
11 \mathrm{cB}\end{array}$ & $\begin{array}{l}50 \mathrm{aBC} \\
28 \mathrm{bA} \\
25 \mathrm{bcAB} \\
14 \mathrm{cAB}\end{array}$ & $\begin{array}{l}39 \mathrm{aCD} \\
27 \mathrm{aA} \\
19 \mathrm{abB} \\
11 \mathrm{bB}\end{array}$ \\
\hline $\begin{array}{c}0-5 \\
5-10 \\
10-20 \\
20-30\end{array}$ & $\begin{array}{l}31 \mathrm{aB} \\
31 \mathrm{aA} \\
34 \mathrm{aA} \\
22 \mathrm{aA}\end{array}$ & $\begin{array}{l}47 \mathrm{aA} \\
33 \mathrm{bA} \\
27 \mathrm{bA} \\
26 \mathrm{bA}\end{array}$ & $\begin{array}{c}9 \text { anos } \\
51 \mathrm{aA} \\
30 \mathrm{bA} \\
27 \mathrm{bA} \\
27 \mathrm{bA}\end{array}$ & $\begin{array}{l}48 \mathrm{aA} \\
30 \mathrm{bA} \\
25 \mathrm{bA} \\
25 \mathrm{bA}\end{array}$ & $\begin{array}{l}33 \mathrm{aB} \\
22 \mathrm{aA} \\
26 \mathrm{aA} \\
25 \mathrm{aA}\end{array}$ \\
\hline$\frac{\text { C.V. }}{\text { Percentage }}$ & $\begin{array}{l}\frac{25,9 \%}{\text { necessári }} \\
\text { te. }{ }^{(2)} \text { Letra } \\
\text { s compara }\end{array}$ & & & & dec \\
\hline
\end{tabular}




\subsubsection{Soma de Bases}

A aplicação superficial das maiores doses de corretivo, em geral, resultou maior soma de bases na camada de $0-5 \mathrm{~cm}$ do que a realizada de forma incorporada (Tabela 14). No solo com menor TCSSD, o maior valor de soma de bases na camada superficial foi proporcionado pela aplicação das maiores doses na superfície. Por outro lado, nos locais sob 6 e 9 anos de cultivo, todas as doses de calcário aplicadas na superficie resultaram valores semelhantes de soma de bases na camada de $0-5 \mathrm{~cm}$.

Tabela 14. Valores de soma de bases do Latosssolo Vermelho Escuro em função de doses de calcário, para diferentes tempos de cultivo sob sistema de semeadura direta (TCSSD) e profundidades.

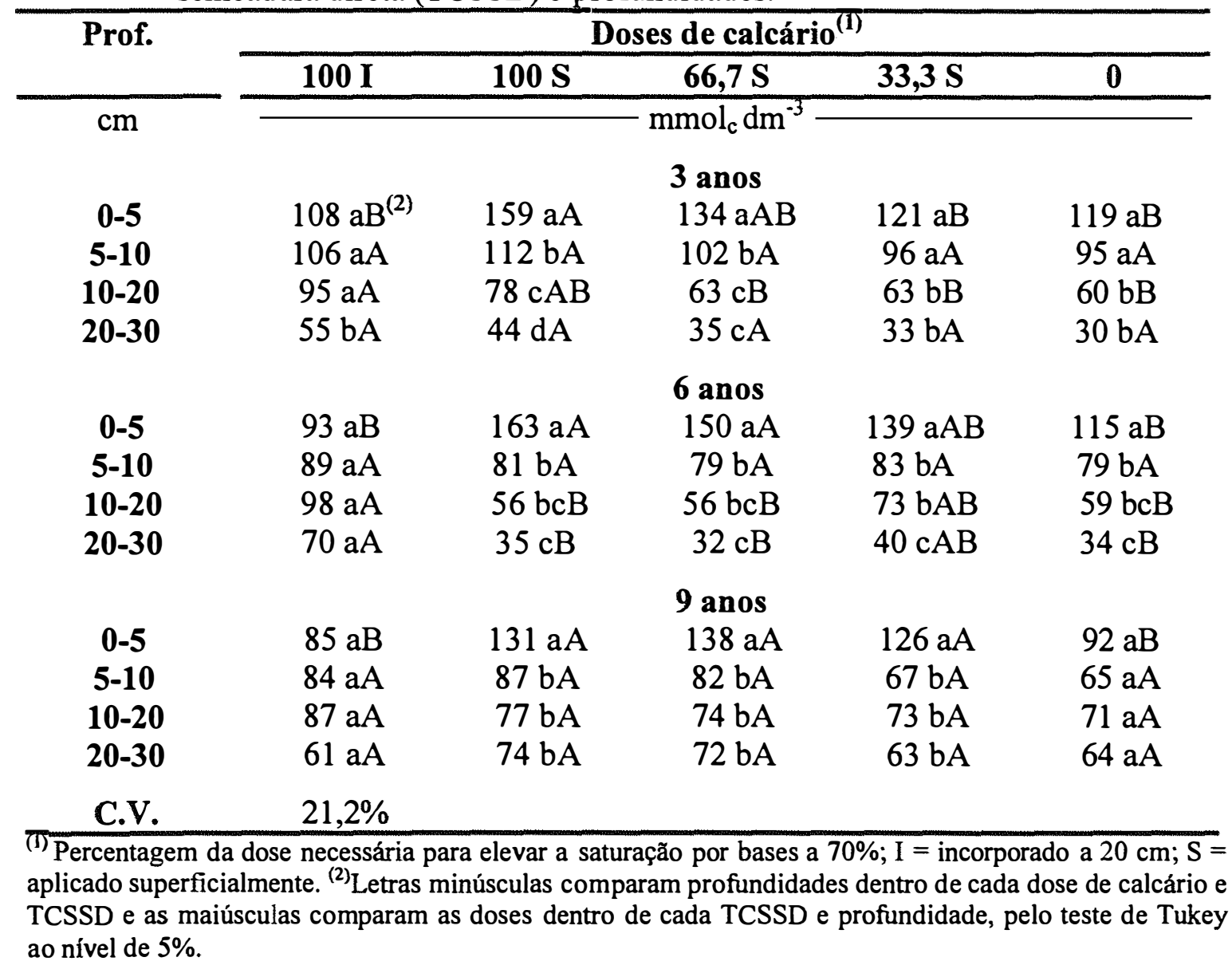

No solo há 6 anos de SSD as duas camadas inferiores apresentaram maiores valores de soma de bases quando o corretivo foi incorporado. Abaixo da camada de 0-5 
cm, a aplicação superficial de quaisquer das doses de corretivo não modificaram os valores originais de soma de bases no solo.

A aplicação do corretivo de forma incorporada resultou valores mais uniformes de soma de bases no perfil do solo. No solo com maior TCSSD, essa uniformidade ocorreu também onde o corretivo não foi incorporado. $\mathrm{O}$ aumento do TCSSD deve ter favorecido a distribuição do $\mathrm{Ca}$ e $\mathrm{Mg}$ no perfil, e consequentemente aumentou os valores de soma de bases nas camadas inferiores. Este fato pode ocorrer em função da movimentação física do calcário no solo e/ou química das bases, por meio de substâncias orgânicas (Miyazawa et al., 1996; Oliveira \& Pavan, 1996; Caires et al., 1999).

\subsubsection{Saturação por Bases}

No local com menor TCSSD os valores de saturação por bases das camadas superficiais não variaram com as doses de calcário (Tabela 15), mas nas inferiores, a incorporação resultou maior valor, mas geralmente não diferiu das maiores doses aplicadas na superfície. No solo com 6 anos de cultivo, os valores na camada de $0-5 \mathrm{~cm}$ diminuiu quando o calcário foi incorporado, e a aplicação na superfície não alterou esta característica. Por sua vez, no solo com 9 anos sob SSD, as maiores doses na superfície resultou os maiores valores de soma de bases nesta camada. Sá (1995c) também observou maiores valores de saturação por bases nas camadas superficiais de solos que receberam aplicação superficial de calcário do que em locais onde o corretivo foi incorporado.

Como demonstrado para $\mathrm{Ca}, \mathrm{Mg}$ e soma de bases (Tabelas 12, 13 e 14), a incorporação do corretivo também resultou valores de saturação por bases mais uniformes entre as camadas do solo (Tabela 15), e no solo com maior TCSSD houve melhor distribuição no perfil dos valores de saturação por bases em todos os tratamentos. 
Tabela 15. Valores de saturação por bases do Latosssolo Vermelho Escuro em função de doses de calcário, para diferentes tempos de cultivo sob sistema de semeadura direta (TCSSD) e profundidades.

\begin{tabular}{|c|c|c|c|c|c|}
\hline \multirow[t]{2}{*}{ Prof. } & \multicolumn{5}{|c|}{ Doses de calcário $^{(\mathrm{I})}$} \\
\hline & $100 \mathrm{I}$ & $100 \mathrm{~S}$ & $66,7 \mathrm{~S}$ & $33,3 \mathrm{~S}$ & $\mathbf{0}$ \\
\hline $\mathrm{cm}$ & & & $-\%$ & & \\
\hline $\begin{array}{c}0-5 \\
5-10 \\
10-20 \\
20-30\end{array}$ & $\begin{array}{l}75 \mathrm{aA}^{(2)} \\
70 \mathrm{aA} \\
69 \mathrm{aA} \\
45 \mathrm{bA}\end{array}$ & $\begin{array}{l}84 \mathrm{aA} \\
75 \mathrm{aA} \\
62 \mathrm{bAB} \\
40 \mathrm{cAB}\end{array}$ & $\begin{array}{l}3 \text { anos } \\
81 \mathrm{aA} \\
73 \mathrm{aA} \\
53 \mathrm{bBC} \\
37 \mathrm{cAB}\end{array}$ & $\begin{array}{l}79 \mathrm{aA} \\
70 \mathrm{bA} \\
48 \mathrm{cC} \\
28 \mathrm{~dB}\end{array}$ & $\begin{array}{l}78 \mathrm{aA} \\
70 \mathrm{bA} \\
50 \mathrm{cBC} \\
27 \mathrm{~dB}\end{array}$ \\
\hline $\begin{array}{c}0-5 \\
5-10 \\
10-20 \\
20-30\end{array}$ & $\begin{array}{l}57 \mathrm{abB} \\
61 \mathrm{aA} \\
59 \mathrm{abA} \\
47 \mathrm{bA}\end{array}$ & $\begin{array}{l}79 \mathrm{aA} \\
42 \mathrm{bB} \\
35 \mathrm{bcB} \\
24 \mathrm{cB}\end{array}$ & $\begin{array}{l}6 \text { anos } \\
78 \mathrm{aA} \\
49 \mathrm{bAB} \\
36 \mathrm{cB} \\
23 \mathrm{~dB}\end{array}$ & $\begin{array}{l}74 \mathrm{aA} \\
53 \mathrm{bAB} \\
46 \mathrm{bB} \\
29 \mathrm{cB}\end{array}$ & $\begin{array}{l}73 \mathrm{aA} \\
50 \mathrm{bAB} \\
38 \mathrm{bcB} \\
24 \mathrm{cB}\end{array}$ \\
\hline $\begin{array}{c}0-5 \\
5-10 \\
10-20 \\
20-30\end{array}$ & $\begin{array}{l}63 \mathrm{aB} \\
61 \mathrm{aA} \\
65 \mathrm{aA} \\
53 \mathrm{aA}\end{array}$ & $\begin{array}{l}77 \mathrm{aA} \\
61 \mathrm{bA} \\
59 \mathrm{bA} \\
59 \mathrm{bA}\end{array}$ & $\begin{array}{l}9 \text { anos } \\
78 \mathrm{aA} \\
58 \mathrm{bA} \\
55 \mathrm{bA} \\
55 \mathrm{bA}\end{array}$ & $\begin{array}{c}75 \mathrm{aAB} \\
58 \mathrm{bA} \\
54 \mathrm{bA} \\
52 \mathrm{bA}\end{array}$ & $\begin{array}{l}64 \mathrm{aB} \\
49 \mathrm{bB} \\
53 \mathrm{abA} \\
53 \mathrm{abA}\end{array}$ \\
\hline $\begin{array}{l}\text { C.V. } \\
\text { (1) Percentage } \\
\text { aplicado sup } \\
\text { TCSSD e as } \\
\text { ao nivel de } 5\end{array}$ & $\frac{13,0 \%}{\text { necessári }}$ & - & & . & 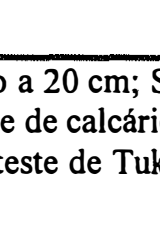 \\
\hline
\end{tabular}

\subsubsection{Micronutrientes}

Para os teores de B no solo, houve interação significativa somente entre doses de calcário e TCSSD, e nos solos com menores TCSSD, os teores não variaram com as doses de corretivo (Tabela 16). Por outro lado, no local com maior TCSSD, a incorporação da dose integral resultou menor teor $\left(0,14 \mathrm{mg} \mathrm{dm}^{-3}\right)$ do que quando $2 / 3$ desta foram aplicados à superfície $\left(0,23 \mathrm{mg} \mathrm{dm}^{-3}\right)$. Contudo, esperava-se efeito das doses nos teores de $\mathrm{B}$, uma vez que há muito se sabe, que o aumento do $\mathrm{pH}$ pode diminuir a disponibilidade deste elemento (Malavolta, 1980). 
Tabela 16. Teores de B do Latosssolo Vermelho Escuro em função de doses de calcário, para diferentes tempos de cultivo sob sistema de semeadura direta (TCSSD) e profundidades.

\begin{tabular}{|c|c|c|c|c|c|c|}
\hline \multirow[t]{2}{*}{ Prof. } & \multicolumn{6}{|c|}{ Doses de calcário $^{(1)}$} \\
\hline & $100 \mathrm{I}$ & $100 \mathrm{~S}$ & $66,7 \mathrm{~S}$ & $33,3 \mathrm{~S}$ & $\mathbf{0}$ & Médias \\
\hline \multirow[t]{2}{*}{$\mathrm{cm}$} & \multicolumn{6}{|c|}{$\mathrm{mg} \mathrm{dm}^{-3}$} \\
\hline & \multicolumn{6}{|c|}{3 anos } \\
\hline $0-5$ & 0,19 & 0,20 & 0,21 & 0,19 & 0,20 & 0,20 \\
\hline $5-10$ & 0,20 & 0,17 & 0,17 & 0,16 & 0,19 & 0,18 \\
\hline $10-20$ & 0,20 & 0,18 & 0,19 & 0,18 & 0,18 & 0,23 \\
\hline 20-30 & 0,21 & 0,19 & 0,17 & 0,23 & 0,23 & 0,21 \\
\hline \multirow[t]{2}{*}{ Médias } & $0,20 \mathrm{~A}^{(2)}$ & $0,19 \mathrm{~A}$ & $0,19 \mathrm{~A}$ & $0,19 \mathrm{~A}$ & $0,20 \mathrm{~A}$ & \\
\hline & \multicolumn{6}{|c|}{6 anos } \\
\hline $0-5$ & 0,24 & 0,30 & 0,29 & 0,31 & 0,38 & 0,30 \\
\hline $5-10$ & 0,24 & 0,33 & 0,28 & 0,29 & 0,33 & 0,29 \\
\hline $10-20$ & 0,27 & 0,31 & 0,28 & 0,27 & 0,31 & 0,29 \\
\hline 20-30 & 0,35 & 0,32 & 0,29 & 0,26 & 0,31 & 0,31 \\
\hline \multirow[t]{2}{*}{ Médias } & $0,28 \mathrm{~A}$ & $0,32 \mathrm{~A}$ & $0,29 \mathrm{~A}$ & $0,29 \mathrm{~A}$ & $0,33 \mathrm{~A}$ & \\
\hline & \multicolumn{6}{|c|}{9 anos } \\
\hline $0-5$ & 0,15 & 0,18 & 0,23 & 0,20 & 0,23 & 0,20 \\
\hline $5-10$ & 0,14 & 0,21 & 0,23 & 0,18 & 0,19 & 0,19 \\
\hline $10-20$ & 0,13 & 0,19 & 0,19 & 0,19 & 0,17 & 0,17 \\
\hline 20-30 & 0,14 & 0,18 & 0,26 & 0,15 & 0,20 & 0,19 \\
\hline Médias & $0,14 \mathrm{~B}$ & $0,19 \mathrm{AB}$ & $0,23 \mathrm{~A}$ & $0,18 \mathrm{AB}$ & $0,20 \mathrm{AB}$ & \\
\hline C.V. & $27,3 \%$ & & & & & \\
\hline
\end{tabular}

(T) Percentagem da dose necessária para elevar a saturação por bases a $70 \%$; I = incorporado a $20 \mathrm{~cm} ; \mathrm{S}=$ aplicado superficialmente. ${ }^{(2)}$ Letras maiúsculas comparam doses dentro de cada TCSSD, pelo teste de Tukey ao nivel de $5 \%$.

Houve algumas correlações negativas entre os teores de $\mathrm{B}$ e o $\mathrm{pH}$ do solo (Tabelas 17 e 18), apesar de os teores de B não terem sido influenciados pela calagem. Em estudo realizado por Brasil Sobrinho (1965) em amostras de solos do Estado de São Paulo, também foram observadas correlações inversas entre os teores de $\mathrm{B}$ e $\mathrm{opH}$, embora tenham sido baixas para alguns solos e/ou não significativas para outros. Por sua vez, Horowitz \& Dantas (1973) não observaram correlações entre os teores de B e o pH de solos do litoral de Pernambuco. 
Tabela 17. Coeficientes de correlação linear (r) entre teores de micronutrientes no solo e $\mathrm{pH}$ nos tratamentos sem incorporação do corretivo, em diferentes épocas e profundidades de coletas.

\begin{tabular}{|c|c|c|c|c|c|}
\hline Prof. & B & $\mathrm{Cu}$ & $\mathrm{Fe}$ & Mn & $\mathbf{Z n}$ \\
\hline $\mathrm{cm}$ & \multicolumn{5}{|c|}{ Amostragem $1^{(1)}$} \\
\hline $0-5$ & $-0,20 \mathrm{~ns}$ & $-0,10 \mathrm{~ns}$ & $-0,50 * *$ & $-0,10 \mathrm{~ns}$ & $0,10 \mathrm{~ns}$ \\
\hline $5-10$ & $-0,60 * *$ & $0,00 \mathrm{~ns}$ & $-0,80 * *$ & $-0,10 \mathrm{~ns}$ & $0,24 \mathrm{~ns}$ \\
\hline $10-20$ & $-0,60 * *$ & $0,17 \mathrm{~ns}$ & $-0,70^{* *}$ & $-0,40 * *$ & $0,00 \mathrm{~ns}$ \\
\hline \multirow[t]{2}{*}{$20-30$} & $-0,70^{* *}$ & $0,47 * *$ & $-0,70 * *$ & $-0,30 *$ & $0,22 \mathrm{~ns}$ \\
\hline & \multicolumn{5}{|c|}{ Amostragem 2} \\
\hline $0-5$ & $-0,20 \mathrm{~ns}$ & $0,08 \mathrm{~ns}$ & $-0,60 * *$ & $0,26 \mathrm{~ns}$ & $0,64 * *$ \\
\hline $5-10$ & $-0,40 * *$ & $0,12 \mathrm{~ns}$ & $-0,50 * *$ & $0,36 *$ & $0,44 * *$ \\
\hline $10-20$ & $-0,40 * *$ & $0,26 \mathrm{~ns}$ & $-0,60 * *$ & $0,11 \mathrm{~ns}$ & $0,05 \mathrm{~ns}$ \\
\hline $20-30$ & $-0,20 \mathrm{~ns}$ & $0,58 * *$ & $-0,40 * *$ & $0,44 * *$ & $0,08 \mathrm{~ns}$ \\
\hline
\end{tabular}

Encontraram-se correlações positivas e significativas entre os teores de B e os de matéria orgânica, sendo que o maior coeficiente de correlação foi de 0,84 (Tabelas 19 e 20). De forma semelhante, Brasil Sobrinho (1965) observaram correlações positivas entre os teores de B e os de matéria orgânica em solos do Estado de São Paulo. Horowitz $\&$ Dantas (1973) encontraram resultados similares utilizando amostras de horizontes superficiais de solos do litoral de Pernambuco.

Tabela 18. Coeficientes de correlação linear (r) entre teores de micronutrientes no solo e $\mathrm{pH}$ no tratamento com incorporação do corretivo, em diferentes épocas e profundidades de coletas.

\begin{tabular}{|c|c|c|c|c|c|}
\hline Prof. & B & $\mathbf{C u}$ & $\mathbf{F e}$ & Mn & $\mathbf{Z n}$ \\
\hline $\mathrm{cm}$ & \multicolumn{5}{|c|}{ Amostragem $1^{(i)}$} \\
\hline $0-5$ & $-0,60 *$ & $0,32 \mathrm{~ns}$ & $-0,80 * *$ & $0,00 \mathrm{~ns}$ & $0,52 \mathrm{~ns}$ \\
\hline $5-10$ & $-0,52 \mathrm{~ns}$ & $-0,16 \mathrm{~ns}$ & $-0,52 \mathrm{~ns}$ & $0,00 \mathrm{~ns}$ & $0,10 \mathrm{~ns}$ \\
\hline $10-20$ & $-0,60 *$ & $0,13 \mathrm{~ns}$ & $-0,81 * *$ & $-0,25 \mathrm{~ns}$ & $0,41 \mathrm{~ns}$ \\
\hline \multirow[t]{2}{*}{$20-30$} & $-0,53 \mathrm{~ns}$ & $0,29 \mathrm{~ns}$ & $-0,58 * *$ & $-0,23 \mathrm{~ns}$ & $0,44 \mathrm{~ns}$ \\
\hline & \multicolumn{5}{|c|}{ Amostragem 2} \\
\hline $0-5$ & $0,31 \mathrm{~ns}$ & $-0,20 \mathrm{~ns}$ & $-0,70^{*}$ & $0,10 \mathrm{~ns}$ & $0,46 \mathrm{~ns}$ \\
\hline $5-10$ & $-0,10 \mathrm{~ns}$ & $-0,14 \mathrm{~ns}$ & $-0,59 \mathrm{~ns}$ & $-0,12 \mathrm{~ns}$ & $-0,16 \mathrm{~ns}$ \\
\hline $10-20$ & $0,18 \mathrm{~ns}$ & $0,07 \mathrm{~ns}$ & $-0,62 *$ & $0,00 \mathrm{~ns}$ & $0,39 \mathrm{~ns}$ \\
\hline $20-30$ & $0,20 \mathrm{~ns}$ & $0,36 \mathrm{~ns}$ & $-0,26 \mathrm{~ns}$ & $-0,45 \mathrm{~ns}$ & $-0,11 \mathrm{~ns}$ \\
\hline
\end{tabular}


Tabela 19. Coeficientes de correlação linear (r) entre teores de micronutrientes no solo e matéria orgânica no tratamento sem incorporação do corretivo, em diferentes épocas e profundidades de coletas.

\begin{tabular}{|c|c|c|c|c|c|}
\hline Prof. & B & $\mathbf{C u}$ & $\mathrm{Fe}$ & Mn & $\mathbf{Z n}$ \\
\hline $\mathrm{cm}$ & \multicolumn{5}{|c|}{ Amostragem $1^{(1)}$} \\
\hline $0-5$ & $0,56 * *$ & $-0,10 \mathrm{~ns}$ & $0,55 * *$ & $0,44 * *$ & $-0,30 *$ \\
\hline $5-10$ & $0,31 *$ & $0,00 \mathrm{~ns}$ & $0,68 * *$ & $0,51 * *$ & $-0,10 \mathrm{~ns}$ \\
\hline $10-20$ & $0,62 * *$ & $-0,20 \mathrm{~ns}$ & $0,67 * *$ & $0,69 * *$ & $0,00 \mathrm{~ns}$ \\
\hline \multirow[t]{2}{*}{$20-30$} & $0,37 * *$ & $-0,20 \mathrm{~ns}$ & $0,53 * *$ & $0,46 * *$ & $-0,20 \mathrm{~ns}$ \\
\hline & \multicolumn{5}{|c|}{ Amostragem 2} \\
\hline $0-5$ & $-0,10 \mathrm{~ns}$ & $0,06 \mathrm{~ns}$ & $-0,50 * *$ & $0,12 \mathrm{~ns}$ & $0,25 \mathrm{~ns}$ \\
\hline $5-10$ & $-0,30 *$ & $-0,10 \mathrm{~ns}$ & $-0,30 *$ & $0,30^{*}$ & $0,14 \mathrm{~ns}$ \\
\hline $10-20$ & $0,06 \mathrm{~ns}$ & $-0,30 *$ & $-0,10 \mathrm{~ns}$ & $0,31 *$ & $0,29 *$ \\
\hline $20-30$ & $-0,20 \mathrm{~ns}$ & $-0,20 \mathrm{~ns}$ & $0,07 \mathrm{~ns}$ & $0,09 \mathrm{~ns}$ & $0,17 \mathrm{~ns}$ \\
\hline
\end{tabular}

Tabela 20. Coeficientes de correlação linear (r) entre teores de micronutrientes no solo e matéria orgânica nos tratamentos com incorporação do corretivo, em diferentes épocas e profundidades de coletas.

\begin{tabular}{|c|c|c|c|c|c|}
\hline Prof. & B & $\mathbf{C u}$ & $\mathbf{F e}$ & Mn & $\mathbf{Z n}$ \\
\hline $\mathrm{cm}$ & \multicolumn{5}{|c|}{ Amostragem $1^{(1)}$} \\
\hline $0-5$ & $0,61 *$ & $-0,30 \mathrm{~ns}$ & $-0,33 \mathrm{~ns}$ & $0,64 *$ & $-0,20 \mathrm{~ns}$ \\
\hline $5-10$ & $0,56 \mathrm{~ns}$ & $-0,38 \mathrm{~ns}$ & $0,32 \mathrm{~ns}$ & $0,50 \mathrm{~ns}$ & $-0,03 \mathrm{~ns}$ \\
\hline $10-20$ & $0,84 * *$ & $-0,40 \mathrm{~ns}$ & $0,87 * *$ & $0,70^{*}$ & $-0,09 \mathrm{~ns}$ \\
\hline \multirow[t]{2}{*}{ 20-30 } & $0,44 \mathrm{~ns}$ & $-0,23 \mathrm{~ns}$ & $0,79 * *$ & $0,67^{*}$ & $-0,18 \mathrm{~ns}$ \\
\hline & \multicolumn{5}{|c|}{ Amostragem 2} \\
\hline $0-5$ & $0,32 \mathrm{~ns}$ & $-0,50 \mathrm{~ns}$ & $-0,60^{*}$ & $0,05 \mathrm{~ns}$ & $0,03 \mathrm{~ns}$ \\
\hline $5-10$ & $0,32 \mathrm{~ns}$ & $-0,31 \mathrm{~ns}$ & $-0,46 \mathrm{~ns}$ & $0,19 \mathrm{~ns}$ & $0,63 *$ \\
\hline $10-20$ & $0,22 \mathrm{~ns}$ & $-0,09 \mathrm{~ns}$ & $-0,50 \mathrm{~ns}$ & $0,50 \mathrm{~ns}$ & $0,68 *$ \\
\hline $20-30$ & $0,02 \mathrm{~ns}$ & $-0,31 \mathrm{~ns}$ & $-0,01 \mathrm{~ns}$ & $0,10 \mathrm{~ns}$ & $0,45 \mathrm{~ns}$ \\
\hline
\end{tabular}

Como a interação tripla entre TCSSD, doses de calcário e profundidades não foi significativa para os teores de $\mathrm{Cu}$ do solo, estudou-se a interação dupla entre TCSSD e profundidades, e entre TCSSD e doses. O efeito da calagem nesses teores ocorreu somente no local sob 3 anos de cultivo (Tabela 21). Neste TCSSD, o calcário diminuiu o teor de $\mathrm{Cu}$, mas apenas quando aplicado à superfície nas duas maiores doses. Shuman \& 
McCracken (1999b) também não observaram efeito da calagem superficial nos teores de $\mathrm{Cu}$ em solos submetidos há 9 anos de SSD. Em outro solo, cultivado sob SSC, os teores de $\mathrm{Cu}$ diminuíram somente quando foram empregadas altas doses de calcário (Prevedello et al., 1995).

Tabela 21. Teores de $\mathrm{Cu}$ do Latosssolo Vermelho Escuro em função de doses de calcário, para diferentes tempos de cultivo sob sistema de semeadura direta (TCSSD) e profundidades.

\begin{tabular}{|c|c|c|c|c|c|c|}
\hline \multirow[t]{2}{*}{ Prof. } & \multicolumn{6}{|c|}{ Doses de calcário $^{(1)}$} \\
\hline & $100 \mathrm{I}$ & $100 \mathrm{~S}$ & $66,7 \mathrm{~S}$ & $33,3 \mathrm{~S}$ & 0 & Médias \\
\hline \multirow[t]{2}{*}{$\mathrm{cm}$} & \multicolumn{6}{|c|}{$\mathrm{mg} \mathrm{dm}^{-3}$} \\
\hline & \multicolumn{6}{|c|}{3 anos } \\
\hline $0-5$ & 2,4 & 2,2 & 1,9 & 2,1 & 2,9 & $2,3 b^{(2)}$ \\
\hline $5-10$ & 2,4 & 2,1 & 2,0 & 2,7 & 3,8 & $2,6 \mathrm{a}$ \\
\hline $10-20$ & 2,7 & 2,5 & 2,6 & 2,7 & 2,9 & $2,7 \mathrm{a}$ \\
\hline 20-30 & 2,8 & 2,7 & 2,7 & 2,6 & 2,9 & $2,7 \mathrm{a}$ \\
\hline \multirow[t]{2}{*}{ Médias } & $2,6 \mathrm{AB}^{(3)}$ & $2,4 \mathrm{~B}$ & $2,3 \mathrm{~B}$ & $2,5 \mathrm{AB}$ & $3,1 \mathrm{~A}$ & \\
\hline & \multicolumn{6}{|c|}{6 anos } \\
\hline $0-5$ & 1,7 & 1,3 & 1,2 & 1,3 & 1,5 & $1,4 \mathrm{~b}$ \\
\hline $5-10$ & 1,7 & 1,6 & 1,8 & 1,7 & 1,7 & $1,7 \mathrm{ab}$ \\
\hline $10-20$ & 1,9 & 1,8 & 1,9 & 1,8 & 1,9 & $1,8 \mathrm{a}$ \\
\hline $20-30$ & 1,8 & 1,7 & 1,6 & 1,6 & 1,6 & $1,7 \mathrm{ab}$ \\
\hline \multirow[t]{2}{*}{ Médias } & $1,7 \mathrm{~A}$ & $1,6 \mathrm{~A}$ & $1,6 \mathrm{~A}$ & $1,6 \mathrm{~A}$ & $1,7 \mathrm{~A}$ & \\
\hline & \multicolumn{6}{|c|}{9 anos } \\
\hline $0-5$ & 3,9 & 3,0 & 3,0 & 2,9 & 3,1 & $3,2 \mathrm{~b}$ \\
\hline $5-10$ & 4,1 & 3,3 & 4,5 & 4,8 & 4,2 & $4,3 \mathrm{a}$ \\
\hline $10-20$ & 4,1 & 3,1 & 3,9 & 3,9 & 4,1 & $4,0 \mathrm{a}$ \\
\hline 20-30 & 4,0 & 4,3 & 3,0 & 4,0 & 4,1 & $4,0 \mathrm{a}$ \\
\hline Médias & $4,0 \mathrm{~A}$ & $3,7 \mathrm{~A}$ & $3,8 \mathrm{~A}$ & $3,9 \mathrm{~A}$ & 3,9 A & \\
\hline C.V. & $22,0 \%$ & & & & & \\
\hline
\end{tabular}

Em todos os TCSSD, de modo geral, a camada superficial apresentou os menores teores de $\mathrm{Cu}$. Estes resultados concordam com os apresentados por Motta \& Prevedello (1995) para solos do Paraná, e com os obtidos por Franzluebbers \& Hons 
(1996) para solos norte americanos. O menor teor de $\mathrm{Cu}$ nesta camada foi atribuído ao maior teor de matéria orgânica na superfície, resultando em maior grau de complexação deste elemento. Estudos anteriores de Basta \& Tabatabai (1992) com adsorção de metais já haviam demonstrado a forte complexação do $\mathrm{Cu}$ pela matéria orgânica. Por outro lado, existem trabalhos na literatura em que se observaram maiores teores de $\mathrm{Cu}$ na camada superficial do que nas inferiores (Shuman \& Hargrove, 1985; Follett \& Peterson, 1988; Castro et al. 1992).

Os coeficientes de correlação entre $\mathrm{pH}$ e teores de $\mathrm{Cu}$ foram positivos, porém baixos e/ou não significativos (Tabelas 17 e 18). Esses resultados foram semelhantes aos observados por Prevedello et al. (1995), em solos cultivados sob SSC, mas discordam dos obtidos por Camargo et al. (1982), cujas correlações foram negativas. Os coeficientes de correlação entre os teores de $\mathrm{Cu}$ e os teores de matéria orgânica também foram baixos e/ou não significativos (Tabelas 19 e 20). Castro et al. (1992) também não observaram correlações entre os teores de matéria orgânica e os teores de $\mathrm{Cu}$ de Latossolos paulistas, após 3 anos de cultivo em SSD.

Os teores de Fe do solo com menor TCSSD não variaram com as doses de calcário (Tabela 22). Por sua vez, no solo com 6 anos de cultivo, a aplicação de 2/3 da dose recomendada na superfície resultou menor teor $\left(38,4 \mathrm{mg} \mathrm{dm}^{-3}\right)$ que a incorporação da dose integral $\left(46,6 \mathrm{mg} \mathrm{dm}^{-3}\right)$, e na camada de $5-10 \mathrm{~cm}$, este efeito foi inverso. No solo com 9 anos de cultivo, quaisquer das doses aplicadas na superfície diminuíram os teores de $\mathrm{Fe}$ na camada de 0-5 cm. Este efeito era esperado, uma vez que o aumento do $\mathrm{pH}$ diminui a disponibilidade de Fe (Malavolta, 1980).

Os teores de Fe variaram pouco com a profundidade, sendo que as maiores diferenças ocorreram no solo com 6 anos de cultivo. Neste TCSSD, em geral, os menores teores ocorreram nas camadas de 0-5 e 20-30 cm nos tratamentos sem revolvimento do solo. Menor teor de Fe na camada superficial pode ser devido ao maior pH desta camada, o que reduz a disponibilidade de micronutrientes (Motta \& Prevedello, 1995). 
Tabela 22. Teores de $\mathrm{Fe}$ do Latosssolo Vermelho Escuro em função de doses de calcário, para diferentes tempos de cultivo sob sistema de semeadura direta (TCSSD) e profundidades.

\begin{tabular}{|c|c|c|c|c|c|}
\hline \multirow[t]{2}{*}{ Prof. } & \multicolumn{5}{|c|}{ Doses de calcário $^{(1)}$} \\
\hline & $100 I$ & $100 \mathrm{~S}$ & $66,7 \mathrm{~S}$ & $33,3 \mathrm{~S}$ & 0 \\
\hline $\mathrm{cm}$ & & & $\mathrm{mg} \mathrm{dm} \mathrm{m}^{-3}$ & & \\
\hline $\begin{array}{c}0-5 \\
5-10 \\
10-20 \\
20-30\end{array}$ & $\begin{array}{l}23,8 \mathrm{abA}^{(2)} \\
23,0 \mathrm{bA} \\
26,6 \mathrm{bA} \\
30,4 \mathrm{aA}\end{array}$ & $\begin{array}{l}23,6 \mathrm{aA} \\
24,0 \mathrm{aA} \\
27,6 \mathrm{aA} \\
28,0 \mathrm{aA}\end{array}$ & $\begin{array}{c}3 \text { anos } \\
20,7 \mathrm{aA} . \\
26,4 \mathrm{aA} \\
27,0 \mathrm{aA} \\
27,1 \mathrm{aA}\end{array}$ & $\begin{array}{l}20,8 \mathrm{bA} \\
25,3 \mathrm{abA} \\
29,1 \mathrm{aA} \\
27,6 \mathrm{abA}\end{array}$ & $\begin{array}{l}24,9 \text { aA } \\
27,2 \text { aA } \\
30,3 \text { aA } \\
30,8 \text { aA }\end{array}$ \\
\hline $\begin{array}{c}0-5 \\
5-10 \\
10-20 \\
20-30\end{array}$ & $\begin{array}{l}46,6 \mathrm{aA} \\
47,7 \mathrm{aB} \\
48,5 \mathrm{aA} \\
45,3 \mathrm{aA}\end{array}$ & $\begin{array}{c}41,0 \mathrm{bAB} \\
52,3 \mathrm{aAB} \\
54,3 \mathrm{aA} \\
47,4 \mathrm{abA}\end{array}$ & $\begin{array}{c}6 \text { anos } \\
38,4 \text { bB } \\
57,1 \text { aA } \\
54,8 \text { aA } \\
44,2 \text { bA }\end{array}$ & $\begin{array}{c}40,6 \mathrm{bAB} \\
53,3 \mathrm{aAB} \\
53,6 \mathrm{aA} \\
41,9 \mathrm{bA}\end{array}$ & $\begin{array}{l}40,0 \mathrm{cAB} \\
53,7 \mathrm{abAB} \\
55,2 \mathrm{aA} \\
45,0 \mathrm{bcA}\end{array}$ \\
\hline $\begin{array}{c}0-5 \\
5-10 \\
10-20 \\
20-30\end{array}$ & $\begin{array}{l}37,0 \mathrm{aAB} \\
38,0 \mathrm{aA} \\
34,5 \mathrm{aA} \\
34,8 \mathrm{aA}\end{array}$ & $\begin{array}{l}31,8 \mathrm{aB} \\
36,8 \mathrm{aA} \\
31,0 \mathrm{aA} \\
30,3 \mathrm{aA}\end{array}$ & $\begin{array}{l}9 \text { anos } \\
30,9 \mathrm{bB} \\
40,8 \mathrm{aA} \\
34,2 \mathrm{abA} \\
29,5 \mathrm{bA}\end{array}$ & $\begin{array}{l}31,4 \mathrm{aB} \\
37,5 \mathrm{aA} \\
36,0 \mathrm{aA} \\
31,4 \mathrm{aA}\end{array}$ & $\begin{array}{l}43,1 \mathrm{aA} \\
43,0 \mathrm{aA} \\
36,6 \mathrm{abA} \\
35,0 \mathrm{bA}\end{array}$ \\
\hline C.V. & $11,0 \%$ & & & & \\
\hline
\end{tabular}

Encontraram-se correlações significativas negativas entre os valores de $\mathrm{pH} \mathrm{e}$ teores de $\mathrm{Fe}$ (Tabelas 17 e 18), sendo que alguns coeficientes alcançaram -0,81. Em solos sob SSC, Camargo et al. (1982) também observaram que estas correlações foram inversas. As correlações com a matéria orgânica em geral foram positivas, tendo os coeficientes alcançado 0,87 (Tabelas 19 e 20). De forma semelhante, Castro et al. (1992) observaram correlações positivas entre os teores de matéria orgânica e os teores de Fe de um Latossolo Vermelho-Amarelo com 3 anos de cultivo sob SSD.

Para o Mn, o efeito das doses de calcário ocorreu geralmente nas camadas superficiais (Tabela 23). No solo com menor TCSSD, a incorporação da dose integral resultou menor teor de $\mathrm{Mn}$ na camada de $0-5 \mathrm{~cm}$ do que quando esta dose foi aplicada 
superficialmente. No local com 6 anos de cultivo, o menor teor de $\mathrm{Mn}$ até $10 \mathrm{~cm}$ de profundidade ocorreu quando o corretivo foi incorporado, e no local com maior TCSSD, este efeito da incorporação ocorreu apenas na camada superficial. Por outro lado, em todos os TCSSD a aplicação superficial do corretivo não reduziu os teores de Mn. Shuman \& McCracken (1999b) também não observaram efeito da calagem superficial na disponibilidade de Mn em solos sob SSD.

Tabela 23. Teores de Mn do Latosssolo Vermelho Escuro em função de doses de calcário, para diferentes tempos de cultivo sob sistema de semeadura direta (TCSSD) e profundidades.

\begin{tabular}{|c|c|c|c|c|c|}
\hline \multirow[t]{2}{*}{ Prof. } & \multicolumn{5}{|c|}{ Doses de calcário $^{(1)}$} \\
\hline & $100 \mathrm{I}$ & $100 \mathrm{~S}$ & $66,7 \mathrm{~S}$ & $33,3 \mathrm{~S}$ & 0 \\
\hline $\mathrm{cm}$ & & & $\mathrm{mg} \mathrm{dm}{ }^{-3}$ & & \\
\hline $\begin{array}{c}0-5 \\
5-10 \\
10-20 \\
20-30\end{array}$ & $\begin{array}{l}4,6 \mathrm{aB}^{(2)} \\
3,7 \mathrm{abA} \\
2,9 \mathrm{bA} \\
1,6 \mathrm{bA}\end{array}$ & $\begin{array}{l}6,2 \mathrm{aA} \\
3,2 \mathrm{bA} \\
2,2 \mathrm{bcA} \\
1,1 \mathrm{cA}\end{array}$ & $\begin{array}{l}3 \text { anos } \\
4,8 \mathrm{aB} \\
4,1 \mathrm{aA} \\
2,0 \mathrm{bcA} \\
0,8 \mathrm{cA}\end{array}$ & $\begin{array}{l}4,9 \mathrm{aAB} \\
4,0 \mathrm{aA} \\
2,4 \mathrm{bA} \\
0,9 \mathrm{cA}\end{array}$ & $\begin{array}{l}5,6 \mathrm{aAB} \\
3,8 \mathrm{bA} \\
2,2 \mathrm{cA} \\
1,0 \mathrm{cA}\end{array}$ \\
\hline $\begin{array}{c}0-5 \\
5-10 \\
10-20 \\
20-30\end{array}$ & $\begin{array}{l}4,2 \mathrm{aB} \\
3,4 \mathrm{aB} \\
3,1 \mathrm{abA} \\
1,8 \mathrm{bA}\end{array}$ & $\begin{array}{l}6,8 \mathrm{aA} \\
4,1 \mathrm{bAB} \\
2,9 \mathrm{bcA} \\
1,4 \mathrm{cA}\end{array}$ & $\begin{array}{c}6 \text { anos } \\
5,7 \mathrm{aA} \\
4,4 \mathrm{aA} \\
2,9 \mathrm{bA} \\
1,2 \mathrm{cA}\end{array}$ & $\begin{array}{l}6,6 \mathrm{aA} \\
4,9 \mathrm{bA} \\
3,4 \mathrm{cA} \\
1,2 \mathrm{dA}\end{array}$ & $\begin{array}{l}6,5 \mathrm{aA} \\
4,3 \mathrm{bAB} \\
3,0 \mathrm{bA} \\
1,2 \mathrm{cA}\end{array}$ \\
\hline $\begin{array}{c}0-5 \\
5-10 \\
10-20 \\
20-30\end{array}$ & $\begin{array}{l}3,3 \mathrm{aB} \\
2,5 \mathrm{aA} \\
2,0 \mathrm{abA} \\
1,1 \mathrm{bA}\end{array}$ & $\begin{array}{l}4,3 \mathrm{aAB} \\
2,5 \mathrm{bA} \\
1,6 \mathrm{bA} \\
1,4 \mathrm{bA}\end{array}$ & $\begin{array}{l}9 \text { anos } \\
4,8 \mathrm{aA} \\
3,3 \mathrm{bA} \\
1,8 \mathrm{cA} \\
1,1 \mathrm{cA}\end{array}$ & $\begin{array}{l}4,5 \mathrm{aAB} \\
2,8 \mathrm{bA} \\
1,9 \mathrm{bcA} \\
1,3 \mathrm{cA}\end{array}$ & $\begin{array}{l}5,6 \mathrm{aA} \\
2,8 \mathrm{bA} \\
1,7 \mathrm{bcA} \\
1,3 \mathrm{cA}\end{array}$ \\
\hline C.V. & $25,8 \%$ & & & & \\
\hline
\end{tabular}

Os maiores teores de $\mathrm{Mn}$ foram encontrados nas camadas superficiais, embora estas tenham sido as camadas que apresentaram os maiores valores de $\mathrm{pH}$. Estes resultados concordam com os obtidos por outros autores, para o SSD (Shuman \& 
Hargrove, 1985; Follett \& Peterson, 1988; Castro et al., 1992; Edwards et., 1992), e discordam do que há muito tem sido relatado na literatura sobre o efeito do $\mathrm{pH}$ na disponibilidade de micronutrientes (Malavolta, 1980). Desta forma, os maiores teores de micronutrientes encontrados na superfície dos solos em SSD têm sido atribuídos mais aos altos teores de matéria orgânica presentes nessa camada (Castro et al., 1992; Edwards et al., 1992) do que aos valores de $\mathrm{pH}$.

As correlações entre os valores de $\mathrm{pH}$ e os teores de $\mathrm{Mn}$ da camada superficial do solo não foram significativas (Tabelas 17 e 18). Contudo, Camargo et al. (1982) encontraram correlações negativas entre os valores de $\mathrm{pH}$ e os teores de $\mathrm{Mn}$ de solos cultivados sob SSC. Por sua vez, correlações entre os teores de matéria orgânica e os teores de $\mathrm{Mn}$, incluindo todos os tratamentos sem revolvimento do solo, foram significativas (Tabela 19). Castro et al. (1992) também observaram correlações positivas entre os teores de matéria orgânica e os teores de $\mathrm{Mn}$ de Latossolos paulistas, e relataram que a matéria orgânica é um dos principais atributos responsáveis pela distribuição dos teores de Mn no perfil dos solos.

No caso do $\mathrm{Zn}$, o efeito mais pronunciado das doses de calcário ocorreu no solo com o menor TCSSD, cujos teores originais diminuíram até $20 \mathrm{~cm}$ de profundidade com a aplicação de quaisquer uma das doses na superfície (Tabela 24). Shuman \& McCracken (1999b) observaram maiores teores de $\mathrm{Zn}$ em solos sob SSD do que em solos sob SSC, apesar de os mesmos não terem sido afetados pelo aumento de $\mathrm{pH}$. Em trabalho de Prevedello et al. (1995), conduzido em solo sob SSC, somente as doses de calcário acima de $15 \mathrm{tha}^{-1}$ reduziram os teores de $\mathrm{Zn}$ no solo.

Os teores de $\mathrm{Zn}$ do solo com 6 anos sob SSD não variaram em profundidade, discordando de resultados obtidos por outros autores (Shuman \& Hargrove, 1985; Follett $\&$ Peterson, 1988; Castro et al., 1992; Edwards et., 1992). Por outro lado, os teores de $\mathrm{Zn}$ do solo com menor TCSSD quase sempre foram menores na camada inferior. 
Tabela 24. Teores de $\mathrm{Zn}$ do Latosssolo Vermelho Escuro em função de doses de calcário, para diferentes tempos de cultivo sob sistema de semeadura direta (TCSSD) e profundidades.

\begin{tabular}{|c|c|c|c|c|c|}
\hline \multirow[t]{2}{*}{ Prof. } & \multicolumn{5}{|c|}{ Doses de calcário $^{(1)}$} \\
\hline & $100 I$ & $100 \mathrm{~S}$ & $66,7 \mathrm{~S}$ & $33,3 \mathrm{~S}$ & $\mathbf{0}$ \\
\hline $\mathrm{cm}$ & & & $\mathrm{mg} \mathrm{dm}^{-3}$ & & \\
\hline $\begin{array}{c}0-5 \\
5-10 \\
10-20 \\
20-30\end{array}$ & $\begin{array}{l}4,7 \mathrm{aAB}^{(2)} \\
4,4 \mathrm{aB} \\
3,7 \mathrm{aA} \\
1,3 \mathrm{bA}\end{array}$ & $\begin{array}{l}2,5 \mathrm{aB} \\
1,8 \mathrm{aBC} \\
0,8 \mathrm{abB} \\
0,4 \mathrm{bA}\end{array}$ & $\begin{array}{l}3 \text { anos } \\
2,3 \mathrm{aB} \\
1,6 \mathrm{abC} \\
1,3 \mathrm{abB} \\
0,4 \mathrm{bA}\end{array}$ & $\begin{array}{l}2,0 \mathrm{aB} \\
2,3 \mathrm{aBC} \\
1,1 \mathrm{abB} \\
0,3 \mathrm{bA}\end{array}$ & $\begin{array}{c}9,8 \mathrm{aA} \\
10,4 \mathrm{aA} \\
4,1 \mathrm{bA} \\
1,0 \mathrm{cA}\end{array}$ \\
\hline $\begin{array}{c}0-5 \\
5-10 \\
10-20 \\
20-30\end{array}$ & $\begin{array}{l}1,5 \mathrm{aA} \\
1,0 \mathrm{aA} \\
1,4 \mathrm{aA} \\
0,6 \mathrm{aA}\end{array}$ & $\begin{array}{l}0,8 \mathrm{aA} \\
0,6 \mathrm{aA} \\
1,5 \mathrm{aA} \\
0,8 \mathrm{aA}\end{array}$ & $\begin{array}{l}6 \text { anos } \\
0,7 \mathrm{aA} \\
0,7 \mathrm{aA} \\
0,7 \mathrm{aA} \\
0,2 \mathrm{aA}\end{array}$ & $\begin{array}{l}0,8 \mathrm{aA} \\
0,6 \mathrm{aA} \\
0,9 \mathrm{aA} \\
0,3 \mathrm{aA}\end{array}$ & $\begin{array}{l}1,3 \mathrm{aA} \\
0,9 \mathrm{aA} \\
1,5 \mathrm{aA} \\
0,4 \mathrm{aA}\end{array}$ \\
\hline $\begin{array}{c}0-5 \\
5-10 \\
10-20 \\
20-30\end{array}$ & $\begin{array}{l}2,5 \mathrm{aA} \\
2,4 \mathrm{aB} \\
1,2 \mathrm{abAB} \\
0,5 \mathrm{bA}\end{array}$ & $\begin{array}{l}1,3 \mathrm{aA} \\
1,0 \mathrm{aB} \\
0,6 \mathrm{aB} \\
0,7 \mathrm{aA}\end{array}$ & $\begin{array}{l}9 \text { anos } \\
2,1 \mathrm{bA} \\
5,0 \mathrm{aA} \\
2,8 \mathrm{abA} \\
0,5 \mathrm{cA}\end{array}$ & $\begin{array}{l}2,1 \mathrm{abA} \\
1,7 \mathrm{abB} \\
2,5 \mathrm{aA} \\
0,5 \mathrm{bA}\end{array}$ & $\begin{array}{l}1,8 \mathrm{aA} \\
2,7 \mathrm{aB} \\
1,1 \mathrm{aAB} \\
0,5 \mathrm{aA}\end{array}$ \\
\hline $\begin{array}{l}\text { C.V. } \\
\text { Percenta } \\
\text { plicado s } \\
\text { ransforma } \\
\text { e cada d } \\
\text { rofundida }\end{array}$ & $\frac{34,0 \%}{\text { ose necessári }^{\text {Imente. (2) }}}$ & & & ses de & $\begin{array}{l}\text { a } 20 \mathrm{~cm} \text {; } \\
\text { idades de } \\
\text { ida TCSS }\end{array}$ \\
\hline
\end{tabular}

As correlações entre os teores de $\mathrm{Zn}$ e os valores de $\mathrm{pH}$ foram positivas, mas ocorreram apenas nas duas camadas superficiais dos locais sem revolvimento do solo e na segunda época de amostragem (Tabelas 17 e 18). Camargo et al. (1982), estudando 24 solos do Estado de São Paulo cultivados sob SSC, encontraram correlações negativas entre os teores de $\mathrm{Zn}$ e o valores de $\mathrm{pH}$ somente em $25 \%$ dos solos. Prevedello et al. (1995) observaram que estas correlações não foram significativas, a exemplo da maioria dos casos estudados no presente trabalho. Ocorreram algumas correlações diretas entre os teores de $\mathrm{Zn}$ no solo e os de matéria orgânica na camada superficial (Tabelas 19 e 20), como as observadas por Castro et al. (1992) e por Hamilton et al. (1993). 


\subsection{Nutrientes nas Plantas}

Houve interações significativas entre épocas de amostragens e TCSSD para todos os nutrientes nas folhas das plantas de soja (N, P, K, S, Ca, Mg, B, Cu, Fe, Mn e $\mathrm{Zn}$ ). Por outro lado, não houve interação entre épocas de amostragens e doses de calcário, como também efeito isolado de doses para $\mathrm{N}, \mathrm{P}, \mathrm{K}, \mathrm{S}, \mathrm{B}, \mathrm{Cu}, \mathrm{Fe}$ e $\mathrm{Zn}$. Contudo, ocorreu interação tripla entre TCSSD, épocas de amostragens e doses de calcário para $\mathrm{Ca}, \mathrm{Mg}$ e $\mathrm{Mn}$.

\subsubsection{Efeito das Épocas de Amostragens}

Em nenhuma das épocas de amostragens houve deficiência visual de nutrientes nas folhas de soja, apesar de alguns elementos estarem em níveis abaixo dos considerados adequados por Malavolta et al. (1997). Sá (1995c) também não observou sintomas de deficiências de $\mathrm{Mn}$ e de $\mathrm{Zn}$ para as culturas da soja e do milho, respectivamente, cultivadas em SSD por longo tempo. Por outro lado, no campo tem sido comum deficiências de Zn em plantas de milho (Motta \& Prevedello, 1995), e de Mn em plantas de soja (Pauletti, 1998), nos primeiros estágios de desenvolvimento destas culturas, o que eqüivale, para a soja, aproximadamente ao estágio vegetativo V4 (primeira época de coleta das amostras).

Para todos os TCSSD, os teores de $\mathrm{N}, \mathrm{Ca}, \mathrm{Mg}$ e S nas folhas diminuíram da primeira para a segunda amostragem, com exceção do $\mathrm{S}$ e $\mathrm{N}$ nas plantas cultivadas nos locais com 3 e 6 anos de cultivo, respectivamente, cujos teores não variaram entre as amostragens (Tabela 25). As concentrações foliares de $\mathrm{P}$ e $\mathrm{K}$, por sua vez, foram maiores na segunda amostragem, o que era esperado, pois no início do crescimento da soja, a taxa de acumulação de matéria seca e de absorção de nutrientes é reduzida. A partir de 30 a 60 dias da semeadura intensifica-se o desenvolvimento da cultura e a absorção de água e de nutrientes (Tanaka \& Mascarenhas, 1992). Contudo, existe uma 
tendência de as concentrações de nutrientes diminuírem após os 90 dias (Fauconnier \& Malavolta, 1999).

Tabela 25. Concentração de macronutrientes nas folhas de soja em função da época de amostragem, para diferentes tempos de cultivo sob sistema de semeadura direta (TCSSD).

\begin{tabular}{|c|c|c|c|c|c|c|}
\hline Amostragem $^{(I)}$ & $\mathbf{N}$ & $\mathbf{P}$ & $\bar{K}$ & $\mathbf{C a}$ & $\overline{M g}$ & $\mathbf{S}$ \\
\hline & \multicolumn{6}{|c|}{3 anos } \\
\hline 1 & $40,1 a^{(2)}$ & $2,2 \mathrm{~b}$ & $18,0 \mathrm{~b}$ & $14,0 \mathrm{a}$ & $7,9 \mathrm{a}$ & $1,4 \mathrm{a}$ \\
\hline \multirow[t]{2}{*}{2} & $36,6 \mathrm{~b}$ & $3,9 \mathrm{a}$ & $25,5 \mathrm{a}$ & $6,6 \mathrm{~b}$ & $3,7 \mathrm{~b}$ & $1,5 \mathrm{a}$ \\
\hline & \multicolumn{6}{|c|}{6 anos } \\
\hline 1 & $39,5 \mathrm{a}$ & $2,2 \mathrm{~b}$ & $16,7 \mathrm{~b}$ & $13,5 \mathrm{a}$ & $6,7 \mathrm{a}$ & $1,6 \mathrm{a}$ \\
\hline \multirow[t]{2}{*}{2} & $39,0 \mathrm{a}$ & $3,6 a$ & $26,7 \mathrm{a}$ & $7,2 \mathrm{~b}$ & $3,3 \mathrm{~b}$ & $1,3 \mathrm{~b}$ \\
\hline & \multicolumn{6}{|c|}{9 anos } \\
\hline 1 & $43,4 \mathrm{a}$ & $2,3 \mathrm{~b}$ & $16,8 \mathrm{~b}$ & $11,5 \mathrm{a}$ & $7,4 \mathrm{a}$ & $1,7 \mathrm{a}$ \\
\hline 2 & $38,6 \mathrm{~b}$ & $3,3 \mathrm{a}$ & $23,1 \mathrm{a}$ & $6,2 \mathrm{~b}$ & $3,8 \mathrm{~b}$ & $1,4 \mathrm{~b}$ \\
\hline
\end{tabular}

(1) amostragem 1, realizada no estágio vegetativo da soja (V4) e a 2 , no início do florescimento. ${ }^{(2)}$ Letras comparam época de amostragem dentro de cada TCSSD, pelo teste de Tukey ao nível de 5\%.

Nos solos com 3 e 6 anos sob SSD os teores de $\mathrm{B}$ e de $\mathrm{Cu}$ nas folhas aumentaram da primeira para a segunda amostragem (Tabela 26), embora nesta época os valores de $\mathrm{pH}$ do solo tenham sido maiores (Tabela 7). Em todos os TCSSD, os teores de Fe e Mn diminuíram da primeira para a segunda amostragem, enquanto os de $\mathrm{Zn}$ diminuíram apenas no solo com maior TCSSD. Essa diminuição pode ser, em parte, atribuída ao maior valor de $\mathrm{pH}$ na segunda amostragem, tornando esses elementos menos disponíveis no solo (Malavolta, 1980). 
Tabela 26. Concentração de micronutrientes nas folhas de soja em função da época de amostragem, para diferentes tempos de cultivo sob sistema de semeadura direta (TCSSD).

\begin{tabular}{|c|c|c|c|c|c|}
\hline Amostragem $^{(1)}$ & B & $\mathbf{C u}$ & $\mathrm{Fe}$ & Mn & $\mathrm{Zn}$ \\
\hline & & & $\mathrm{g} \mathrm{kg}^{-1}$ & & \\
\hline $\begin{array}{l}1 \\
2\end{array}$ & $\begin{array}{l}20 b^{(2)} \\
41 a\end{array}$ & $\begin{array}{c}8 \mathrm{~b} \\
11 \mathrm{a}\end{array}$ & $\begin{array}{c}3 \text { anos } \\
136 \mathrm{a} \\
69 \mathrm{~b}\end{array}$ & $\begin{array}{l}36 \mathrm{a} \\
30 \mathrm{~b}\end{array}$ & $\begin{array}{l}25 \mathrm{~b} \\
33 \mathrm{a}\end{array}$ \\
\hline $\begin{array}{l}1 \\
2\end{array}$ & $\begin{array}{l}28 \mathrm{~b} \\
40 \mathrm{a}\end{array}$ & $\begin{array}{l}7 \mathrm{~b} \\
8 \mathrm{a}\end{array}$ & $\begin{array}{c}6 \text { anos } \\
114 \mathrm{a} \\
54 \mathrm{~b}\end{array}$ & $\begin{array}{l}53 \mathrm{a} \\
32 \mathrm{~b}\end{array}$ & $\begin{array}{l}31 \mathrm{a} \\
30 \mathrm{a}\end{array}$ \\
\hline $\begin{array}{l}1 \\
2\end{array}$ & $\begin{array}{l}24 \mathrm{a} \\
25 \mathrm{a}\end{array}$ & $\begin{array}{l}9 \mathrm{a} \\
9 \mathrm{a}\end{array}$ & $\begin{array}{c}9 \text { anos } \\
215 \mathrm{a} \\
60 \mathrm{~b}\end{array}$ & $\begin{array}{l}34 \mathrm{a} \\
25 \mathrm{~b}\end{array}$ & $\begin{array}{l}33 \mathrm{a} \\
29 \mathrm{~b}\end{array}$ \\
\hline
\end{tabular}

\subsubsection{Efeito da Calagem nos Teores de Nutrientes}

\subsubsection{Nitrogênio}

Os teores de $\mathrm{N}$ nas folhas não variaram com a calagem em nenhuma das amostragens (Tabela 27). Estudos de Caires et al. (1998) mostraram que a aplicação de doses de calcário na superfície não afetaram os teores de $\mathrm{N}$ em folhas de soja, e Centurion (1988) observou teores semelhantes em folhas de plantas de milho submetido a diferentes sistemas de cultivo.

A concentração de $\mathrm{N}$ nas folhas de soja foram pouco modificadas pelos TCSSD, apesar de as diferenças entre os tempos de cultivo terem sido significativas. De modo geral, os teores de $\mathrm{N}$ estavam abaixo dos níveis considerados adequados $(\mathrm{N}=45$ a $55 \mathrm{~g} \mathrm{~kg}^{-1}$ ) por Malavolta et al. (1997). 
Tabela 27. Concentração de $\mathrm{N}$ na folhas de soja em função de doses de calcário, para diferentes tempos de cultivo sob sistema de semeadura direta (TCSSD) e épocas de amostragens.

\begin{tabular}{|c|c|c|c|c|c|c|}
\hline \multirow[t]{2}{*}{ TCSSD } & \multicolumn{6}{|c|}{ Doses de calcário $^{(1)}$} \\
\hline & $100 \mathrm{I}$ & $100 \mathrm{~S}$ & $66,7 \mathrm{~S}$ & $33,3 \mathrm{~S}$ & $\mathbf{0}$ & Médias \\
\hline \multicolumn{7}{|c|}{$\mathrm{g} \mathrm{kg}^{-1}$} \\
\hline & \multicolumn{6}{|c|}{ Amostragem $1^{(2)}$} \\
\hline 3 & 40,9 & 40,8 & 38,9 & 39,2 & 40,6 & $40,1 b^{(3)}$ \\
\hline 6 & 39,5 & 40,0 & 38,4 & 40,4 & 39,4 & $39,5 \mathrm{~b}$ \\
\hline 9 & 43,6 & 41,8 & 42,4 & 43,9 & 45,0 & $43,4 \mathrm{a}$ \\
\hline \multicolumn{7}{|c|}{ Amostragem 2} \\
\hline 3 & 38,0 & 36,4 & 37,6 & 35,7 & 35,5 & $36,6 \mathrm{~b}$ \\
\hline 6 & 36,6 & 37,3 & 41,3 & 40,3 & 39,4 & $39,0 \mathrm{a}$ \\
\hline 9 & 39,2 & 37,1 & 37,2 & 39,2 & 40,4 & $38,6 \mathrm{ab}$ \\
\hline
\end{tabular}

C.V. $\quad 6,8 \%$

(7) Percentagem da dose necessária para elevar a saturação por bases a 70\%; I = incorporado a $20 \mathrm{~cm}$; $\mathrm{S}$ = aplicado superficialmente. ${ }^{(2)}$ amostragem 1 , realizada no estágio vegetativo da soja (V4) e a 2, no início do florescimento. ${ }^{(3)}$ Letras minúsculas comparam TCSSD dentro de cada amostragem, pelo teste de Tukey ao nível de $5 \%$.

\subsubsection{Fósforo}

Os teores de $\mathrm{P}$ das folhas de soja não foram modificados pelas doses de calcário (Tabela 28). O efeito dos TCSSD ocorreu somente na segunda amostragem, tendo os teores diminuído com o aumento do TCSSD. Centurion (1988) comparou os teores de nutrientes em plantas de milho cultivadas sob vários sistemas de cultivo e observou maiores teores de $\mathrm{P}$ em folhas de milho cultivadas sob SSD do que nas cultivadas sob SSC. Resultados semelhantes foram encontrados por Muzilli (1983).

Os teores de $\mathrm{P}$ na primeira amostragem estão abaixo dos níveis considerados adequados ( $\mathrm{P}=2,6$ a 5,0 $\mathrm{g} \mathrm{kg}^{-1}$ ) por Malavolta et al. (1997), e na segunda, estão dentro dessa faixa. Correlações diretas entre os teores de $\mathrm{P}$ no solo e nas folhas ocorreram somente na segunda época de amostragem e no tratamento submetido à aração $(r=0,59$ a 0,69 ) (Tabelas 29 e 30 ). 
Tabela 28. Concentração de $\mathrm{P}$ nas folhas de soja em função de doses de calcário, para diferentes tempos de cultivo sob sistema de semeadura direta (TCSSD) e épocas de amostragens.

\begin{tabular}{|c|c|c|c|c|c|c|}
\hline \multirow[t]{2}{*}{ TCSSD } & \multicolumn{6}{|c|}{ Doses de calcário $^{(I)}$} \\
\hline & $100 \mathrm{I}$ & $100 \mathrm{~S}$ & $66,7 \mathrm{~S}$ & $33,3 \mathrm{~S}$ & $\mathbf{0}$ & Médias \\
\hline \multirow[t]{2}{*}{ ano } & \multicolumn{6}{|c|}{$\mathrm{g} \mathrm{kg}^{-1}$} \\
\hline & \multicolumn{6}{|c|}{ Amostragem $1^{(2)}$} \\
\hline 3 & 2,1 & 2,1 & 2,3 & 2,3 & 2,2 & $2,2 a^{(3)}$ \\
\hline 6 & 2,1 & 2,2 & 2,3 & 2,3 & 2,4 & $2,2 \mathrm{a}$ \\
\hline 9 & 2,2 & 2,2 & 2,3 & 2,3 & 2,4 & $2,3 \mathrm{a}$ \\
\hline \multicolumn{7}{|c|}{ Amostragem 2} \\
\hline 3 & 3,8 & 3,8 & 4,1 & 3,7 & 4,0 & $3,9 \mathrm{a}$ \\
\hline 6 & 3,4 & 3,7 & 3,9 & 3,8 & 3,6 & $3,6 \mathrm{~b}$ \\
\hline 9 & 3,3 & 3,3 & 3,1 & 3,7 & 3,4 & $3,3 \mathrm{c}$ \\
\hline
\end{tabular}

C.V. $\quad 10,9 \%$

(7) Percentagem da dose necessária para elevar a saturação por bases a $70 \%$; $=$ incorporado a $20 \mathrm{~cm}$; $\mathrm{S}=$ aplicado superficialmente. ${ }^{(2)}$ amostragem 1 , realizada no estágio vegetativo da soja (V4) e a 2, no início do florescimento. ${ }^{(3)}$ Letras minúsculas comparam TCSSD dentro de cada amostragem, pelo teste de Tukey ao nível de $5 \%$.

Tabela 29. Coeficientes de correlação linear ( $\mathrm{r}$ ) entre teores de macronutrientes no solo e nas folhas, nos tratamentos sem incorporação, em diferentes épocas e profundidades de coletas.

\begin{tabular}{|c|c|c|c|c|c|}
\hline Prof. & $\mathbf{P}$ & $\mathbf{K}$ & $\mathbf{C a}$ & $\mathbf{M g}$ & $\mathbf{S}$ \\
\hline $\mathrm{cm}$ & \multicolumn{5}{|c|}{ Amostragem $1^{(1)}$} \\
\hline $0-5$ & $-0,05 \mathrm{~ns}$ & $0,04 \mathrm{~ns}$ & $0,00 \mathrm{~ns}$ & $-0,31 *$ & $0,00 \mathrm{~ns}$ \\
\hline $5-10$ & $-0,19$ ns & $-0,07 \mathrm{~ns}$ & $0,48 \mathrm{~ns}$ & $0,49 * *$ & $0,15 \mathrm{~ns}$ \\
\hline $10-20$ & $0,03 \mathrm{~ns}$ & $-0,14 \mathrm{~ns}$ & $0,00 \mathrm{~ns}$ & $0,41 * *$ & $0,01 \mathrm{~ns}$ \\
\hline \multirow[t]{2}{*}{$20-30$} & $-0,19$ ns & $0,10 \mathrm{~ns}$ & $-0,34 *$ & $0,05 \mathrm{~ns}$ & $-0,21 \mathrm{~ns}$ \\
\hline & \multicolumn{5}{|c|}{ Amostragem 2} \\
\hline $0-5$ & $0,27 \mathrm{~ns}$ & $0,47 * *$ & $-0,11 \mathrm{~ns}$ & $-0,07$ ns & $-0,11 \mathrm{~ns}$ \\
\hline $5-10$ & $0,26 \mathrm{~ns}$ & $0,52 * *$ & $-0,13 \mathrm{~ns}$ & $-0,01 \mathrm{~ns}$ & $-0,29 *$ \\
\hline $10-20$ & $0,16 \mathrm{~ns}$ & $0,44 * *$ & $-0,11 \mathrm{~ns}$ & $0,28 \mathrm{~ns}$ & $-0,21 \mathrm{~ns}$ \\
\hline $20-30$ & $-0,05 \mathrm{~ns}$ & $0,39 * *$ & $-0,17 n s$ & $0,50 * *$ & $0,30 *$ \\
\hline
\end{tabular}


Tabela 30. Coeficientes de correlação linear ( $\mathrm{r}$ ) entre teores de macronutrientes no solo e nas folhas, no tratamento com incorporação do corretivo, em diferentes épocas e profundidades de coletas.

\begin{tabular}{|c|c|c|c|c|c|}
\hline Prof. & $\mathbf{P}$ & $\mathbf{K}$ & $\mathbf{C a}$ & Mg & \\
\hline $\mathrm{cm}$ & \multicolumn{5}{|c|}{${\text { Amostragem } 1^{(1)}}^{(1)}$} \\
\hline $0-5$ & $0,14 \mathrm{~ns}$ & $-0,69 *$ & $0,43 \mathrm{~ns}$ & $0,24 \mathrm{~ns}$ & $0,00 \mathrm{~ns}$ \\
\hline $5-10$ & $0,25 \mathrm{~ns}$ & $-0,61 *$ & $0,35 \mathrm{~ns}$ & $0,27 \mathrm{~ns}$ & $0,07 \mathrm{~ns}$ \\
\hline $10-20$ & $-0,45 \mathrm{~ns}$ & $-0,48 \mathrm{~ns}$ & $0,27 \mathrm{~ns}$ & $-0,38 \mathrm{~ns}$ & $-0,26 \mathrm{~ns}$ \\
\hline \multirow[t]{2}{*}{$20-30$} & $-0,25 \mathrm{~ns}$ & $-0,56 \mathrm{~ns}$ & $-0,27 \mathrm{~ns}$ & $-0,10 \mathrm{~ns}$ & $-0,23 \mathrm{~ns}$ \\
\hline & \multicolumn{5}{|c|}{ Amostragem 2} \\
\hline $0-5$ & $0,63 *$ & $0,42 \mathrm{~ns}$ & $0,43 \mathrm{~ns}$ & $0,60 *$ & $0,60 *$ \\
\hline $5-10$ & $0,60 *$ & $0,21 \mathrm{~ns}$ & $0,42 \mathrm{~ns}$ & $0,61 *$ & $0,61 *$ \\
\hline $10-20$ & $0,69 *$ & $0,56 \mathrm{~ns}$ & $0,41 \mathrm{~ns}$ & $0,59 *$ & $0,59 *$ \\
\hline $20-30$ & $0,59 *$ & $0,59 *$ & $-0,23 \mathrm{~ns}$ & $-0,19 \mathrm{~ns}$ & $-0,19 \mathrm{~ns}$ \\
\hline
\end{tabular}

\subsubsection{Potássio}

$\mathrm{O}$ efeito dos TCSSD nos teores de $\mathrm{K}$ nas folhas de soja ocorreu apenas na segunda amostragem, tendo havido pouca variação na concentração (Tabela 31). Os teores de $\mathrm{K}$ também não variaram com as doses do corretivo. Resultados semelhantes foram encontrados por Caires et al. (1998), que não verificaram diferenças nos teores de $\mathrm{K}$ em folhas de soja, devido à calagem superficial. Por outro lado, tem sido relatado na literatura (Estes,1972; Blevins et al., 1986; Centurion, 1988) que o teor de $\mathrm{K}$ em folhas de milho cultivado sob SSD é maior que o de plantas sob SSC.

Os teores de $\mathrm{K}$ para todos os TCSSD estavam dentro ou ligeiramente abaixo dos níveis considerados adequados (17 a $25 \mathrm{~g} \mathrm{~kg}^{-1}$ ) por Malavolta et al. (1997). Por sua vez, as correlações diretas entre estes e os teores de $\mathrm{K}$ no solo ocorreram somente na segunda amostragem, e ainda, foram baixas $(r=0,39$ a 0,59) (Tabelas 29 e 30). Para o tratamento incorporado, na primeira amostragem, a correlação foi inversa (Tabela 30). 
Tabela 31. Concentração de $\mathrm{K}$ nas folhas de soja em função de doses de calcário, para diferentes tempos de cultivo sob sistema de semeadura direta (TCSSD) e épocas de amostragens.

\begin{tabular}{|c|c|c|c|c|c|c|}
\hline \multirow[t]{2}{*}{ TCSSD } & \multicolumn{6}{|c|}{ Doses de calcário $^{(1)}$} \\
\hline & $100 \mathrm{I}$ & $100 \mathrm{~S}$ & $66,7 \mathrm{~S}$ & $33,3 \mathrm{~S}$ & $\mathbf{0}$ & Médias \\
\hline \multirow[t]{2}{*}{ ano } & \multicolumn{6}{|c|}{$\mathrm{g} \mathrm{kg}^{-1}=$} \\
\hline & \multicolumn{6}{|c|}{ Amostragem $1^{(2)}$} \\
\hline 3 & 18,4 & 17,6 & 17,7 & 18,7 & 17,6 & $18,0 \mathrm{a}^{(3)}$ \\
\hline 6 & 13,2 & 17,3 & 18,0 & 16,2 & 18,1 & 16,7 a \\
\hline 9 & 15,3 & 16,0 & 15,5 & 18,8 & 18,6 & $16,8 \mathrm{a}$ \\
\hline & \multicolumn{6}{|c|}{ Amostragem 2} \\
\hline 3 & 24,1 & 27,9 & 24,8 & 25,7 & 24,9 & $25,5 \mathrm{ab}$ \\
\hline 6 & 26,4 & 25,5 & 27,5 & 27,7 & 26,7 & $26,7 \mathrm{a}$ \\
\hline 9 & 22,5 & 22,1 & 21,9 & 25,1 & 22,7 & $23,1 \mathrm{~b}$ \\
\hline C.V. & $11,5 \%$ & & & & & \\
\hline
\end{tabular}

\subsubsection{Cálcio}

Houve efeito das doses de calcário nos teores de $\mathrm{Ca}$ nas folhas apenas na primeira amostragem e para o solo com 6 anos sob SSD. A incorporação do calcário resultou maior concentração de $\mathrm{Ca}$ que a aplicação na superfície, e esta forma de aplicação, em quaisquer das doses, não reduziu os níveis originais de $\mathrm{Ca}$ (Tabela 32). Caires et al. (1998) também não observaram aumento dos teores de Ca em folhas de soja, em função da calagem superficial. Por outro lado, em estudos de Caires et al. (1999), os teores de Ca em folhas de soja aumentaram de forma quadrática com doses de calcário aplicadas à superfície. Estes (1972) relatou maior concentração de Ca em plantas de milho cultivadas sob SSC do que nas cultivadas sob SSD, enquanto Quaggio et al. (1998) constataram que a calagem fez com que o teor de Ca aumentasse em folhas de soja cultivadas sob SSC. 
Tabela 32. Concentração de Ca nas folhas de soja em função de doses de calcário, para diferentes tempos de cultivo sob sistema de semeadura direta (TCSSD) e épocas de amostragens.

\begin{tabular}{|c|c|c|c|c|c|}
\hline \multirow[t]{2}{*}{ TCSSD } & \multicolumn{5}{|c|}{ Doses de calcário $^{(1)}$} \\
\hline & $100 \mathrm{I}$ & $100 \mathrm{~S}$ & $66,7 \mathrm{~S}$ & $33,3 \mathrm{~S}$ & $\mathbf{0}$ \\
\hline \multirow[t]{2}{*}{ ano } & & & $\mathrm{g} \mathrm{kg}^{-1}$ & & \\
\hline & \multicolumn{5}{|c|}{ Amostragem $1^{(2)}$} \\
\hline 3 & $14,7 \mathrm{abA}^{(3)}$ & $13,1 \mathrm{aA}$ & $14,3 \mathrm{aA}$ & $12,9 \mathrm{aA}$ & $15,0 \mathrm{aA}$ \\
\hline 6 & $16,4 \mathrm{aA}$ & $12,3 \mathrm{aB}$ & $13,0 \mathrm{abB}$ & $13,2 \mathrm{aB}$ & $12,9 \mathrm{abB}$ \\
\hline 9 & $12,7 \mathrm{bA}$ & $11,3 \mathrm{aA}$ & $\begin{array}{c}10,6 \mathrm{bA} \\
\text { Amostragem } 2\end{array}$ & $11,9 \mathrm{aA}$ & $11,3 \mathrm{bA}$ \\
\hline 3 & $7,8 \mathrm{aA}$ & $6,4 \mathrm{aA}$ & $6,5 \mathrm{aA}$ & $6,4 \mathrm{aA}$ & $6,2 \mathrm{aA}$ \\
\hline 6 & $6,9 \mathrm{aA}$ & $7,2 \mathrm{aA}$ & $7,5 \mathrm{aA}$ & $6,9 \mathrm{aA}$ & $7,6 \mathrm{aA}$ \\
\hline 9 & $6,6 \mathrm{aA}$ & $6,0 \mathrm{aA}$ & $6,0 \mathrm{aA}$ & $6,1 \mathrm{aA}$ & $6,4 \mathrm{aA}$ \\
\hline C.V. & $10,2 \%$ & & & & \\
\hline
\end{tabular}

Os teores de $\mathrm{Ca}$ para todos os tratamentos estão dentro dos níveis considerados adequados (4 a $20 \mathrm{~g} \mathrm{~kg}^{-1}$ ) por Malavolta et al. (1997). Por sua vez, as correlações entre os teores de Ca nas folhas e no solo foram sempre baixas e geralmente não significativas (Tabelas 29 e 30). Estes resultados discordam dos obtidos por Caires et al. (1999) em um Latossolo Vermelho Escuro há 15 anos sob SSD, cujos coeficientes de correlação foram positivos e significativos desde a camada de $0-5 \mathrm{~cm}$ até $60-80 \mathrm{~cm}$.

\subsubsection{Magnésio}

Houve efeito das doses de calcário e dos TCSSD nos teores de $\mathrm{Mg}$ nas folhas apenas na primeira amostragem, e estes geralmente foram maiores no local com menor TCSSD (Tabela 33). No solo com 6 anos sob SSD a incorporação do calcário resultou no maior teor. No local com maior TCSSD, a dose integral, de forma incorporada, possibilitou maior teor que $2 / 3$ da mesma na superfície. Por outro lado, em todos os TCSSD a aplicação superficial não modificou os teores em relação à 
testemunha, mas, Caires et al. (1998) e Caires et al. (1999) observaram aumento dos teores de Mg após a aplicação de calcário superficialmente. Estes (1972) encontrou maior teor nas plantas de milho cultivadas sob SSC do que nas sob SSD, atribuindo este fato à alta absorção de K pelas plantas sob SSD. No SSC, aumento da concentração de Mg devido à calagem é comum (Bell, 1996; Oliveira et al., 1997; Quaggio et al., 1998).

Tabela 33. Concentração de $\mathrm{Mg}$ nas folhas de soja em função de doses de calcário, para diferentes tempos de cultivo sob sistema de semeadura direta (TCSSD) e épocas de amostragens.

\begin{tabular}{|c|c|c|c|c|c|}
\hline \multirow[t]{2}{*}{ TCSSD } & \multicolumn{5}{|c|}{ Doses de calcário $^{(1)}$} \\
\hline & $100 \mathrm{I}$ & $100 \mathrm{~S}$ & $66,7 \mathrm{~S}$ & $33,3 \mathrm{~S}$ & $\mathbf{0}$ \\
\hline \multirow[t]{2}{*}{ ano } & & & $\mathrm{g} \mathrm{kg}^{-1}$ & & \\
\hline & \multicolumn{5}{|c|}{ Amostragem $1^{(2)}$} \\
\hline 3 & $8,2 \mathrm{aA}^{(3)}$ & $7,5 \mathrm{aA}$ & $8,1 \mathrm{aA}$ & 7,6 aA & $8,1 \mathrm{aA}$ \\
\hline 6 & $8,2 \mathrm{aA}$ & $6,1 \mathrm{bB}$ & $6,2 \mathrm{bB}$ & 6,6 bB & $6,5 \mathrm{bB}$ \\
\hline \multirow[t]{2}{*}{9} & 8,3 aA & 7,4 aAB & $6,6 \mathrm{bB}$ & $7,5 \mathrm{abAB}$ & $7,2 \mathrm{abAB}$ \\
\hline & \multicolumn{5}{|c|}{ Amostragem 2} \\
\hline 3 & $4,4 \mathrm{aA}$ & $3,7 \mathrm{aA}$ & $3,6 \mathrm{aA}$ & $3,4 \mathrm{aA}$ & $3,3 \mathrm{aA}$ \\
\hline 6 & $3,3 \mathrm{aA}$ & $3,2 \mathrm{aA}$ & $3,3 \mathrm{aA}$ & $3,4 \mathrm{aA}$ & $3,4 \mathrm{aA}$ \\
\hline 9 & $3,8 \mathrm{aA}$ & $3,9 \mathrm{aA}$ & $3,5 \mathrm{aA}$ & $3,8 \mathrm{aA}$ & $3,9 \mathrm{aA}$ \\
\hline C.V. & $9,7 \%$ & & & & \\
\hline
\end{tabular}

Os teores de $\mathrm{Mg}$ nas folhas de soja para todos os tratamentos estão dentro dos níveis considerados adequados ( 3 a $10 \mathrm{~g} \mathrm{~kg}^{-1}$ ) por Malavolta et al. (1997). Por sua vez, correlações diretas entre os teores de $\mathrm{Mg}$ nas folhas e no solo, nos tratamentos sem revolvimento do solo, foram baixas $(r=0,41$ a 0,50$)$, e somente observadas nas camadas abaixo de $0-5 \mathrm{~cm}$ (Tabela 29). Nos tratamentos submetidos à aração, as correlações foram maiores, embora tenham ocorrido apenas para a segunda amostragem (Tabela 38). Caires et al. (1999) encontraram correlações significativas entre teores de $\mathrm{Mg}$ nas folhas de soja e o no solo apenas para as camadas 0-5 cm ( $\mathrm{r}=0,59)$ e $10-20 \mathrm{~cm}$ $(r=0,56)$. 


\subsubsection{Enxofre}

As concentrações de enxofre nas folhas de soja não variaram com as doses de calcário, e foram pouco alteradas com os TCSSD (Tabela 34). Caires et al. (1998) e Caires et al. (1999) também não observaram efeito de doses de calcário aplicadas superficialmente nos teores de $\mathrm{S}$ em folhas de soja cultivada em solo com longo tempo de cultivo sob SSD.

Tabela 34. Concentração de S nas folhas de soja em função de doses de calcário, para diferentes tempos de cultivo sob sistema de semeadura direta (TCSSD) e épocas de amostragens.

\begin{tabular}{|c|c|c|c|c|c|c|}
\hline \multirow[t]{2}{*}{ TCSSD } & \multicolumn{6}{|c|}{ Doses de calcário $^{(I)}$} \\
\hline & $100 \mathrm{I}$ & $100 \mathrm{~S}$ & $\overline{66,7 \mathrm{~S}}$ & $\overline{33,3 \mathrm{~S}}$ & 0 & Médias \\
\hline \multirow[t]{2}{*}{ ano } & & & $=$ & & & \\
\hline & \multicolumn{6}{|c|}{ Amostragem $1^{(2)}$} \\
\hline 3 & 1,5 & 1,4 & 1,4 & 1,4 & 1,5 & $1,4 b^{(3)}$ \\
\hline 6 & 1,5 & 1,6 & 1,7 & 1,6 & 1,8 & $1,6 \mathrm{a}$ \\
\hline \multirow[t]{2}{*}{9} & 1,9 & 1,6 & 1,5 & 1,6 & 1,7 & $1,7 \mathrm{a}$ \\
\hline & \multicolumn{6}{|c|}{ Amostragem 2} \\
\hline 3 & 1,5 & 1,5 & 1,4 & 1,5 & 1,5 & $1,5 \mathrm{a}$ \\
\hline 6 & 1,2 & 1,3 & 1,4 & 1,4 & 1,3 & $1,3 \mathrm{~b}$ \\
\hline 9 & 1,3 & 1,3 & 1,3 & 1,5 & 1,4 & $1,4 \mathrm{ab}$ \\
\hline
\end{tabular}

C.V. $\quad 11,8 \%$

(1) Percentagem da dose necessária para elevar a saturação por bases a $70 \%$; I = incorporado a $20 \mathrm{~cm}$; S = aplicado superficialmente. ${ }^{(2)}$ amostragem 1 , realizada no estágio vegetativo da soja (V4) e a 2, no início do florescimento. ${ }^{(3)}$ Letras minúsculas comparam TCSSD dentro de cada amostragem, pelo teste de Tukey ao nível de $5 \%$.

Os teores de $\mathrm{S}$ nas folhas estavam abaixo dos níveis considerados adequados $\left(2,5 \mathrm{~g} \mathrm{~kg}^{-1}\right)$ por Malavolta et al. (1997). As correlações entre os teores de $\mathrm{S}$ nas folhas de soja e no solo foram sempre muito baixas (Tabelas 29 e 30). 


\subsubsection{Micronutrientes}

Os teores de B nas folhas de soja não foram modificados pelas doses de calcário (Tabela 35). Contrariando esses resultados, Quaggio et al. (1998) verificaram que a calagem reduziu os teores de B de plantas de soja cultivadas sob SSC.

Tabela 35. Concentração de B nas folhas de soja em função de doses de calcário, para diferentes tempos de cultivo sob sistema de semeadura direta (TCSSD) e épocas de amostragens.

\begin{tabular}{|c|c|c|c|c|c|c|}
\hline \multirow[t]{2}{*}{ TCSSD } & \multicolumn{6}{|c|}{ Doses de calcário $^{(I)}$} \\
\hline & $100 \mathrm{I}$ & $100 \mathrm{~S}$ & $66,7 \mathrm{~S}$ & $33,3 \mathrm{~S}$ & $\mathbf{0}$ & Médias \\
\hline \multirow[t]{2}{*}{ ano } & \multicolumn{6}{|c|}{$\mathrm{g} \mathrm{kg}^{-1}$} \\
\hline & \multicolumn{6}{|c|}{ Amostragem $1^{(2)}$} \\
\hline 3 & 21 & 18 & 20 & 20 & 21 & $20 c^{(3)}$ \\
\hline 6 & 24 & 29 & 29 & 28 & 29 & $28 \mathrm{a}$ \\
\hline 9 & 23 & 26 & 25 & $24 \mathrm{~b}$ & $24 \mathrm{~b}$ & $24 \mathrm{~b}$ \\
\hline \multicolumn{7}{|c|}{ Amostragem 2} \\
\hline 3 & 39 & 43 & 40 & 40 & 42 & $41 \mathrm{a}$ \\
\hline 6 & 43 & 37 & 40 & 40 & 42 & $40 \mathrm{a}$ \\
\hline 9 & 26 & 24 & 26 & 23 & 28 & $25 \mathrm{~b}$ \\
\hline C.V.\% & $9,9 \%$ & & & & & \\
\hline
\end{tabular}

O efeito dos TCSSD foi significativo para o teor de B nas folhas em ambas as épocas avaliadas. Na primeira amostragem, os menores teores ocorreram para os TCSSD de 3 e 9 anos, e na segunda para o de 9 anos de cultivo. Na primeira amostragem, o teor de B do local com menor TCSSD estava abaixo do nível considerado adequado (21 a $55 \mathrm{mg} \mathrm{kg}^{-1}$ ) por Malavolta et al. (1997).

Ocorreu correlação direta entre os teores de B no solo e o teor na folha (Tabelas 36 e 37), e o maior coeficiente de correlação linear foi de 0,65 . As correlações entre B na folha e pH do solo foram inversas, com coeficientes de correlação linear de até $-0,70$ (Tabelas 38 e 39). 
Tabela 36. Coeficientes de correlação linear (r) entre teores de micronutrientes no solo e nas folhas, nos tratamentos sem incorporação do corretivo, em diferentes épocas e profundidades de coletas.

\begin{tabular}{|c|c|c|c|c|c|}
\hline Prof. & B & $\mathrm{Cu}$ & Fe & Mn & $\mathbf{Z n}$ \\
\hline $\mathrm{cm}$ & \multicolumn{5}{|c|}{ Amostragem $1^{(1)}$} \\
\hline $0-5$ & $0,39 * *$ & $0,48 * *$ & $0,17 \mathrm{~ns}$ & $0,53 * *$ & $-0,12 \mathrm{~ns}$ \\
\hline $5-10$ & $0,52 * *$ & $0,43 * *$ & $-0,10 \mathrm{~ns}$ & $0,50 * *$ & $0,33 *$ \\
\hline $10-20$ & $0,57 * *$ & $0,37 * *$ & $-0,20 \mathrm{~ns}$ & $0,37 * *$ & $0,48 * *$ \\
\hline \multirow[t]{2}{*}{$20-30$} & $0,45 * *$ & $0,36^{*}$ & $-0,10 \mathrm{~ns}$ & $0,36^{*}$ & $0,09 \mathrm{~ns}$ \\
\hline & \multicolumn{5}{|c|}{ Amostragem 2} \\
\hline $0-5$ & $0,08 \mathrm{~ns}$ & $0,14 \mathrm{~ns}$ & $-0,40 * *$ & $0,34 *$ & $0,57 * *$ \\
\hline $5-10$ & $0,11 \mathrm{~ns}$ & $0,12 \mathrm{~ns}$ & $-0,50 * *$ & $0,36^{*}$ & $0,44 * *$ \\
\hline $10-20$ & $0,25 \mathrm{~ns}$ & $0,12 \mathrm{~ns}$ & $-0,50 * *$ & $0,30 *$ & $0,18 \mathrm{~ns}$ \\
\hline $20-30$ & $0,16 \mathrm{~ns}$ & $0,22 \mathrm{~ns}$ & $-0,40^{* *}$ & $-0,20 \mathrm{~ns}$ & $0,20 \mathrm{~ns}$ \\
\hline
\end{tabular}

Tabela 37. Coeficientes de correlação linear (r) entre teores de micronutrientes no solo e nas folhas, no tratamento com incorporação do corretivo, em diferentes épocas e profundidades de coletas.

\begin{tabular}{|c|c|c|c|c|c|}
\hline Prof. & B & $\mathrm{Cu}$ & $\mathrm{Fe}$ & Mn & $\mathbf{Z n}$ \\
\hline $\mathrm{cm}$ & \multicolumn{5}{|c|}{ Amostragem $1^{(1)}$} \\
\hline $0-5$ & $0,44 \mathrm{~ns}$ & $-0,07 \mathrm{~ns}$ & $-0,25 \mathrm{~ns}$ & $0,67 *$ & $-0,25 \mathrm{~ns}$ \\
\hline $5-10$ & $0,36 \mathrm{~ns}$ & $0,11 \mathrm{~ns}$ & $-0,25 \mathrm{~ns}$ & $0,81 * *$ & $-0,28 \mathrm{~ns}$ \\
\hline $10-20$ & $-0,19 \mathrm{~ns}$ & $0,39 \mathrm{~ns}$ & $0,24 \mathrm{~ns}$ & $0,57 \mathrm{~ns}$ & $-0,22 \mathrm{~ns}$ \\
\hline \multirow[t]{2}{*}{$20-30$} & $0,24 \mathrm{~ns}$ & $0,58 *$ & $0,11 \mathrm{~ns}$ & $0,49 \mathrm{~ns}$ & $0,05 \mathrm{~ns}$ \\
\hline & \multicolumn{5}{|c|}{ Amostragem 2} \\
\hline $0-5$ & $0,58 *$ & $0,22 \mathrm{~ns}$ & $-0,70^{*}$ & $0,26 \mathrm{~ns}$ & $0,64 *$ \\
\hline $5-10$ & $0,65 *$ & $0,24 \mathrm{~ns}$ & $-0,63 *$ & $-0,08 \mathrm{~ns}$ & $0,62 *$ \\
\hline $10-20$ & $0,59 *$ & $0,29 \mathrm{~ns}$ & $-0,48 \mathrm{~ns}$ & $-0,15 \mathrm{~ns}$ & $0,35 \mathrm{~ns}$ \\
\hline $20-30$ & $0,41 \mathrm{~ns}$ & $0,23 \mathrm{~ns}$ & $-0,78^{* *}$ & $0,73 * *$ & $0,60 *$ \\
\hline
\end{tabular}


Tabela 38. Coeficientes de correlação linear (r) entre teores de micronutrientes na folha e pH nos tratamentos sem incorporação do corretivo, em diferentes épocas e profundidades de coletas.

\begin{tabular}{|c|c|c|c|c|c|}
\hline Prof. & B & $\mathbf{C u}$ & $\mathrm{Fe}$ & Mn & $\mathbf{Z n}$ \\
\hline $\mathrm{cm}$ & \multicolumn{5}{|c|}{ Amostragem $1^{(15)}$} \\
\hline $0-5$ & $-0,40 * *$ & $0,04 \mathrm{~ns}$ & $-0,40 * *$ & $-0,20 \mathrm{~ns}$ & $-0,30 *$ \\
\hline $5-10$ & $-0,70 * *$ & $0,24 \mathrm{~ns}$ & $-0,10 \mathrm{~ns}$ & $-0,50 * *$ & $-0,30 *$ \\
\hline $10-20$ & $-0,60 * *$ & $0,32 *$ & $0,28 \mathrm{~ns}$ & $-0,60 * *$ & $-0,20 \mathrm{~ns}$ \\
\hline \multirow[t]{2}{*}{$20-30$} & $-0,50 * *$ & $0,45 * *$ & $-0,32 *$ & $-0,80 * *$ & $-0,10 \mathrm{~ns}$ \\
\hline & \multicolumn{5}{|c|}{ Amostragem 2} \\
\hline $0-5$ & $-0,20 \mathrm{~ns}$ & $0,10 \mathrm{~ns}$ & $0,20 \mathrm{~ns}$ & $-0,30 *$ & $-0,20 \mathrm{~ns}$ \\
\hline $5-10$ & $0,07 \mathrm{~ns}$ & $0,46 * *$ & $0,45 * *$ & $-0,10 \mathrm{~ns}$ & $0,26 \mathrm{~ns}$ \\
\hline $10-20$ & $-0,20 \mathrm{~ns}$ & $0,15 \mathrm{~ns}$ & $0,27 \mathrm{~ns}$ & $-0,20 \mathrm{~ns}$ & $-0,10 \mathrm{~ns}$ \\
\hline $20-30$ & $-0,60 * *$ & $0,00 \mathrm{~ns}$ & $0,03 \mathrm{~ns}$ & $-0,60 * *$ & $-0,20 \mathrm{~ns}$ \\
\hline
\end{tabular}

Tabela 39. Coeficientes de correlação linear (r) entre teores de micronutrientes foliar e pH no tratamento com incorporação do corretivo, em diferentes épocas e profundidades de coletas.

\begin{tabular}{|c|c|c|c|c|c|}
\hline Prof. & B & $\mathbf{C u}$ & $\mathrm{Fe}$ & Mn & $\mathbf{Z n}$ \\
\hline $\mathrm{cm}$ & \multicolumn{5}{|c|}{ Amostragem $1^{(\bar{T}}$} \\
\hline $0-5$ & $-0,60 *$ & $-0,20 \mathrm{~ns}$ & $0,54 \mathrm{~ns}$ & $-0,50 \mathrm{~ns}$ & $0,16 \mathrm{~ns}$ \\
\hline $5-10$ & $-0,47 \mathrm{~ns}$ & $-0,05 \mathrm{~ns}$ & $-0,18 \mathrm{~ns}$ & $-0,51 \mathrm{~ns}$ & $0,56 \mathrm{~ns}$ \\
\hline $10-20$ & $-0,07 \mathrm{~ns}$ & $-0,32 \mathrm{~ns}$ & $-0,09 n s$ & $-0,36 n s$ & $-0,04 \mathrm{~ns}$ \\
\hline \multirow[t]{2}{*}{$20-30$} & $-0,56 \mathrm{~ns}$ & $0,19 \mathrm{~ns}$ & $0,04 \mathrm{~ns}$ & $-0,40 \mathrm{~ns}$ & $-0,26 \mathrm{~ns}$ \\
\hline & \multicolumn{5}{|c|}{ Amostragem 2} \\
\hline $0-5$ & $0,14 \mathrm{~ns}$ & $0,37 \mathrm{~ns}$ & $0,63 *$ & $-0,30 \mathrm{~ns}$ & $0,53 \mathrm{~ns}$ \\
\hline $5-10$ & $0,06 \mathrm{~ns}$ & $0,28 \mathrm{~ns}$ & $0,05 \mathrm{~ns}$ & $-0,38 \mathrm{~ns}$ & $-0,20 \mathrm{~ns}$ \\
\hline $10-20$ & $-0,06 \mathrm{~ns}$ & $0,53 \mathrm{~ns}$ & $0,43 \mathrm{~ns}$ & $-0,27 \mathrm{~ns}$ & $0,26 \mathrm{~ns}$ \\
\hline $20-30$ & $-0,39 \mathrm{~ns}$ & $-0,30 \mathrm{~ns}$ & $-0,01 \mathrm{~ns}$ & $-0,46 \mathrm{~ns}$ & $-0,42 \mathrm{~ns}$ \\
\hline
\end{tabular}

Os teores de $\mathrm{Cu}$ nas folhas de soja não variaram com as doses de calcário e foram pouco modificados com os TCSSD (Tabela 40). Shuman \& McCracken (1999a) também não observaram redução no teor de $\mathrm{Cu}$ em plantas de milho, em função da calagem superficial, e Centurion (1988) encontraram menores teores de $\mathrm{Cu}$ em plantas de milho cultivadas sob SSD do que nas cultivadas em outros sistemas. 
Tabela 40. Concentração de $\mathrm{Cu}$ nas folhas de soja em função de doses de calcário, para diferentes tempos de cultivo sob sistema de semeadura direta (TCSSD) e épocas de amostragens.

\begin{tabular}{|c|c|c|c|c|c|c|}
\hline \multirow[t]{2}{*}{ TCSSD } & \multicolumn{6}{|c|}{ Doses de calcário $^{(1)}$} \\
\hline & $100 \mathrm{I}$ & $100 \mathrm{~S}$ & $66,7 \mathrm{~S}$ & $33,3 \mathrm{~S}$ & $\mathbf{0}$ & Médias \\
\hline \multicolumn{7}{|c|}{$\mathrm{g} \mathrm{kg}^{-1}$} \\
\hline & \multicolumn{6}{|c|}{ Amostragem $1^{(2)}$} \\
\hline 3 & 7 & 8 & 8 & 8 & 9 & $8 \mathrm{ab}^{(3)}$ \\
\hline 6 & 7 & 7 & 6 & 7 & 7 & $7 \mathrm{~b}$ \\
\hline 9 & 9 & 9 & 8 & 9 & 9 & $9 \mathrm{a}$ \\
\hline \multicolumn{7}{|c|}{ Amostragem 2} \\
\hline 3 & 9 & 11 & 10 & 10 & 13 & $11 \mathrm{a}$ \\
\hline 6 & 8 & 8 & 8 & 9 & 8 & $8 \mathrm{~b}$ \\
\hline 9 & 9 & 9 & 9 & 9 & 9 & $9 \mathrm{~b}$ \\
\hline C.V. & $18,4 \%$ & & & & & \\
\hline
\end{tabular}

Os teores de $\mathrm{Cu}$ estavam acima do nível crítico $\left(3,9 \mathrm{mg} \mathrm{kg}^{-1}\right)$ estabelecido por Galrão (1999), para solos sob cerrado, e geralmente abaixo da faixa considerada adequada (10 a $30 \mathrm{mg} \mathrm{kg}^{-1}$ ) por Borkert et al. (1994) e por Malavolta et al. (1997), apesar de os teores de $\mathrm{Cu}$ no solo estarem bem acima dos níveis altos, de acordo com Raij et al. (1996). As correlações entre os teores $\mathrm{Cu}$ no solo e nas folhas foram baixas e/ou não significativas (Tabelas 36 e 37). Pode ser que o extrator utilizado (DTPA) não tenha discriminado o teor disponível em solos sob SSD. Estes solos geralmente possuem alto teor de matéria orgânica, a qual pode diminuir a disponibilidade de $\mathrm{Cu}$ às plantas, devido à forte complexação deste elemento no solo pela matéria orgânica (Basta \& Tabatabai, 1992).

Os coeficientes de correlação entre $\mathrm{Cu}$ na folha e $\mathrm{pH}$ foram positivos e não superiores a 0,46 (Tabelas 38 e 39). Shuman \& McCracken (1999a) também não observaram correlações significativas entre a concentração foliar de $\mathrm{Cu}$ em plantas de milho e o pH de solos sob SSD. 
A concentração de $\mathrm{Fe}$ nas folhas de soja não variou com as doses de corretivo em nenhuma das amostragens, mas na primeira época apresentou-se inferior nos solos com menor TCSSD (Tabela 41). Quaggio et al. (1998) observaram que os teores de Fe em plantas de soja cultivadas sob SSC não variaram com a calagem, e, em estudos de Centurion (1988), a concentração de Fe em plantas de milho não foi modificada com os sistemas de cultivo. Por outro lado, em trabalhos desenvolvidos por Muchovej et al. (1993), os teores de Fe em plantas de soja cultivadas sob SSC foram reduzidos devido à calagem.

Tabela 41. Concentração de Fe nas folhas de soja em função de doses de calcário, para diferentes tempos de cultivo sob sistema de semeadura direta (TCSSD) e épocas de amostragens.

\begin{tabular}{|c|c|c|c|c|c|c|}
\hline \multirow[t]{2}{*}{ TCSSD } & \multicolumn{6}{|c|}{ Doses de calcário ${ }^{(\mathrm{I})}$} \\
\hline & $100 I$ & $100 S$ & $66,7 \mathrm{~S}$ & $33,3 \mathrm{~S}$ & 0 & Médias \\
\hline \multicolumn{7}{|c|}{$\mathrm{g} \mathrm{kg}^{-}$} \\
\hline & \multicolumn{6}{|c|}{ Amostragem $1^{(2)}$} \\
\hline 3 & 161 & 111 & 124 & 134 & 150 & $136 b^{(3)}$ \\
\hline 6 & 99 & 122 & 114 & 118 & 118 & $114 \mathrm{~b}$ \\
\hline \multirow[t]{2}{*}{9} & 179 & 265 & 188 & 219 & 225 & $215 \mathrm{a}$ \\
\hline & \multicolumn{6}{|c|}{ Amostragem 2} \\
\hline 3 & 77 & 67 & 62 & 69 & 72 & $69 a$ \\
\hline 6 & 55 & 51 & 56 & 52 & 56 & $50 \mathrm{a}$ \\
\hline 9 & 63 & 60 & 55 & 61 & 60 & $64 \mathrm{a}$ \\
\hline
\end{tabular}

C.V. $\quad 31,5 \%$

(1) Percentagem da dose necessária para elevar a saturação por bases a $70 \% ; \mathrm{I}=$ incorporado a $20 \mathrm{~cm} ; \mathrm{S}=$ aplicado superficialmente. ${ }^{(2)}$ amostragem 1, realizada no estágio vegetativo da soja (V4) e a 2, no início do florescimento. ${ }^{(3)}$ Letras minúsculas comparam TCSSD dentro de cada amostragem, pelo teste de Tukey ao nível de $5 \%$.

As concentrações de $\mathrm{Fe}$ nas folhas de soja estão dentro dos níveis considerados suficientes (51 a $350 \mathrm{mg} \mathrm{kg}^{-1}$ ) por Borkert et al. (1994) e Malavolta et al. (1997), apesar de as correlações entre teor deste elemento na folha e no solo terem sido inversas (Tabelas 36 e 37). As correlações entre o teor na folha e o pH do solo foram baixas e/ou não significativas (Tabelas 38 e 39).

Houve efeito das doses de calcário e dos TCSSD nos teores de Mn em folhas de soja apenas na primeira amostragem (Tabela 42). De modo geral, as plantas 
cultivadas no solo com 6 anos sob SSD apresentaram os maiores teores. No solo com o menor TCSSD, a aplicação de $100 \%$ da dose na superfície foi o único tratamento que diminuiu o teor de Mn. Por outro lado, nos solos com maior TCSSD a aplicação desta dose, de forma incorporada, é que resultou o menor teor, enquanto a calagem superficial não exerceu efeito. Shuman \& McCracken (1999a) observaram redução dos teores de Mn em plantas de milho cultivadas sob SSD devido à calagem superficial, e Centurion (1988) encontrou menores teores em plantas de milho sob SSD do que em outros sistemas, mas os teores estavam em níveis adequados, independentemente do sistema. No SSC é comum observar redução dos teores de Mn com a calagem (Bell, 1996; Oliveira et al., 1997; Quaggio et al., 1998).

Tabela 42. Concentração de Mn nas folhas de soja em função de doses de calcário, para diferentes tempos de cultivo sob sistema de semeadura direta (TCSSD) e épocas de amostragens.

\begin{tabular}{|c|c|c|c|c|c|}
\hline \multirow[b]{2}{*}{ TCSSD } & \multicolumn{5}{|c|}{ Doses de calcário $^{(1)}$} \\
\hline & $100 I$ & $100 \mathrm{~S}$ & $66,7 \mathrm{~S}$ & $33,3 \mathrm{~S}$ & $\mathbf{0}$ \\
\hline ano & & & $\mathrm{mg} \mathrm{kg}^{-1}$ & & \\
\hline $\begin{array}{l}3 \\
6 \\
9\end{array}$ & $\begin{array}{l}35 \mathrm{abAB}^{(3)} \\
44 \mathrm{aB} \\
29 \mathrm{bB}\end{array}$ & $\begin{array}{c}30 \mathrm{bB} \\
55 \mathrm{aAB} \\
31 \mathrm{bAB}\end{array}$ & $\begin{array}{c}\text { ostragem } \\
33 \mathrm{bAB} \\
57 \mathrm{aA} \\
33 \mathrm{bAB}\end{array}$ & $\begin{array}{l}40 \mathrm{bAB} \\
52 \mathrm{aAB} \\
36 \mathrm{bAB}\end{array}$ & $\begin{array}{l}43 \mathrm{bA} \\
57 \mathrm{aA} \\
41 \mathrm{bA}\end{array}$ \\
\hline $\begin{array}{l}3 \\
6 \\
9\end{array}$ & $\begin{array}{l}27 \mathrm{aA} \\
35 \mathrm{aA} \\
24 \mathrm{aA}\end{array}$ & $\begin{array}{l}31 \mathrm{aA} \\
29 \mathrm{aA} \\
22 \mathrm{aA}\end{array}$ & $\begin{array}{c}\text { postrage } \\
29 \mathrm{aA} \\
30 \mathrm{aA} \\
24 \mathrm{aA}\end{array}$ & $\begin{array}{l}30 \mathrm{aA} \\
29 \mathrm{aA} \\
24 \mathrm{aA}\end{array}$ & $\begin{array}{l}35 \mathrm{aA} \\
37 \mathrm{aA} \\
29 \mathrm{aA}\end{array}$ \\
\hline $\begin{array}{l}\text { (1) } \frac{\text { C.V. }}{\text { Percentag }} \\
\text { aplicado sup } \\
\text { do florescim } \\
\text { maiúsculas } \\
\text { nível de } 5 \%\end{array}$ & $\begin{array}{l}\frac{13,1 \%}{\text { dose necessá }} \\
\text { almente. }{ }^{(2)} \text { an } \\
\text { (3)Letras min } \\
\text { aram as doses }\end{array}$ & $\begin{array}{l}\text { ara eleva } \\
\text { agem } 1 \text {, }\end{array}$ & e época & $\begin{array}{l}\% ; \mathrm{I}=\mathrm{in} \\
\text { tivo da so } \\
\text { ses e époc } \\
\text { ostragens, }\end{array}$ & $\begin{array}{l}\text { o a } 20 \\
\text { a } 2, \mathrm{n} \\
\text { ostrag } \\
\text { e de T }\end{array}$ \\
\hline
\end{tabular}

Os teores de Mn nas folhas de soja estão dentro dos níveis considerados adequados (21 a $100 \mathrm{mg} \mathrm{kg}^{-1}$ ) por Borkert et al. (1994) e Malavolta et al. (1997). Ocorreram correlações diretas entre o teor na planta e no solo, sendo o maior coeficiente de correlação igual a 0,81 (Tabelas 36 e 37). Shuman \& McCracken (1999a) 
observaram correlações negativas entre os teores de Mn nas folhas de plantas de milho cultivadas sob SSD e os teores no solo, extraídos pelo método Mehlich 1.

As correlações entre o teor na folha e o $\mathrm{pH}$ do solo foram inversas, e as mais importantes ocorreram nas camadas abaixo de $0-5 \mathrm{~cm}$, com valores de $\mathrm{r}$ de até $-0,80$ (Tabelas 38 e 39). Shuman \& McCracken (1999a) encontraram correlações altamente significativas entre o $\mathrm{pH}$ do solo e o teor de $\mathrm{Mn}$ em folhas de plantas de milho cultivadas em solo com 9 anos sob SSD.

Os teores de $\mathrm{Zn}$ nas folhas de soja não variaram com a aplicação de quaisquer uma das doses na superficie (Tabela 43). Shuman \& McCracken (1999a) também não observaram redução nos teores em plantas de milho devido à calagem superficial, mas constataram que os teores diminuíram nas plantas cultivadas sob SSC. Por outro lado, Estes (1972) relatou menor teor de $\mathrm{Zn}$ em plantas de milho cultivadas sob SSD do que nas sob SSC, e que a calagem não afetou os teores de $\mathrm{Zn}$ em nenhum dos sistemas de cultivo. Centurion (1988) não observou diferenças nos teores de $\mathrm{Zn}$ devido a diversos sistemas de cultivo utilizados para a cultura do milho.

Tabela 43. Concentração de $\mathrm{Zn}$ nas folhas de soja em função de doses de calcário, para diferentes tempos de cultivo sob sistema de semeadura direta (TCSSD) e épocas de amostragens.

\begin{tabular}{|c|c|c|c|c|c|c|}
\hline \multirow[t]{2}{*}{ TCSSD } & \multicolumn{6}{|c|}{ Doses de calcário $^{(1)}$} \\
\hline & $100 I$ & $100 \mathrm{~S}$ & $66,7 \mathrm{~S}$ & $33,3 \mathrm{~S}$ & $\mathbf{0}$ & Médias \\
\hline \multirow[t]{2}{*}{ ano } & \multicolumn{6}{|c|}{$\mathrm{g} \mathrm{kg}^{-1}$} \\
\hline & \multicolumn{6}{|c|}{ Amostragem $1^{(2)}$} \\
\hline 3 & 24 & 24 & 24 & 25 & 31 & $25 b^{(3)}$ \\
\hline 6 & 21 & 32 & 33 & 30 & 39 & $31 \mathrm{a}$ \\
\hline \multirow[t]{2}{*}{9} & 29 & 33 & 35 & 35 & 33 & $33 a$ \\
\hline & \multicolumn{6}{|c|}{ Amostragem 2} \\
\hline 3 & 34 & 33 & 31 & 32 & 36 & $33 a$ \\
\hline 6 & 32 & 29 & 31 & 30 & 30 & $30 \mathrm{ab}$ \\
\hline 9 & 30 & 28 & 27 & 30 & 31 & $29 \mathrm{~b}$ \\
\hline C.V. & $15,7 \%$ & & & & & \\
\hline
\end{tabular}


O maior efeito dos TCSSD nas concentrações de $\mathrm{Zn}$ ocorreu na primeira amostragem, e o menor teor foi observado no solo com 3 anos de cultivo. Mas, os teores de $\mathrm{Zn}$ de todos os tratamentos estão dentro dos níveis considerados adequados (21 a 50 $\mathrm{mg} \mathrm{kg}^{-1}$ ) por Borkert et al. (1994) e Malavolta et al. (1997).

As correlações entre os teores de $\mathrm{Zn}$ nas folhas e o $\mathrm{pH}$ do solo, e entre os teores no solo e na planta foram baixas e/ou não significativas (Tabelas 36 a 39). Shuman \& McCracken (1999a) também não encontraram correlações significativas entre o $\mathrm{pH}$ do solo e o teor de $\mathrm{Zn}$ em folhas de plantas de milho cultivadas em solo com 9 anos sob SSD. Esses autores também observaram correlações negativas entre os teores de $\mathrm{Zn}$ no solo e nas plantas. 


\subsection{Efeito da calagem e dos tempos de cultivo sob sistema de semeadura direta na produção de soja}

A produção de grãos de soja não foi influenciada pelas doses de calcário (Tabela 44), concordando com os resultados obtidos por Caires et al. (1998) e Caires et al. (1999) em solos ácidos do Paraná, e discordando da recomendação de Mascarenhas \& Tanaka (1996), de se elevar a saturação por bases a $60 \%$. Esses fatos evidenciam que a dose e o intervalo de aplicação de calcário em solos sob SSD devem ser repensados, e a razão pela qual a cultura não respondeu à calagem pode ser devido à saturação por bases inicial (camada de 0-20 cm) por volta de 50\%, já ser suficiente. Sá (1995), através de observações práticas, sugere que a calagem em solos sob SSD não é necessária quando a saturação por bases estiver próxima de $45 \%$ a $50 \%$ devido à possibilidade de essa prática induzir deficiências de micronutrientes e, consequentemente, diminuir a produção.

Tabela 44. Produção de soja em função da calagem, para diferentes tempos de cultivo sob sistema de semeadura direta (TCSSD).

\begin{tabular}{|c|c|c|c|c|c|c|}
\hline \multirow[t]{2}{*}{ TCSSD } & \multicolumn{6}{|c|}{ Doses de calcário $^{(1)}$} \\
\hline & $100 \mathrm{I}$ & $100 S$ & $66,7 \mathrm{~S}$ & $33,3 \mathrm{~S}$ & $\mathbf{0}$ & Médias \\
\hline ano & & & $=-\mathrm{k}$ & & & \\
\hline 3 & 3418 & 3206 & 3198 & 3111 & 3194 & $3225 c^{(2)}$ \\
\hline 6 & 4153 & 4159 & 4124 & 4384 & 4325 & $4229 \mathrm{a}$ \\
\hline 9 & 3863 & 3453 & 3306 & 3515 & 3724 & $3572 \mathrm{~b}$ \\
\hline C.V. & $7,0 \%$ & & & & & \\
\hline
\end{tabular}

(7) Percentagem da dose necessária para elevar a saturação por bases a 70\%; I = incorporado a $20 \mathrm{~cm} ; \mathrm{S}=$ aplicado superficialmente. ${ }^{(2)}$ Letras comparam TCSSD, pelo teste de Tukey ao nível de $5 \%$.

O maior crescimento inicial das plantas ocorreu quando o corretivo foi incorporado, possivelmente devido à rapidez na mineralização da matéria orgânica devido ao revolvimento do solo, disponibilizando maior quantidade de $\mathrm{N}$ nos períodos iniciais de desenvolvimento. Apesar disso, a análise foliar não demonstrou diferenças no teor de $\mathrm{N}$ das folhas, em função das doses de calcário. Por outro lado, a aplicação do corretivo de forma incorporada, além de não ter aumentado o rendimento de grãos, 
causou acamamento das plantas, fato que poderia ter diminuído a produção da cultura caso a colheita tivesse sido realizada mecanicamente.

A ausência de respostas à calagem, que tem sido observada em SSD, pode ser explicada pelo fato de os teores de $\mathrm{Ca}, \mathrm{Mg}$ e $\mathrm{K}$ estarem em níveis adequados no solo, apresentando uma relação adequada com o $\mathrm{Al}$ trocável (Caires et al., 1998). Por sua vez, Caires et al. (1999) acreditam também que as menores respostas às doses de calcário, em $\mathrm{SSD}$, podem estar relacionadas com o menor efeito tóxico do $\mathrm{Al}$, uma vez que compostos orgânicos solúveis presentes nos restos culturais das plantas podem complexá-lo (Kretzschmar et al., 1991; Miyazawa et al., 1996).

A produção de grãos foi influenciada pelos TCSSD (Tabela 44), tendo sido maior no local com 6 anos de cultivo, apesar de este TCSSD ter apresentado os menores valores de $\mathrm{pH}$, soma de bases e saturação por bases (43\% e 55\% na primeira e segunda amostragem, respectivamente).

O fato de o solo com 6 anos de cultivo ter apresentado a maior produção de grãos não era esperado. Contudo, as análises de micronutrientes no solo e folha mostraram os teores de B e $\mathrm{Mn}$ no solo e nas folhas de soja, na primeira amostragem, foram maiores para esse TCSSD do que para os demais. As plantas cultivadas nos solos com 3 anos sob SSD apresentaram, no estágio vegetativo V4 (primeira amostragem), baixos teores de B, segundo classificação de Malavolta et al. (1997), e no local com maior TCSSD, teores ligeiramente acima do teor considerado baixo, que podem ser reflexo dos baixos níveis de B no solo encontrados nestes TCSSD, de acordo com os critérios estabelecidos por Raij et al. (1996).

Observaram-se correlações positivas entre a produção de grãos e os teores de B $(0,63)$ e de $\mathrm{Mn}(0,53)$ nas folhas de soja (Tabelas 45 e 46$)$. Assim, os maiores teores destes micronutrientes neste TCSSD podem ter influenciado positivamente a produção de grãos, uma vez que reduções de produtividades devido à deficiência, principalmente de Mn, têm sido freqüentes quando os valores de pH são elevados (Novaes et al., 1989; Sanzonowicz, 1995). 
Tabela 45. Coeficientes de correlação linear ( $r$ ) entre teores de macronutrientes nas folhas de soja e a produção de grãos de soja.

\begin{tabular}{|c|c|c|c|c|c|c|}
\hline Amostragem $^{(1)}$ & $\mathbf{N}$ & $\mathbf{P}$ & $\mathbf{K}$ & $\mathbf{C a}$ & Mg & $\mathbf{S}$ \\
\hline 1 & $0,00 \mathrm{~ns}$ & $0,00 \mathrm{~ns}$ & $-0,30 \mathrm{~ns}$ & $0,00 \mathrm{~ns}$ & $-0,40^{*}$ & $0,19 \mathrm{~ns}$ \\
\hline 2 & $0,43 *$ & $-0,10 \mathrm{~ns}$ & $0,20 \mathrm{~ns}$ & $0,29 \mathrm{~ns}$ & $-0,20 \mathrm{~ns}$ & $-0,30 \mathrm{~ns}$ \\
\hline
\end{tabular}

(1) amostragem 1, realizada no estágio vegetativo da soja (V4) e a 2, no início do florescimento; ns = não significativo; *significativo a $1 \%$.

Tabela 46. Coeficientes de correlação linear (r) entre teores de micronutrientes nas folhas de soja e a produção de grãos de soja.

\begin{tabular}{|c|c|c|c|c|c|}
\hline Amostragem $^{(1)}$ & B & $\overline{\mathbf{C u}}$ & $\mathbf{F e}$ & $\overline{M n}$ & $\overline{\mathbf{Z n}}$ \\
\hline 1 & $0,63^{*}$ & $-0,40^{*}$ & $-0,20 \mathrm{~ns}$ & $0,53 *$ & $0,12 \mathrm{~ns}$ \\
\hline 2 & $0,13 \mathrm{~ns}$ & $-0,40 *$ & $-0,50 *$ & $0,14 \mathrm{~ns}$ & $-0,10 \mathrm{~ns}$ \\
\hline
\end{tabular}

(T) amostragem 1, realizada no estágio vegetativo da soja (V4) e a 2, no início do florescimento; ns = não significativo; *significativo a $1 \%$. 


\section{CONCLUSÕES}

$\checkmark$ O incremento do tempo de cultivo sob sistema de semeadura direta (TCSSD) causou distribuição mais homogênea dos nutrientes no perfil do solo;

$\checkmark$ A aplicação da dose total recomendada na superfície, ou 2/3 dela, aumentou os teores de nutrientes e diminuiu a acidez na camada de $0-5 \mathrm{~cm}$ em todos os TCSSD;

$\checkmark$ Nos solos com menores TCSSD, a incorporação da dose integral resultou maior $\mathrm{pH}$, $\mathrm{Ca}, \mathrm{Mg}$, soma de bases e saturação por bases nas camadas inferiores, e nessa profundidade, estes atributos não foram alterados pela calagem superficial;

$\checkmark$ Com exceção do B, que apresentou baixo teor no solo com menor TCSSD, independentemente da calagem, os teores de micronutrientes no solo permaneceram dentro da faixa de teores adequados com a calagem;

$\checkmark$ Os teores de $\mathrm{N}, \mathrm{P}, \mathrm{K}, \mathrm{S}, \mathrm{B}, \mathrm{Cu}, \mathrm{Fe}$ e $\mathrm{Zn}$ nas folhas da soja não variaram com a calagem, e os teores de $\mathrm{Ca}$ e $\mathrm{Mg}$ foram pouco modificados;

$\checkmark$ Na primeira amostragem, a incorporação do calcário diminuiu os teores de Mn nas folhas nos locais com maiores TCSSD. No local com menor TCSSD, a aplicação da dose integral na superficie diminuiu os teores de $\mathrm{Mn}$ nas folhas;

$\checkmark \mathrm{Na}$ época do florescimento, com exceção dos teores de $\mathrm{Cu}$ e $\mathrm{S}$, que se apresentaram baixos, os nutrientes estavam em níveis considerados adequados. Em todo o ciclo de desenvolvimento da soja não houve sintomas visuais de deficiência de nutrientes;

$\checkmark$ A calagem não influenciou a produção de grãos em nenhum TCSSD. O solo com 6 anos de cultivo apresentou a maior produção de grãos. Esse TCSSD possuía o menor valor de $\mathrm{pH}$, soma de bases e saturação por bases em ambas as épocas de amostragens, e maior teor de B e Mn no solo e nas folhas de soja, na primeira amostragem. Todos os solos possuíam saturação por bases inicial por volta de $50 \%$. 


\section{REFERÊNCIAS BIBLIOGRÁFICAS}

ABREU, C.A. de; ABREU, M.F. de. A Extração com DTPA: Determinação de cobre, ferro, manganês e zinco em solos. Campinas-SP: IAC, 1996a. 9p.

ABREU, C.A. de; ABREU, M.F. de. Análise de Boro em Solos usando a Solução de Cloreto de Bário. Campinas-SP: IAC, 1996b. 8p

ARSHAD, M.A.; GILL, K.S.; Field pea response to liming of an acid soil under two tillage systems. Canadian Journal of Soil Science, v.76, n.4, p.549-545, 1996.

ARSHAD, M.A.; GILL, K.S.; TURKINGTON, T.K.; WOODS, D.L. Canola root rot and yield response to liming and tillage. Agronomy Journal, v.89, n.1, p.17-22, 1997.

BASTA, N.T.; TABATABAI, M.A. Effects of cropping systems on adsorption of metals by soils: 1. Single-metal adsorption. Soil Science, v.153, n.2, p.108-114, 1992.

BEEL, P.F. Predicting liming needs of soybean using soil $\mathrm{pH}$, aluminium, and manganese soil tests. Communications in Soil Science and Plant Analysis, v.27, n.13-14, p.2749-2764, 1996.

BEN, JR.; POTTKER, D.; FONTANELI, R.S. WIETHOLTER, S. Efeito da aplicação de calcário na superficie do solo sobre fatores de acidez em campo natural. In: II SEMINÁRIO INTERNACIONAL DO SISTEMA PLANTIO DIRETO, Passo Fundo, RS. Anais. Passo Fundo, RS: EMBRAPA, 1997. p.209-211. 
BLEVINS, R.L.; GROVE, J.H.; KITUR, B.K. Nutrition uptake of corn grown using moldboard plow or no-tillage soil management. Communications in Soil Science and Plant Analysis, v. 17, n.4, p.401-417, 1986.

BORKERT, C.M. Manganês. In: FERREIRA, M.E.; CRUZ, M.C.P. da (eds.), SIMPÓSIO SOBRE MICRONUTRIENTES NA AGRICULTURA, Jaboticabal, 1988. Anais. Piracicaba: POTAFOS/CNPq, 1991. p. 173-190.

BORKERT, C.M.; YORINORI, J.T; FERREIRA, B.S.C. et al. Seja o Doutor da sua Soja. POTAFOS, 1994, 16p. (Informações Agronômicas, 66).

BRASIL SOBRINHO, M.O.C. de. Levantamento do teor de boro em alguns solos do Estado de São Paulo. Piracicaba, 1965. 135p. Tese (Livre-Docência) - Escola Superior de Agricultura "Luiz de Queiroz", Universidade de São Paulo.

CAIRES, E.F.; MADRUGA, E. F.; CHUEIRI, W.A.; FIGUEIREDO. Alterações das características químicas do solo e resposta da soja ao calcário e gesso aplicados na superfície em sistema de cultivo sem preparo do solo. Revista Brasileira de Ciência do Solo, v.22, n.1, p.27-34, 1998.

CAIRES, E.F.; FONSECA, A.F.; MENDES, J.; CHUEIRI, W.A.; MADRUGA, E. F. Produção de milho, trigo e soja em função das alterações das características químicas do solo pela aplicação de calcário e gesso na superficie, em sistema de plantio direto. Revista Brasileira de Ciência do Solo, v.23, n.2, p.315-327, 1999.

CAMARGO, O.A.; VALADARES, J.M.A.S.; DECHEN, A.R. Efeito do pH na extração do manganês, zinco, cobre e ferro do solo. Revista Brasileira de Ciência do Solo, v.6, n.2, p.83-88, 1982. 
CASSOL, L.C.; ANGHINONI, I.; MIELNCZUK, J. Características químicas do solo após a reaplicação de calcário, com e sem incorporação em sistemas de preparo. In: XXV CONGRESSO BRASILEIRO DE CIÊNCIA DO SOLO, Viçosa, 1995. Anais. Viçosa: SBCS, 1995. v.2, p.1106-1107.

CASTRO, O.M. de. Comportamento físico e químico de um Latossolo Roxo em função do seu preparo na cultura do milho (Zea Mays L.). Piracicaba, 1995. 174p. Tese (Doutorado) - Escola Superior de Agricultura "Luiz de Queiroz", Universidade de São Paulo.

CASTRO, O.M. de. Manejo e preparo do solo e erosão. In: Aspectos de Manejo do solo. Campinas-SP: Fundação Cargill, 1985. cap.2, p-43-70.

CASTRO, O.M. de; CAMARGO, O.A. de; CANTARELLA, H.; VIEIRA, S.R; DECHEN, S.C.F. Teores de zinco cobre, manganês e ferro em dois Latossolos sob plantio direto e convencional. Bragantia, v.51, n.1, p.77-84, 1992.

CASTRO, O.M. de; LOMBARDI NETO, F.; QUAGGIO, J.A.; MARIA, I.C. de; VIEIRA, S.R; DECHEN, S.C.F. Perdas por erosão de nutrientes vegetais na sucessão soja/trigo em diferentes sistemas de manejo. Revista Brasileira de Ciência do Solo, v.10, n.3, p.293-297, 1986.

CATTELAN, A.F.; VIDOR, C.; Flutuações na biomassa, atividade e população microbiana do solo, em função das variações ambientais. Revista Brasileira de Ciência do Solo, v.14, n.1, p.133-142, 1990.

CENTURION, J.F. Efeito de sistemas de preparo nas propriedades químicas e fisicas de um solo argiloso sob cerrado e na cultura do milho implantada. Piracicaba, 1988. 125p. Tese (Doutorado)-Escola Superior de Agricultura "Luiz de Queiroz", Universidade de São Paulo. 
CENTURION, J.F. Efeito de sistemas de preparo do solo na cultura da soja (Glycine $\max (\mathrm{L})$ Merril). Piracicaba, 1984. 124p. Dissertação (Mestrado)-Escola Superior de Agricultura "Luiz de Queiroz", Universidade de São Paulo.

CROZIER, C.R.; NADERMAN, G.C.; TUCKER, M.R. SUGG, R.E. Nutrient and pH stratification with convencional and no-till management. Communication in Soil Science and Plant Analysis, v. 30, n.1-2, p.65-74, 1999.

DAVIS-CARTER, J.G.; SHUMAN, L.M. Influence of texture and $\mathrm{pH}$ of kaolinitic soils on zinc fractions and zinc uptake by peanuts. Soil Science, v.155, n.6, p.376-384, 1993.

DEDECEK, R.A.; RESK, D.V.S.; FREITAS Jr., E. de. Perdas de solo, água e nutrientes por erosão em Latossolo Vermelho Escuro dos cerrados em diferentes cultivos sob chuva natural. Revista Brasileira de Ciência do Solo, v.10, n.3, p.265-272, 1986.

DERPSCH, R. Histórico, requisitos, importância e outras considerações sobre plantio direto no Brasil. In: TORRADO, P.V.; ALOISI, R.R. (coords.) Plantio Direto no Brasil Atualização em Plantio Direto. Campinas-SP: Fundação Cargill, 1984. cap.1, $\mathrm{p}-1-12$.

DICK, W.A.; McCOX, E.L.; EDWARDS, W.M.; LAL, R. Continuos application of notillage to Ohio soil. Agronomy Journal, v.83, n.1, p.63-73, 1991.

EDWARDS, J.H.; THURLOW, D.L. EASON, J.T. Influence of tillage and crop rotation on yields of corn, soybean, and wheat. Agronomy Journal, v.80, n.1, p.76-80, 1988.

EDWARDS, J.H.; WOOD, C.W.; THURLOW, D.L.; RUF, M.E. Tillage and crop rotation on fertility status of a Hapludult soil. Soil Science Society American Journal, v.56, n.5, p.1577-1582, 1992. 
ERNANI, P.R.; NASCIMENTO, J.A.L.; OLIVEIRA, L.C. Increase of grain and green matter of corn by liming. Revista Brasileira de Ciência do Solo, v.22, n.2, p. 275280, 1998.

ESTES, O.G. Elemental composition of maize grown under no-till and conventional tillage. Agronomy Journal, v.64, n.6, p.733-735, 1972.

FAUCONNIER, D.; MALAVOLTA, E. Adubação para Produtividade e Qualidade: Soja. Basel-Suíça: Instituto Internacional da Potassa, 1999. 74p. (IIP Boletim, 9).

FOLLETT, R.F.; PETERSON, G.A. Surface soil nutrient distribution as affected by wheat- fallow tillage systems. Soil Science Society American Journal, v.52, n.1, p.141-147, 1988.

FRANZLUEBBERS, A.J.; HONS, F.M. Soil-profile distribution of primary and secondary plant-available nutrients under conventional and no-tillage. Soil \& Tillage Research, v.39, n.3-4, p.229-239, 1996.

GALRÃO, E.Z. Métodos de aplicação de cobre e avaliação da disponibilidade para a soja num Latossolo Vermelho-Amarelo franco-argilo-arenoso fase cerrado. Revista Brasileira de Ciência do Solo, v.23, n.2, p.265-272, 1999.

GASSEN, D. Os insetos na estrutura e na fertilidade do solo sob plantio direto. In: CURSO SOBRE ASPECTOS BÁSICOS DE FERTILIDADE E MICROBIOLOGIA DO SOLO NO SISTEMA PLANTIO DIRETO, 2., Passo Fundo-RS, 1998. Passo Fundo-RS: Promoção Revista Plantio Direto, 1998. p.77-95.

GRIFFTH, D.R.; KLADIVKO, E.J., MANNERING, J.V.; WEST, T.D.; PARSONS, S.D. Long term tillage and rotation effects on corn growth and high and low organic matter, poorly drained soil. Agronomy Journal, v.80, n.4, p.599-605, 1988. 
GROVE, J.H.; BLEVINS, R.L. Correcting soil acidification in continuous corn (Zea mays L.). Communication in Soil Science and Plant Analysis, v.19, n.7-12, p.13311342, 1988.

HAMILTON, M.A.; WESTERMANN, D.T.; JAMES, D.W. Factors affecting zinc uptake in cropping systems. Soil Science Society American Journal, v.57, p.1310$1315,1993$.

HARGROVE, W.L.; REID, J.T.; TOUCHTON, J.T.; GALLAHER, R.N. Influence of tillage practices on the fertility status of an acid soil double-cropped to wheat and soybeans. Agronomy Journal, v.74, n.4, p.674-687, 1982.

HAVLIN, J.L.; KISSEL, D.E.; MADDUX, L.D. CLAASSEN, M.M.; LONG, J. H. Crop rotation and tillage effects on soil organic carbon and nitrogen. Soil Science Society American Journal, v.54, n.2, p.448-452, 1990.

HOROWITZ, A.; DANTAS, H.S. da. Boro disponível nos solos da zona litoral-mata de Pernambuco. Pesquisa Agropecuária Brasileira, v.8, n.7, p.163-168, 1973.

HUE, N.V. Correcting soil acidity of a highly weathered Ultisol with chicken manure and sewage sludge. Communication in Soil Science and Plant Analysis, v.23, n.34, p.241-264, 1992.

HUE, N.V.; CRADDOCK, G.R., ADAMS, F. Effects of organic acids on aluminum toxicity in subsoils. Soil Science Society American Journal, v.50, n.1, p.28-34, 1986.

HUNGRIA, M.; ANDRADE, D. de S.; BALOTA, E.L.; COLOZZI-FILHO, A. Importância do sistema de semeadura direta na população microbiana do solo. Londrina: EMBRAPA- CNPS, Comunicado Técnico, n.7, 9p., 1997. 
KITUR, B.K.; PHILLIPS, S.R.; OLSON, K.R.; EBELHAR, S.A. Tillage effects on selected chemical properties of Grantsburg silt loam. Communication in Soil Science and Plant Analysis, v.25, n.3-4, p.225-246, 1994.

KRETZSCHMAR, R.M.; HAFNER, H.; BATIONO, A.; MARSCHNER, H. Long and short-term effects of crop residues on aluminum toxicity, phosphorus availability and growth of pearl millet in na acid sandy soil. Plant and Soil, v.136, n.2, p.215-223, 1991.

LAL, R. No-tillage effects soil properties under different crops in Western Nigeria. Soil Science Society American Journal, v.40, n.5, p.762-768, 1976.

LAL, R.; LOGAN, T.J.; FAUSEY, NR Long term tillage effects on Molic Ochraqualf in North-West Ohio. III Soil nutrient profile. Soil \& Tillage Research, v.15, n.4, p.371$382,1990$.

LOPES, A.S. Solos sob cerrado: Manejo da fertilidade para a produção agropecuária. São Paulo: ANDA, 1994. 60 p. (ANDA. Boletim Técnico, 5).

LOPES, A.S. Solos sob "cerrado", características, propriedades e manejo. Piracicaba-SP: POTAFOS, 1983. 162p.

LOPES, A.S.; GUIMARÃES, P.T.G. (coords.). Recomendações para o uso de Corretivos e Fertilizantes em Minas Gerais: 4² Aproximação. Lavras-MG: CFSEMG, 1989. 176p.

MALAVOlTA, E. Elementos de Nutrição Mineral de Plantas. São Paulo: Agronômica Ceres, 1980. 251p.

MALAVOLTA, E.; VITTI, G.C.; OLIVEIRA, S.A. de. Avaliação do Estado Nutricional das Plantas: princípios e aplicações. 2.ed. Piracicaba-SP: POTAFOS, 1997. 319p. 
MARIA, I.C. de; CASTRO, O.M. de. Fósforo, potássio e matéria orgânica em um Latossolo Roxo, sob sistemas de manejo com milho e soja. Revista Brasileira de Ciência do Solo, v.17, n.3, p.471-477, 1993.

MASCARENHAS, H.A.A.; BATAGLIA, O.C.; QUAGGIO, J.A.; GALLO, P.B. Zinco nas folhas de soja em função da calagem. Bragantia, v.47, n.1, p.137-142, 1988. (Nota).

MASCARENHAS, H.A.A.; TANAKA, R.T. Soja. In: RAIJ, B. van; CANTARELLA, H.; QUAGGIO, J.A.; FURLANI, A.M.C. (eds.). Recomendações de calagem e adubação para o Estado de São Paulo. 2. ed. Campinas: IAC \& Fundação IAC, 1996, p.202-203.

MELLO, J.W.V.; FONTES, M.F.P.; RIBEIRO, A.C.; ALVAREZ, V.H. Inundação e calagem em solos de várzea: I alterações em $\mathrm{pH}$, Eh e teores de $\mathrm{Fe}^{2+}$ e $\mathrm{Mn}^{2+}$ em solução. Revista Brasileira de Ciência do Solo, v.16, n.3, p.309-317, 1992.

MIYAZAWA, M.; CHIERICE, G.O.; PAVAN, M.A. Amenização da toxicidade de alumínio às raízes do trigo pela amenização com ácidos orgânicos. Revista Brasileira de Ciência do Solo, v.17, n.3, p.411-416, 1993.

MIYAZAWA, M.; PAVAN, M.A.; CALEGARI, A. Efeito do material vegetal na acidez do solo. Revista Brasileira de Ciência do Solo, v.16, n.2, p.209-215, 1992.

MIYAZAWA, M.; PAVAN, M.A.; SANTOS, J.C.F. Effects of addtion of crop residues on the leaching of $\mathrm{Ca}$ and $\mathrm{Mg}$ in Oxysols. In INTERNATIONAL SYMPOSIUM ON PLANT-SOIL INTERACTIONS AT LOW pH 4., Belo Horizonte, 1996. resumos. Belo Horizonte, SBCS/EMBRAPA-CPAC, 1996. p.8.

MOSCHLER, W.W.; MARTENS, D.C.; RICH, C.I.; SHEAR, G.M. Comparative lime effects on continuous no-tillage na convencional tilled corn. Agronomy Journal, v.65, n.4, p.781-783, 1973. 
MUCHOVEJ, R.M.C.; BORGES, A.C.; NOVAES, R.F. Mineral nutrient composition of soybean grown in soil acid as affected by rate and $\mathrm{Ca}: \mathrm{Mg}$ ratio of liming material. Revista Ceres, v.40, n.228, p.162-175, 1993.

MUCHOVEJ, R.M.C.; ALLEN, V.G.; MARTENS, D.C.; MUCHOVEY, J.J. Effects of aluminum chelates in nutrition solution on the growth and composition of ryegrass. Journal of Plant Nutrition, v.11, n.2, p.117-129, 1988.

MULLIGAN, M.F.; SMUCKER, A.J.M.; SAFIR, FG.F. Tillage modifications of dry edible bean root colonization by VAM fungi. Agronomy Journal, v.77, n.1, p.140$144,1985$.

MUZILLI, O. Influência do sistema de plantio direto, comparado ao convencional, sobre a fertilidade da camada arável do solo. Revista Brasileira de Ciência do Solo, v.7, n.1, p.95-102, 1983.

MUZILLI, O. O Plantio direto no Brasil. In: FANCELLI, L.A.; TORRADO, P.V.; MACHADO, J. Atualização em Plantio Direto. Campinas-SP: Fundação Cargill, 1985a. cap.1, p-3-16.

MUZILLI, O. Plantio direto: viabilidade e perspectivas. In: Aspectos de Manejo do solo. Campinas-SP: Fundação Cargill, 1985b. cap.4, p-87-97.

MUZILLI, O. A Fertilidade do solo em plantio direto. In: FANCELLI, L.A.; TORRADO, P.V.; MACHADO, J. Atualização em Plantio Direto. Campinas-SP: Fundação Cargill, 1985c. cap.7, p-147-159.

NOGUEIRA, M.C.S. Estatística experimental aplicada à experimentação agronômica. Piracicaba-SP, Escola Superior de Agricultura 'Luiz de Queiroz", ESALQ/USP, 1997, p.99-114 (Apostila de aula da pós-graduação). 
NOVAES, R.F.; NEVES, J.C.L.; BARROS, N.F.; SEDIYAMA, T. Deficiências de manganês em plantas de soja cultivadas em solo de cerrado. Revista Brasileira de Ciência do Solo, v.13, n.2, p.199-204, 1989.

OLIVEIRA, E.L. de; PARRA, M.S.; COSTA, A. Resposta da cultura do milho, em Latossolo Vermelho Escuro álico, à calagem. Revista Brasileira de Ciência do Solo, v.21, n.1, p.65-70, 1997.

OLIVEIRA, E.L. de; PAVAN, M.A. Control of acidity in no-tillage system soybean production. Soil \& Tillage Research, v.38, n.1-2, p.47-57, 1996.

PARKER, M.B.; BOSWELL, F.C.; OHKI, K.; SHUMAN, M.L.; WILSON, D.O. Manganese effects on yield and nutrient concentration in leaves and seed of soybean cultivars. Agronomy Journal, v.73, n.4, p.643-646, 1981.

PAULETTI, V. Nutrientes: Teores e Interpretações. Campinas-SP, Fundação ABC/Fundação Cargill, 1998, 59p.

PAVAN, M.A.; Mobilização orgânica do calcário no solo através de adubo verde. /Apresentado na Fundação ABC, Castro, PR, 1998/.

PHILLIPS, E.R.; BLEVINS, R.L.; THOMAS, G.W.; FRYE, W.W.; PHILLIPS, S.H. No-tillage agriculture. Science, v.208, n.4448, p.1108-1113, 1980.

POTTKER, D. Calagem em solos sob plantio direto e em campos nativos do Planalto médio gaúcho. Curso sobre o Manejo do Solo no Sistema de Plantio Direto. Castro-PR: Fundação ABC, 1995. p.108-118.

POTTKER, D.; BEN, J.R. Calagem para uma rotação de culturas no sistema de plantio direto. Revista Brasileira de Ciência do Solo, v.22, n.4, p.675-684, 1998. 
PREVEDELLO, B.M.S.; BITTENCOURT, A.; BORDINGNON, J.M.T.; SILVEIRA, P. de C.C. da. Efeito da calagem, aplicada à cultura da alfafa, nos teores de $\mathrm{Zn} \mathrm{e} \mathrm{Cu}$, em profundidade. Revista do Setor de Ciências Agrárias, v.14, n.1-2, p.183-188, 1995.

QUAGGIO, J.A.; GALLO, P.B.; FURLANI, A.M.C.; MASCARENHAS, H.A.A. Isoquantas de produtividade de soja e sorgo para níveis de calagem e molibdênio. Revista Brasileira de Ciência do Solo, v.22, n.2, p.337-344, 1998.

QUAGGIO, J.A.; SILVA, N.M.; BERTON, RS. Culturas oleaginosas. In: FERREIRA, M.E.; CRUZ, M.C.P. da (eds.). SIMPÓSIO SOBRE MICRONUTRIENTES NA AGRICULTURA, Jaboticabal, 1988. Anais. Piracicaba: POTAFOS/CNPq, 1991. p.462-484.

RAIJ, B. van; QUAGGIO, J.A; CANTARELLA, H.; ABREU, C.A. Interpretação de resultados de análise de solo. In: RAIJ, B. van; CANTARELLA, H.; QUAGGIO, J.A.; FURLANI, A.M.C. (eds.). Recomendações de calagem e adubação para o Estado de São Paulo. 2. ed. Campinas: IAC \& Fundação IAC, 1996, p.8-13.

RAIJ, B. van; QUAGGIO, J.A; CANTARELLA, H.; FERREIRA, M.E.; LOPES, A.S.; BATAGLIA, O.C. Análise Química do Solo para fins de Fertilidade. CampinasSP: Fundação Cargill, 1987. 170p.

RAIJ, B. van. Fertilidade do Solo e Adubação. Piracicaba-SP: Ceres, POTAFOS, $1991.343 \mathrm{p}$.

RAIJ, B. van; CANTARELLA, H.; FURLANI, P.R. Efeito, na reação dos solo, da absorção de amônio e nitrato pelo sorgo, na presença e na ausência de gesso. Revista Brasileira de Ciência do Solo, v.12, n.1, p.131-136, 1988.

ROBERTSON, W.K.; THOMPSON, L.G.; MARTIN, F.G. Manganese and copper requirements for soybeans. Agronomy Journal, v.65, n.4, p. 641-644, 1973. 
SÁ, J.C.M. de. Reciclagem de nutrientes dos resíduos culturais, e estratégia de fertilização para produção de grãos no sistema de plantio direto. In: Seminário sobre o Sistema de Plantio Direto na UFV. Viçosa-MG:UFV, 1998. 61p.

SÁ, J.C.M. de. Plantio direto em campos nativos. In: PEIXOTO, R.T. dos G.; AHRENS, D.C.; SAMAHA, M.J (eds.). Plantio Direto: O Caminho para uma Agricultura Sustentável. Ponta Grossa-PR: IAPAR-PRP/PG, 1997. p.53-65.

SÁ, J.C.M. de. Plantio direto: Transformações e benefícios ao agroecossistema. In: SÁ, J.C.M de (coord.). Curso sobre o Manejo do Solo no Sistema de Plantio Direto. Castro-PR: Fundação ABC, 1995a. p.1-13.

SÁ, J.C.M. de. Fósforo: frações, formas de ocorrência e distribuição no perfil do solo. In: SÁ, J.C.M de (coord.). Curso sobre o Manejo do Solo no Sistema de Plantio Direto. Castro-PR: Fundação ABC, 1995b. p.229-243.

SÁ, J.C.M. de. Calagem em solos sob plantio direto da Região dos Campos Gerais, Centro Sul do Paraná. In: SÁ, J.C.M de (coord.). Curso sobre o Manejo do Solo no Sistema de Plantio Direto. Castro-PR: Fundação ABC, 1995c. p.73-107.

SÁ, J.C.M. de. Manejo da Fertilidade do solo no Plantio Direto. Fundação ABC, 1993. 96p.

SALET, R.L.; BOHNEN, H.; KOCHANN, R.A.; DENARDIN, J.E. Atividade de alumínio na solução de um solo no sistema de plantio direto. In: REUNIÃO BRASILEIRA DE MANEJO E CONSERVAÇÃO DO SOLO E DA ÁGUA, 10., Florianópolis, 1994. Pequena propriedade $\mathrm{x}$ desenvolvimento sustentável; resumos. Florianópolis: EPAGRI/SBCS, 1994. p.224-225.

SANTOS, H.P. dos; REIS, E.M. Rotação de culturas $\mathrm{x}$ efeitos das culturas de inverno e de soja na evolução dos níveis de nutrientes e matéria orgânica no solo. Revista Brasileira de Ciência do Solo, v.13, n.3, p.295-302, 1989. 
SANTOS, H.P. dos; SIQUEIRA, O.J.W. de. Plantio direto e rotação de culturas para a cevada: Efeitos sobre a fertilidade do solo. Revista Brasileira de Ciência do Solo, v.20, n.1, p.163-169, 1996.

SANTOS, H.P. dos; TOMM, G.O. Fertilidade do solo em rotação culturas com triticale. Revista Brasileira de Ciência do Solo, v.20, n.3, p.415-421, 1996.

SANTOS, H.P. dos; TOMM, G.O.; LHAMBY, J.C.B. Plantio direto versus convencional: efeito na fertilidade do solo e no rendimento de grãos de culturas em rotação com cevada. Revista Brasileira de Ciência do Solo, v.19, n.3, p.449-454, 1995.

SANZONOWICZ, C. Deficiência de manganês em solos do cerrado. POTAFOS, 1995. 7p. (POTAFOS: Informações Agronômicas, 71).

SHUMAN, L.M.; HARGROVE, W.L. Effect of tillage on distribution of manganese, copper, iron and zinc in soil fractions. Soil Science Society American Journal, v.49, n.5, p.117-1121, 1985.

SHUMAN, L.M.; McCRACKEN, D.V. Tillage, and poultry litter effects on plant concentrations of zinc, manganese, and copper. Journal of Plant Nutrition, v.22, n.3, p.609-620, 1999a.

SHUMAN, L.M.; McCRACKEN, D.V. Tillage, and poultry litter effects on soil zinc, manganese, and copper. Communication in Soil Science and Plant Analysis, v.30, n.9-10, p.1267-1277, 1999 b.

SIDIRAS, N.; DERPSCH, R.; MONDARDO, A. Influência de diferentes sistemas de preparo do solo na variação da umidade e rendimento da soja, em Latossolo Roxo distrófico (Oxisol). Revista Brasileira de Ciência do Solo, v.7, n.1, p.103-106, 1983. 
SIDIRAS, N.; PAVAN, M.A. Influência do sistema de manejo do solo no seu nível de fertilidade. Revista Brasileira de Ciência do Solo, v.9, n.2, p.249-254, 1985.

SOUSA, D.M.G. de; CARVALHO, L.J.C.B.; MIRANDA, L.N. de. Correção da acidez do solo. In: GOEDERT, W.J. (Ed.). Solo dos cerrados: Tecnologias e estratégias de manejo. São Paulo: Nobel, 1987, p.99-127.

TANAKA, R.T.; MASCARENHAS, H.A.A. Soja: Nutrição, Correção do Solo e Adubação. Campinas-SP: Fundação Cargill, 1992. 60 p. (Fundação Cargill. Série Técnica, 7).

TANAKA, R.T.; MASCARENHAS, H.A.A.; BULISANI, E.A. Manganese deficiency in soybean induced by excess lime. Better Crops International, v.9, n.2, p.7, 1993.

TISDALE, S.L.; NELSON, W.L.; BEATON, J.D. Soil Fertility and Fertilizers. 4.ed. New York: $1985.754 \mathrm{p}$.

VIEIRA, M.J.; COGO, N.P.; CASSOL, E.A. Perdas por erosão, em diferentes sistemas de preparo do solo, para a cultura da soja (Glycine max (L) merr.) em condições de chuva simulada. Revista Brasileira de Ciência do Solo, v.2, n.3, p.209-214, 1978.

VIVEKANANDAN, M.; FIXEN, P.E. Cropping systems effects on micorrhizal colonization, early growth, and phosphorus uptake by corn. Soil Science Society American Journal, v.55, n.1, p.136-140, 1991.

VOSS, M.; SIDIRAS, N. Nodulação da soja em plantio direto em comparação com o plantio convencional. Pesquisa Agropecuária Brasileira, v.20, v.2, p.775-782, 1985.

WALTERS, D.T.; AULAKH, M.S.; DORAN, J.W. Effects of aeration, legume residue, and texture on transformations of macro and micronutrients in soils. Soil Science, v.153, n.2, p.100-107, 1992. 